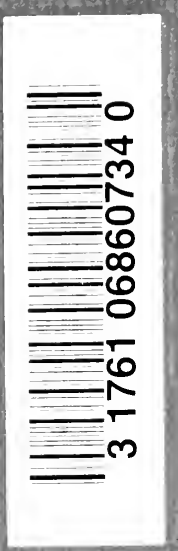

Sely 







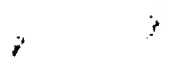

.

THE UNIVERSITY OF CHICAGO PRESS CHICAGO, ILLINOIS

Ifgentg

THE BAKER \& TAYLOR COMPANY NEW YORK

CAMBRIDGE UNIVERSITY PRESS

LONDON AND EDINBURGH 


\section{PRAGMATISM AND ITS CRITICS}

BY

ADDISON WEBSTER MOORE, PH.D.

PROFESSOR OF PHILOSOPHY IN THE

UNIVERSITY OF CHICAGO

THE UNIVERSITY OF CHICAGO PRESS

- CHICAgo, ILliNOIS

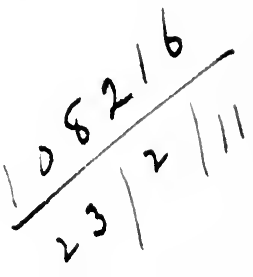


Copyright igto By

The University of Chicago

All Rights Reserved

Published November rgro

Composed and Printed By The University of Chicago Press Chicago, lllinois, U.S.A. 
At once someone will ask: "Can it be possible that the only or the fundamental issue at stake in Professor James's book is merely that of $a$ new name for an old way of thinking ?" It may be that much philosophic discussion, possibly more than other sorts, turns out to be about names. Still, a philosopher could hardly be expected to confess that his subject has come to a pass where the question whose discussion has filled most of the space in philosophical periodicals for the past ten years is merely that of a name. And we do not read far before we discover that Professor James means that while pragmatism is "an old way of thinking" in science and practical life it has not. been the conscious and avowed method in philosophy, and that the present pragmatic movement is precisely an attempt to bring this "old way of thinking" in science and practical social life into philosophy, and to this extent, therefore, is a new way of thinking-in philosophy.

Many critics have been quick to concede that pragmatism is "an old way of thinking" -so old, indeed, they say, that it is a pathetic 


\section{I \\ THE ISSUE}

A few years ago "pragmatism", was a technical term known to a small circle of metaphysicians and makers of philosophical dictionaries. Now, it is a sweet morsel in the mouth of the undergraduate, a favorite theme of "culture" clubs and "advanced" pulpits, and a "feature" of the Sunday paper and the popular magazine. Hunting for new species of pragmatism is now a favorite diversion of some philosophers. Not long since Professor Lovejoy announced that he had discovered thirteen varieties, but as some pragmatists deny belonging to any of these, it seems certain that there are more.

If we begin with appreciative general statements, doubtless many of us will first think of the subtitle of Professor James's brilliant lectures on "pragmatism." The entire caption is: Pragmatism-a New Name for an Old Way of Thinking. 



\section{CONTENTS}

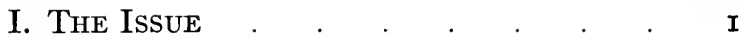

II. The Rise of Absolutism . . . . 23

III. Some Difficulties . . . . . 44

IV. The Rise of Pragmatism . . . . 70

V. HOW IDEAS "WorK" . . . . . . 87

VI. Truth-Value . . . . . . . I Io

VII. Pragmatism and Its CRitics . . .

VIII. The Pragmatic "Universal" . . . I74

IX. Professor Perry on Pragmatism . . 195 *

X. Pragmatism and Solipsism . . . 220

XI. The Social Character of Habit and Attention . . . . . . . 245

XII. The Ethical Aspect . . . . . 257

INDEX . . . . . . . . 279 

My obligations are indeed "too numerous to mention." Not the least of these is to writers, especially Bradley and Royce, with whose teachings the doctrines of this volume are often in conflict. No one, of course, in these days or in days to come, could write on pragmatism without confessing the influence of William James. But my greatest debt in the way of content and standpoint is to Professor Dewey, to whom these unworthy pages are inscribed. For indulgent patience in reading and listening to many of the papers, and for subsequent valuable suggestions, I am indebted to my wife and to my colleagues, Professor J. H. Tufts, Professor G. H. Mead, and Professor J. R. Angell.

For permission to use material already published, I wish to thank the editors of the Journal of Philosophy, Psychology, and Scientific Methods, the Philosophical Review, and the Psychological Bulletin.

The University of Chicago

November I, I9IO 
tion in the development of pragmatism; (3) the social, or, perhaps better, the "situational" character of consciousness and a fortiori of thinking. The neglect of the last point seemed especially vital. In view of this I persuaded myself that the emphasis of these features by the lectures and papers gave them relevance and unity enough to justify their publication together.

The material of the lecture course is contained in the first five chapters. If any who heard the lectures should chance to see this volume, they will have difficulty in recognizing some parts of the course. The revision consists largely in the introduction of some technical considerations, omitted from the spoken lectures. This is especially the case in the fifth chapter on "How, Ideas 'Work," which is almost entirely new.

The historical treatment does not attempt, as some may expect, an enumeration and appraisement of personal contributions to the movement, but confines itself to an account of the connections of certain ideas. 


\section{PREFACE}

The "proximate cause," as the Schoolmen would say, of the appearance of this little volume was a short course of semi-popular lectures on "The Origin and Meaning of Pragmatism," delivered at the University of Chicago in the series of "Open Lectures" of the Summer Quarter of I908.

When, at the close of the course, the publication of the lectures was suggested, I hesitated, recognizing, as I still do, that the time had come in the development of the pragmatic movement for systematic and detailed applications of pragmatic conceptions and methods to specific problems, rather than further discussion of general principles. But as the general discussion went on with unabated fervor, much of it appeared to neglect some phases of the movement which the lectures and some published papers had especially emphasized. These phases were: (I) the historical background of the movement (this especially in the lectures); (2) the central rôle of the conception of evoluvii 

TO

JOHN DEWEY

TEACHER AND FRIEND 
exploitation of a truism. But the pragmatist rejoins that all the critics' instances of the antiquity and ubiquity of the pragmatic method are taken precisely from the history of science and of industrial and social life, not from the history of philosophy, and are therefore beside the mark. In the development of science and of concrete practical life pragmatism is an old and universal way of thinking; as a conscious and acknowledged method in philosophy it is neither so "old" nor so "universal."

The term "pragmatism" raises lively anticipations of a doctrine in which the conception of conduct would be central. Obviously it belongs to the same word-family as our "practice" and the Greek praxis. Philologically a pragmatist might be expected to agree with Matthew Arnold that life is three-fourths conduct, and perhaps to add that the remaining fourth is very like the other three. Etymologically "pragmatism" might well mean "practicism." The terms "conduct," "practice," "action," etc., have indeed become pragmatic shibboleths -so much so that many suppose pragmatism to 
be the prescribed philosophy of "the strenuous life." The pragmatist's motto is, often, taken to be, "Keep going, no matter where, so you are going; and the faster the better." But a little acquaintance with the beginnings of the pragmatic movement would show both the origin and the fallacy of this notion. The present pragmatic movement began in a discussion of the nature and function of thinking in "experience"-or, if we prefer the more cosmic term, in the "world." In that discussion, the pragmatist's thesis was and is, not that experience is nothing but conduct; but that all thinking - that is, reflective, deliberative thinking - is a mode or a stage of conduct. And by "conduct" the pragmatist means action which is seeking to maintain and develop that which is satisfying or "valuable," or to get rid of that which is dissatisfying and worthless.

Now, in these experiences of "worth" and "value" the pragmatist obviously recognizes a phase of experience that we do not include under the term "conduct." It would seem 
quite possible, therefore, to be a pragmatist without believing that life is nothing but "conduct." So far, indeed, a pragmatist might well go on and insist that conduct is merely secondary, existing only for the sake of maintaining or getting rid of these experiences of value, and that pragmatism is a philosophy in which "value" rather than "practice" is the fundamental category.

However, any such sharp separation of "conduct" from, or its subordination to, "value" soon encounters a difficulty in the fact that what we immediately value depends much upon the conduct involved in getting it or in getting rid of it. We are prone to value highly that which costs much to attain or avoid. On the other hand, "the game must be worth the candle." Moreover, we have all experienced the fact that in the process of maintaining or getting rid of or altering values new values emerge. So in the end, it seems, we must say that conduct is not merely instrumental $t o$, but creative or re-creative of, values. At all events, the belief that thinking 
is a mode or stage of conduct does not warrant us in calling pragmatism "mere practicism."

Coming back to the original issue between pragmatism and its critics, namely, whether thinking is a part of conduct, the critic is waiting to say: "Granting that the above definition of conduct is the common-sense one, yet is it either common, or sense, to make thinking a part of conduct? Do we not everywhere insist on the distinction between knowing and doing, between theory and practice? Moreover, do not knowledge and truth belong among those direct immediate 'values' which we have said it is the business of conduct to maintain and develop? Is there not a special instinct for knowledge as much as there is for food or shelter or art or friends?" In this introductory paper our purpose is to state some of the principal aspects of the issue between pragmatism and its critics, rather than to discuss them in detail. But we may observe, what we shall see more fully later, ${ }^{1}$ that whenever this special instinct view of thought goes on I See VI, pp. I Io ff. 
to describe the specific object of the thoughtinstinct and the conditions under which the instinct is satisfied or dissatisfied it invariably ends, the pragmatist says, in statements which make the relation of thought to the other instincts different from that of a mere fellowinstinct. In other words, if we insist that thought is or has a value of its own we have still to state just in what that value consists. 2 Meanwhile let us note, says the pragmatist, that our common consciousness, to which the objector has appealed, is not so unambiguous on this point as he assumes. There is, to be sure, the ancient and honorable, not to say sacred tradition-ever a favorite theme of the poets and orators-of "truth for truth's sake"; of "science pure and undefiled by any contact with a base utility" ; of the scientist as a high priest whose laboratory is his temple wherein he makes offerings to the goddess of Pure Truth. This is our heritage from the Greek conception of the intellect as the mark of an immortal, as the only thing that survives the wreck of our bodies, and of heaven as an eternity of cognitive bliss. 
On the other hand, we quite as religiously believe that "as a man thinketh in his heart, so he is"; and " as a man is, so he does"; and "as the wish is father to the thought, so the thought is father to the deed." And though we may ask, "Who by taking thought can add a cubit to his stature?" still we find it difficult to believe that all the thinking going on throughout the world is just a panorama of photographic or algebraic representations of an eternally fixed world. We find ourselves inveterately assuming that thought is in some way an efficient and organic part of our efforts to bring things to pass. And if we cannot merely by thinking instantaneously add a cubit to our stature, yet in this Burbank-age we may well believe that by taking enough and the right kind of thought, along with the indicated practice, our ancestors might easily have added a cubit to our stature and that we may do the same for our children.

And despite our conception of the scientist or philosopher as the high priest and of his laboratory as "the temple of pure truth," we find the suspicion will not down that when 
the priest enters his "temple" he does not leave the world of the other human instincts, needs, and interests entirely behind. First, there is the priest himself, who after all is human. "Hath not a scientist or a philosopher hands, eyes, organs, dimensions, affections, passions? Is he not fed with the same food, hurt by the same weapons? If you prick him does he not bleed? If you tickle him [enough] does he not laugh?"

Again, what are regarded even by the scientist himself as the important problems of his subject? Are not these, one and all, in the end, questions which primarily concern directly or indirectly the increase of control over the subject-matter of his science? And this would not imply that the important discovery is always the one most heavily headlined in the newspapers. It may be recognized only by the members of the "inner shrine" of fellow-workers. But what is the basis of their recognition? Is it not in the fact that the discovery either brings a new content into experience, which is felt as directly valuable and desirable, or that it points the way to new 
"explanations" and therefore new "control" of our desirable and undesirable experiences?

And we hold all this without believing that we are in the least invading the tradition of wissenschaftliche Freiheit, or that we are substituting "a philistine opportunism" for "the scientific spirit." We insist that this doctrine does not call upon the scientist to turn out every week a new flying machine or a new breakfast food. It has nothing but approval for the investigator who shuts himself up with his "biophors," his "ions" and "electrons," provided only he finally emerge with some connection established between these "idols of the den" and the problems of life and death, of growth and decay, and of social interaction.

Furthermore, it asserts that if we follow the scientist into his laboratory we shall find that this connection is not something outside but a part of the method of science itself; that "biophors," "ions," etc., have no scientific meaning or value, no scientific truth, except in their relation to an actual efficient control of these experiences. This doctrine recognizes that science should 
indeed be free from the pressure of immediate response to current wants and problems, but only in the belief that ultimately its response may be larger and more effective. It freely concedes the "impersonal" character of the scientist's work. But again, it is with the understanding that this is only an immediate impersonalism, for the sake of a larger personalism in the end. Like the impersonalism of the just judge, it takes the impersonal standpoint in order the better to serve all persons.

In the more specific and technical terms of the psychologist these general considerations of the relation of thinking to the rest of experience involve, first, the problem of the connection between our thinking and our willing or purposing. We often speak as if we first do our thinking, then make our choice, or form our purpose. On the other hand, we also observe that thinking is a process of "making up our minds." And when our minds are "fully made up" we find our "choice" is made, and our "purpose" formed. This would indicate that we are willing, choosing, purposing, all the while we are thinking; that 
thinking is just the detailed process or method of willing and purposing; that when all the thinking is done on a given problem there seems to be nothing left over for a special faculty of will or choice to perform.

This is the doctrine of most present-day psychologists. To those who make a sharp separation between thinking and willing, this appears at first to be a decapitation of will. But the expounders of the doctrine reply that on the contrary it is the "capitation" of will; it is literally putting a head on what would otherwise be a miserable torso of instinct and impulse. It is therefore those who sharply separate thinking and willing who are the real decapitators. On the other hand, those who hold this conception of the continuity of willing and thinking insist that it is just as truly a volitionizing and vitalizing of thought. If all willing, choosing, is thoughtful impulse, it is equally true that it is impulseful thought.

But even if we agree that all willing and purposing has thought as its modus operandi, does it follow that all thinking must be 'purposive? 
May not our thinking have two functions: one, as the method of purposing-its "practical" function; the other as merely the expression of the specific and independent instinct to know-its intellectual function?

In the period immediately preceding the present pragmatic movement this duplex conception of thinking was expounded by both idealists and realists. The challenge of this conception marks the beginnings of the pragmatic movement. Some pragmatists confess that their dissatisfaction with this account began in a predilection for continuity, engendered in biological and sociological studies, where they found that pronounced differences of function-differentiations of labor - develop in some kind of organic relations with one another. And when they turned to this question of the function of thought, they found that their general bias in favor of continuity was supported by a number of observations: (I) When all suggestions of conduct are removed from even our most general ideas, such, e.g., as justice, essence, matter, liberty, etc., there is left only an empty verbal husk, often full of sound 
and fury, but signifying nothing. (2) Even those who hold the duplex view admit a one-sided dependence; they insist that the value of an idea for conduct depends upon its first being true "in itself." Value thus depends on truth, but truth confesses no dependence upon value. But, (3), when they began to inquire, in what this independent truth consists, and how it may be tested and distinguished from error, the pragmatist says that he found the trail of the answer to these questions leading straight back to the purposive, volitional character of the idea.

(4) If we strip an idea of all its volitional, purposive character, it is difficult to see what we can mean by its truth or falsity. Imagine a "cosmic" stroke of paralysis that should reduce our activity to a mere stream of images; on what possible basis could we call some of these images "true" and others "false"? And if we reply: But ideas are not mere images, the pragmatist answers: Precisely so; then what else are they?

But here we can only state, not discuss in detail, these issues between pragmatists and nonpragmatists. Suffice it to say, therefore, that 
concerning the place and function of thinking in experience (or in the world) the pragmatist became convinced that not only do all will and purpose involve ideas, but that all ideas are volitional and purposive, and therefore ideas cannot be "true" or "false" entirely independent of their purposive and volitional character.

If at this point we should be tempted to identify pragmatism with what is often called "Kantian (orpost-Kantian) voluntarism," many pragmatists would at once protest. They would insist that most historic voluntarism, despite its name, is still non-pragmatic in its conception of the nature and function of thinking; that it believes that thought in its own independent character and right makes demands and sets up "ideals" which in the same breath it admits cannot be realized. Thus, following Kant's account, thought demands that science should discover elements that are absolutely "simple" and "ultimate"; that we should be able to reach a completed explanation of everything; that is, an explanation that would have no assumptions, no unanalyzed "elements" in it. Finding these demands or 
"ideals" of knowledge unrealizable, we turn for relief from this intellectualistic impasse to "conduct." And this "turn," the pragmatist would say, is indeed in the right direction. But he would also observe, and would insist upon its importance, that there should be a re-turn to, and a reconstruction of, logic and metaphysics so as to bring them into line with the conception of thought as inside and not alongside conduct, and with the method by which science, in spite of an intellectualistic psychology and logic, makes its actual advances. But this, voluntarism has thus far failed to do. The result is that voluntarism is voluntaristic in aspiration only. In its psychological and logical theory it is still intellectualistic. It regards thought as that special and unfortunate part of our experience whose powers are unequal to its demands. Most voluntarism is thus a defeated and impotent but still unregenerate intellectualism.

It is just this logical regeneration of voluntarism that the pragmatic movement is seeking to bring about. How it proposes to do this we shall see in some measure farther on. It is 
enough here to make this general distinction in view of the frequent statement that pragmatism is only another edition of historic voluntarism. If it be allowed indeed that it is a revised edition with sufficient emphasis on "revised," doubtless most pragmatists would accept it. Pragmatists are not averse, some critics to the contrary, to acknowledging their historical connections. Indeed, they profess to trace the roots of their family tree much farther back than Kant.

And this suggests that in current discussion we frequently see both pragmatists and idealists setting pragmatism and idealism in opposition to each other. But if by idealism we mean a doctrine which believes in the real power and efficiency of the ideas and ideals with which we are trying to work out our salvation, we may discover, as we proceed, good ground for thinking that pragmatists are better idealists than many who sail under that name. For we shall find that some who profess to be "soldiers of the ideal" and "defenders of the faith" harbor grave doubts of the competency of our ideas to lead us to truth and goodness. The more we think over it the 
stranger it grows that a philosophy which teaches the impotence and untrustworthiness of our ideas should call itself "idealism," while those who fervently believe in the real efficacy of ideas, even of "our" ideas, should be accused of undermining "the inspirational power" of idealism. True, pragmatic idealism is a militant idealism. It does not find its inspiration in ideas and ideals handed down from some other sphere, either metaphysical or social, in whose construction it has had no part. The ideas and ideals to which it pins its faith, and from which it draws its "inspiration" are those which are wrought out and tried out in our world of struggle, of defeats and victories. They are

As iron, dug out from central gloom

And heated hot with burning fears

And dipped in baths of hissing tears,

And battered with the shocks of doom.

Meanwhile, so long as the beginnings of the pragmatic movement were confined simply to a "psychological" discussion of the connection between thinking and willing, it attracted little attention. It is interesting to note in passing 
what unlimited license the psychologist holds. Under the aegis of psychology one apparently may preach any sort of doctrine on any subject without being taken very seriously. So long as pragmatism was in its "psychological" stage and contented itself with observing that all ideas are purposive, we merely exclaimed, "How interesting!" But when some adventurous souls began to carry the implications of this psychology over into logic and ethics, into metaphysics and theology, and to point out the discrepancies between it and the current conception of truth and error, of right and wrong, and of God, the plot began to thicken; alarums were sounded; signals were hoisted; cobwebbed armor and weapons were seized, and the most active campaign in philosophy since Kant was on.

Here the pragmatist asks us to observe that no better general confirmation of his conception of thinking as an organic part of conduct could be asked than is found in the basis of the opposition to it when its implications for logic, metaphysics, ethics, and religion are developed. As psychology it is just an interesting subject for 
a lecture or a laboratory demonstration. As a view of truth, of good and evil, and of religion, it lays hold at once of the whole structure and content of life. If thinking is inside and part of conduct, what then becomes of truth as "our contact with" an "eternal" and "immutable" world of reality? Where, indeed, in this view is there any place for such a world? And if there be no such world, how can there be any truth or falsity? And how may we talk of moral progress or regress unless there be an absolutely fixed goal or order toward which, or away from which, we are moving? And if God be not "the same yesterday, today and forever," what is to become of religion? And if our faith in the foundation (the conception of an immutable world) of these distinctions between truth and falsity, right and wrong, moral progress and regress, religion and irreligion be thus undermined, how shall we maintain faith in one another, and without faith in one another, what is left of life?

How social, ethical, and religious interests became bound up with the conception of the world 
as completed and changeless will be considered in our next discussion. Meanwhile, it is the pragmatist's contention that it is precisely this conception of a finished and immutable world that has led to the divorce of the theoretical and practical functions of thinking, which in turn is responsible for the obscuration of the distinctions between truth and error, right and wrong, and that he is trying to save these distinctions by restoring thought to its place in "conduct," that is, in a process of self-supporting and selfpropelling activity.

Briefly summed, the important aspects of the issue between pragmatism and its critics are:

r. Psychologically, is thinking the expression of a separate and independent "side," "aspect," or "instinct" of our nature-co-ordinate with other instincts, as those of food, sex, etc.-whose satisfaction consists in setting up algebraic, psychical symbols of an immutable world, or is it just the process of the interaction and consequent development of our instincts and appreciations?

2. Logically, is an idea a mere psychical $x$ for 
a world which remains unaffected by our algebra, or is an idea a perfectly organic part of the process of real change of a developing world?

3. Ethically, does moral conduct consist in merely executing, "carrying out," eternally given ideals and plans, or does it demand a conscious participation in the creation of these ideals?

4. Politically, if moral responsibility demands conscious participation in the creation as well as in the execution of the community ideal and program, ${ }^{\mathrm{I}}$ must not the social organization be essentially (whatever its name) that of a social democracy as against all forms of hierarchism?

5. Metaphysically, the issue is whether movement, change, evolution are "real" or only "apparent" characters of the world.

6. Theologically, (5) would read: Does the concept "God" mean an eternally completed, all-inclusive, unmoved, and immovable sum or unity of being, or does it mean active, working being engaged in real struggles with real problems?

${ }^{x}$ For expansion and applications of this principle, cf. Dewey and Tufts, Ethics, Part III. 


\section{THE RISE OF ABSOLUTISM}

As we turn the rapidly multiplying pages of pragmatic literature we may notice that the terms "absolutism" and "intellectualism" occur about as frequently as "pragmatism." And if the writer happens to be a pragmatist, these are likely to be terms of "invidious comparison." The pragmatist appears to be constantly defining his own doctrines by contrasting them with what he calls "intellectualism" and "absolutism." The historical significance of this is that pragmatism has in fact developed out of continued attempts to escape a number of difficulties into which it believes absolutism and intellectualism have always fallen. To get at the historical roots of pragmatism we should, then, understand something of what the pragmatist means by these terms.

Let us recall that the philosophic development of which we are the direct heirs began among the 
Greeks in an attempt to reduce the world of "things" to a common stuff, "a common denominator." One sought it in water, another in air, another in fire, another in the "infinite." For reasons which will appear more clearly as we proceed, the pragmatic historian of philosophy says it is important to note that these first "philosophers" were also the first physicists, the first chemists, the first biologists, and the first sociologists. $\mathrm{He}$ also suggests that no better illustration of the difference between intellectualism and pragma-

$\checkmark$ tism can be found than in the interpretations of this attempt to find a common denominator of things. The intellectualistic historian says that the effort was due simply to the "large and free intellectual speculative interest of the Greek mind, to its great passion for unification which the existing and pre-existing theology or mythology did not satisfy." And here the intellectualistic account is prone to stop. But if the pragmatic historian insists on asking: "Why this search for unity ?" the intellectualist is ready to reply that it is just the nature of an intellectual being to find a common ground, a common denominator for 
things; that an intellect simply cannot "sleep o' nights" until this is done. "But if that be all," says the pragmatist, "why is not one common denominator as good as another? If it is a matter of just thinking things into a unity, what difference does it make whether the unifying conception be fire, air, water, the "infinite"? And why were not the Greeks satisfied, as is the Oriental, with just the abstract conception of unity?" If the rejoinder be that our intellect is just so constituted that it cannot be satisfied with a mere carry-all kind of unity but wants to see things connected with one another as well, the pragmatist will then ask: But just what does this mean? If connection with one another does not mean merely being together in a common bag or bin of being, what is it to mean? Doubtless the reply will be that it is a connection in which the being of one thing depends upon and in turn conditions that of another or others. And why, continues the intellectualist, may not the intellect as such simply demand all this? And if we next ask how the intellect can be sure when it has reached this sort of connection 
between things, doubtless we shall be told in the language of science: When our conception of this connection is such that it enables us to reproduce or anticipate the reproduction of things or of changes in things.

But now observe, says the pragmatist, that by a most interesting coincidence this statement of what the intellect, as such, demands, is a statement of just what is involved in the control of experience. And here the difference between the intellectualist and the pragmatist emerges. The intellectualist insists that this agreement between intellectual demands and the conditions of control of experience is either a happy coincidence or a "pre-established harmony" between the demands of the intellect and our "practical" interests, and that the intellect makes its demands independent of the control-interest. But the pragmatist cannot get over the feeling that this is something more than a mere coincidence or a preestablished harmony. He is haunted by the notion that there must be an organic connection between

$v$ the intellectual and the "practical" interest; that the significance, the value, and the test of each is found 
in its relation to the other; that the Greeks found the concepts of air, water, etc., more intellectually satisfying because they promised-however much they may have failed for the Greeks in the fulfilment of that promise-more control over the changes of things than the whims of the denizens of Olympus.

Returning to our historical sketch, let us recall that in this search for a common denominator the Ionians were not very successful. The investigation ended with a number of rival conceptions. And the atomists, who followed, succeeded only in adding another "opinion," because, as even the non-pragmatic historians confess, scientific technique was not sufficiently developed to put their conceptions to the test of control. In short, the unity these conceptions expressed was too purely, too successfully intellectual. It was a "speculative" unity. As a formula for a purely intellectual unity why is not water or fire as good as the "infinite"?

Meanwhile, in their rapidly increasing interaction with one another and with foreign tribes the Greeks came into contact and conflict with 
a variety of political, commercial, and religious customs and standards, so that the demand for "a common denominator" in social and ethical affairs was even more pressing than in the physical world. But the outcome of the search for it was much the same-a mass of rival and conflicting conceptions with no conscious method of testing them.

But while this first search for a common Stoff of things and a common social standard failed in its own object, it had another outcome, the historical importance of which can scarcely be overstated. As the differences between these rival conceptions grew they soon became so great that they drew attention from the original problem and centered it upon the fact of the lack of agreement itself. "How does it happen," they said "that we Greeks, the most intelligent people on earth, living here in what purports to be a common world, should have such differing and conflicting ideas of it? What is the source of this difference, and how can we determine which of these ideas or 'opinions' are true and good? Clearly, these are questions that should be discussed 
before continuing farther the hunt for the ultimate elements of matter, politics, art, or religion. Before further search in these directions we would better examine the search-light."

In this wise does philosophy at last get a problem and a standing of its own. Up to this time the problems of philosophy have not been set apart from those of physics and social science. But in this general problem of knowledge, in the demand for a standard for the distinction between truth and falsity, it acquires a realm of its own, independent, it believes, of the problems of physical science, politics, art, and religion. The process of knowing an sich, not the knowledge of earth, fire, air, water, etc., now marks the special field of philosophy.

We hear much of over-specialization in presentday investigation. But there are some who think that here at the beginning of philosophy this isolation of the problem of knowledge from the concrete problems of science and social life is one of the most far-reaching cases of over-specialization in the history of thought, and subsequently the source of innumerable philosophic woes. At 
any rate, we may observe what immediately follows. Thinking is now to be regarded as a special process co-ordinate with other processes, as those of fire, air, water, etc. As such a special process, it must have a locus, it must be a function of some specific and assignable machinery. This seemed obviously to be our individual bodies or souls; logically it does not much matter which, as the Greek soul was but a more ethereal body. Now, as soon as consciousness and thought are thus regarded as a function of the individual body or soul, the differences and disagreements of opinions formerly so puzzling at once seem explained. They are just what should be expected. So obvious did this seem, once it was stated, that with a sudden but epoch-making shift the problem falls on the other side and the question now becomes: "How can there be any agreement? How can ideas as functions of different bodies or souls possibly agree except by coincidence? Is it not clear that there can be no common truth or error, no common right and wrong? Each individual can have only his own truth and error, his own good 
and bad. The individual is the measure of all things."

Here perhaps is the place to note the remarkable fact that not only were the Greeks unable to meet this individualistic psychology of the sophists directly, but that it stood unrefuted on its own psychological ground for twenty-three hundred years. For it is only within our own generation that we have begun to treat the consciousness of each one of us as a function, not merely of our $V$ individual bodies or "souls," but of the entire community life in which it has its existence.

But if no one was able to meet the sophists' psychology on its own ground, it did not follow that the social and ethical implications of that psychology were accepted. As Socrates pointed out, the sophists' psychology applied to society was a polite invitation to general suicide. But society was in no suicidal mood, even if at times it was a little discouraged. It did not propose to shut up shop and go out of business at the point of a psychological theory. If it could not refute the sophists' premises, it could shrug its shoulders at the conclusions and go on about 
its affairs. In all of which the pragmatist finds support and comfort in his view of the organic connection between thinking and practical social life.

Socrates made no attempt to deal directly in its own terms with the individualistic psychology of the sophists. He was content to show that whenever the sophist went to the shoemaker or tried to convert anyone to his own view, his doctrine of a merely individualistic truth or good was doubly refuted: (I) He refuted it himself in assuming that the shoemaker could understand his order; (2) The shoemaker refuted it in showing him that he had understood him by filling his order. But how this social co-operation could $\checkmark$ exist with ideas generated in individual bodies or souls, Socrates did not attempt to make out. Like Kant in his treatment of moral freedom, he could show that agreement existed but not how it existed. But so long as the how of social interaction remained in the dark the sophist would continue to be a social menace, or at least a social irritation. While the sophist could not practice his own theory, much less hope to con- 
vert the community to it, it would still be a nonsocial and disintegrating tendency. ${ }^{\mathrm{I}}$

To Plato, then, fell the task of supplying the "how" of Socrates' "that," but Plato was quite as unable as Socrates to grapple directly with the sophists' psychology. What, then, was to be done? This truly is a crisis in the history not merely of philosophy, but of civilization. It is of course utterly idle to speculate on what would have been the course of the history of philosophy and society if Plato had been able to make a direct analysis of the individual consciousness in social terms. At all events, Plato's method of meeting the sophists' conclusion and of explaining social interaction has in essence been the dominant one ever since. And little wonder, for so long as we accept the sophists' account of consciousness and ideas, no other method is possible. This method is simply to oppose to the transient, shifting, "psychological" conscious-

I When we are told that the sophistic movement was due to the prostitution of philosophy to "practical" ends, we may reply: (I) that it could quite as well be said to be the result of "pure" and "free" speculation uncontrolled by social applications, and (2) that the ground of its rejection was precisely its social consequences. 
ness of the individual a "metaphysical" world of universal and immutable reality. Plato was the real inventor of metaphysics proper-that is, of "metaphysics" as opposed to "psychology." In the historic sense of the term, metaphysics might well be defined as the essence of all attempts to maintain a world of continuity and order in the face of an individualistic theory of human consciousness.

The system of eternal and immutable "Ideas" is then Plato's answer both to the sophist and to Socrates. The shoemaker and his customer understand each other, because, although they are different "organisms," "minds," or "souls," yet both have a "recollection" or "reminiscence" of an eternal or "celestial" shoe which each has apprehended in a previous supernal existence, and of which all "terrestrial" shoes are "imitations" or "shadows."

Just how this does anything more than transfer the problem from the terrestrial to the celestial $\checkmark$ sphere, and what, if this explains agreement and co-operation, is to account for disagreement and opposition, are questions - not to mention many 
others-which Plato himself raises, and which were soon to become very acute.

But all these particular difficulties grow out of the fundamental one of attempting to overcome anarchical change with absolute fixity. It is the immutability and perfection of the celestial archetypes that precipitates the fundamental issue between absolutists and pragmatists, the issue namely between those who regard the universe in the last analysis as absolutely complete and perfected, and those who regard it as still developing - the issue of a static versus an evolving universe. To be sure, Heraclitus and the Eleatics had already held a sort of country-school debate over being and becoming, discussing them in terms of physics and mathematics. But now the issue appears to Socrates and Plato with the content and fate of our entire social life bound up with it. It is no longer merely an academic question. It is literally a matter of life and death. It was in defense of social order and values that Plato-not Moses, nor Parmenides-fixed "real species" with a fixity that has held for twentythree centuries. 
We have just said "fixed real species." This is in view of the fact that many "absolutists" or "perfectionists" will strongly protest this statement of the issue. They profess to be perfectly orthodox evolutionists, and easily grow eloquent over the work of Darwin. But the pragmatist observes that when we follow up the writings of the absolutist we soon discover that what he gives out with his right hand he takes back with his left; that when he declares that he is an "evolutionist" it is, as our theosophic friends would say, "in his scientific, not his philosophic personality." As a scientist he subscribes freely to the doctrine that all terrestrial trees, dogs, shoes, etc., undergo changes which, as we view them, we may call an evolution of species; as a philosopher he believes all these terrestrial changes are only poor "imitations"- to use Plato's term-of a system of Ideas or "species" that itself undergoes no change nor shadow of turning. For the absolutist as a philosopher, the $\checkmark$ "origin of species" can mean only the origin in some way of individuals by or within or under a species or an Idea that is eternally fixed. If 
it be asked whether a new species or type can originate in the universe, whether, in theological terms, God could have a new idea, he is bound to answer, "No." And it is difficult to see, says the pragmatist, how in its relation to evolution modern absolutism or perfectionism has made any logical advance upon that of the Greeks. Plato and Aristotle allowed plenty of room in the world of "imitation" and "participation" for the origin and development of individuals; nor were the difficulties in explaining the origin of such individuals under fixed species any greater then than now.

For the perfectionistic evolutionist, then, there can be no "origin of species." Evolution belongs to the world of "shadows" and "imitations"; or in more modern terms to the world of "appearances," not to the "real" world. In Mr. Bradley's famous phrase, "Nothing real can move."

How such an immutable world can be "purposive" - a character of which absolute idealism is often supposed to be the special guardianis indeed a problem, as we shall see in the next discussion. The very presence of active purpose in the world is prima-facie evidence that 
the world is not completed. And in a genuine philosophical evolutionism the purposive element must also share in the evolution. Indeed, the actual form which the issue between evolutionists and perfectionists takes in discussion is not whether there is movement or no movement but whether development takes place throughout the universe, or whether there is some part or phase or element which remains eternally immune to change. More specifically, it is the question whether in science the species, in logic the universal, in ethics the ideal, in theology

- God, participate in development or whether they stand as Aristotle's unmoved mover entirely aloof from the process which they are supposed somehow to keep going.

But let us not forget the original motif of this fixation of the "real" world. Let us remember that it is Plato's answer to the challenge of the sophist to show how there can be any common truth or common good as a basis for social agreement and co-operation. To be sure, this ignores the fact that disagreement and opposition are as obvious and perva- 
sive as agreement and co-operation. On the other hand, it will have to face those who will ask what place is there for truth, goodness, and selfhood in a changeless universe. And it overlooks also possibility of there being a via media between absolute fixity and absolute dissolution. Greek absolutism, not to say absolutism in general, has great difficulty in using the conception of "between" and "degrees." Its thought is polarized. It tends to move only in leaps from one conception to its opposite. There is no Haltestelle between. It is the "either or," "all or none" way of thinking. It fails to recognize, in Professor James's phrase, "the legitimacy of the word some."

In Greek thought this was a symptom of the unanalyzed and therefore relatively uncontrolled condition of the newly found power of abstraction. Jowett remarks:

The discovery of abstraction was the great source of all mental improvement in after ages. But each of this company of abstractions, if we may speak in the metaphysical language of Plato, became in turn the tyrant of the mind, the dominant idea, which would allow no other to have a share in the throne. 
. . . . Nor did this lead to any difficulty or perplexity so long as the mind, lost in the contemplation of being, asked no more questions and never thought of applying the categories to mind or opinion or practical life. ${ }^{x}$

But having reached and accepted this conception of the absolute completeness and fixedness of the real world as the basis of our social agreement and co-operation, we have now to ask: "About what are we seeking to agree and co-operate ?" It cannot be to effect any change in the "real". world, for that is impossible. The celestial Ideas are already complete and perfect. What then is left, but just to "know" this world of Ideas? For surely, assumed Plato, quite in the spirit of present realism, a thing may be "known" without suffering alteration. Thus did the cognitive function $\checkmark$ come to dominate all the others. And little wonder; for it was the one direct connection with the "real" world. It was the only function in our experience whose activity was supposed to be consistent with the completeness and perfection of that world.

I Introduction to Sophists, sec. 3. 
Thus also began the ever-widening psychological breach between thought and the other activities. Thought soon becomes a "form" or "side" or "phase" of experience alongside other "forms," having its own special function, namely, the cognition of the absolute world, which it exercises under its own laws.

But what now becomes of that social co-operation for the sake of which the appeal to the completed, perfected, celestial world was made? Obviously it has to be "reinterpreted" as a process of falling away from and returning to the experience of celestial contemplation. Social agreement and co-operation at bottom must now mean agreement and co-operation in regaining or losing the celestial vision. Whatever else it may appear to be we must remember that this "else" is but "appearance." Our impulses, instincts, desires, emotions, volitions, are all mere symptoms of the distortion of the celestial vision, or of attempts at its restoration.

Such is the paradoxical finale of Plato's doctrine. Plato begins and indeed remains a social reformer. His absolute system of Ideas 
was conceived precisely as a basis for our "terrestrial" social interaction. And in the Republic he follows this up with a marvelously wrought picture of that social life. Yet the goal of it all is to be an experience of eternal contemplation of the ineffableness of the immutable world.

Owing to the organization of Greek society this "reinterpretation" of social life necessary to bring it into line with Plato's absolutism and intellectualism was much easier in Plato's day than it was later. Indeed, the pragmatic historian would tell us that Plato's absolutism and intellectualism are but reflections of that social system in which thinkers formed a select and "privileged" class, standing with other "privileged" classes on the backs of slaves.

Such in brief is the historical genesis and the connection of that absolutism and intellectualism in opposition to which pragmatism has developed. We have here exhibited these conceptions in wantonly naked abstraction. And doubtless it will be difficult to find absolutists or intellectualists who will stand sponsor for 
them in that condition. It is indeed one of the pragmatic historian's favorite conceits, that, however numerous absolutistic and intellectualistic philosophers may be, there are few absolutistic or intellectualistic citizens. And philosophers have sometimes been good citizens. In the case of Plato, especially, we feel that his absolutism and intellectualism do not express his real spirit and intent. They are the "accidents," however tremendous in historical import, of Plato's attempt to turn the flank of the sophists' individualistic psychology by metaphysical maneuvers instead of meeting it face to face on its own ground. 


\section{III \\ SOME DIFFICULTIES}

How long would the absolutism and intellectualism of Plato and Aristotle have survived, had Greek social life and science run a longer continuous course? Would they have struck deeper root, or would they have disappeared more rapidly? Both Plato and Aristotle were fully aware of the difficulties in their doctrines and stated them very clearly. Would social and scientific development have gone on increasing these perplexities to the point where they would have forced a radical reconstruction of the system, or would the influence of these conceptions have kept social and scientific theory within their limits? These have long been favorite, if idle, speculations of historians. At all events, in what actually did happen it would be difficult to conceive, as Professor Dewey has pointed out, ${ }^{\mathrm{I}}$ conditions more favor× The Significance of the Problem of Knowledge. 
able for the continuation of Greek absolutism and intellectualism. Instead of gradually evolving through toilsome centuries his own indigenous principles of control out of his own tribal experiences, the barbarian found in the Graeco-Roman civilization a ready-to-wear system for organizing and directing his vast but relatively uncontrolled energy. Compared with his own crude formulations, the Graeco-Roman system, especially as edited by the church, seemed to him complete and absolute. And by the same token it seemed no less so to the system itself. In proportion as the pupil became docile the system grew dogmatic. Nevertheless the difficulties which Aristotle and Plato had themselves clearly seen and stated had to be constantly faced by the teachers of the system throughout the whole of the "dark" and "mediaeval" periods. And as fast as the pupils mastered the system they too fell heir to these problems. And as the greater diversity of content and conflicts of the modern period developed, these difficulties became constantly harder to manage. 
Turning now to some of these perplexities which finally issued in the pragmatic movement: we find, first, and in general, that the burden of the necessity for constantly "interpreting" the whole process and content of life as just a departure from and return to an experience of "celestial contemplation" became more and more intolerable. Even the marvelous institutionizing of Plato's doctrines by the church could not prevent the "interpretation" of the problems and projects of social life as due to the loss or attempts to regain the celestial vision from becoming more and more unreal and artificial. It disfranchised too much of life. Ideals, visions, to be sure, we must have. But people came more and more to feel that we cannot live by visions alone any more than by bread alone. The belief grew that these visions should be experiences which point or lead the way to other experiences which should fulfil them; not that the visions may not be of as great worth as the fulfilling experience, but, as Kant saw later (though he could not fully apply it), people began vaguely to feel that 
the value of each depends largely upon its relation to the other.

In psychological terms, the difficulty was that the steps in the passage from these visions to the life of impulse and feeling which they were expected to direct could not be made out. The method by which ideals control experience remained hidden. But for thinking beings the continued efficacy of a controlling conception depends upon the recognition of its method. Hence life had to be reduced to a process with which these celestial visions could be connected-a process, namely, of simply identifying objects as "imitations" or "shadows" of the eternal Ideas.

But the instincts and desires, emotions and volitions are not so easily read out of court. Even monasteries and nunneries could not get rid of them. The result was a sense of cleavage, of division, and finally of hypocrisy, which deepened and widened as new problems developed. The conception of the end and goal of experience was defeating its own aim. It took away meaning and value where it meant to 
bestow it. The principles which were to control and order experience swallowed the experiences they were to order.

But if we ignore this protest of the rest of experience against being reduced to cognition and suppose the reduction accomplished and accepted, are our difficulties at an end? If we accept the immutable world as the basis of our social agreement and co-operation, and if we concede that the content of this agreement and co-operation consists in "imitating" or representing in some way the eternal world, what now are we to do with our disagreements and antagonisms? If we agree and co-operate because we have all stood in the $\checkmark$ presence of the eternal archetypes, how then should we ever disagree or refuse to co-operate?

And we should note that we gain nothing over Plato by substituting for Plato's immutable archetypes the more nebulous conceptions of "absolute reality" of present-day absolutism. For the seat of the difficulty we are here facing lies in the static character of the reality. Whether reality consists of Platonic "Ideas," 
mediaeval "Essences," or Bradleyan "sentience," if it is the basis of agreement and cooperation, and if it is perfect, complete, coherent, and all-inclusive, whence then come disagreement and antagonism? Apparently our absolutistic solution of the problem of a basis for social agreement and co-operation works too well; it proves too much. For disagreement and antagonism, alas, seem to be quite as much in evidence as agreement and cooperation.

As Plato and Aristotle both saw, this is the crucial problem for all static absolutism. In ethical and theological terms it is the ancient $v$ and perennial "problem of evil." In logic it is the problem of error. These problems form the nerve of the history of philosophy since Plato. With them the early church Fathers wrestled; about them the scholastics spun endless webs of speculation. At the beginning of the modern period they are the rock on which the doctrines of Descartes, Spinoza, and Leibnitz split. They are the motive of the movement from Locke to Hegel. And in our present-day 
absolutism, as represented by Bradley and Royce, they are the central issues.

Many and heroic have been the attempts to meet this problem of disagreement, error, and evil, from the standpoint of static absolutism. The church Fathers' struggle with it ended in the confession that if the ground of agreementthe ground of common truth, of common goodis perfectly complete and fixed, then error and evil must have a basis of their own, which they found in the Devil. To be sure, the Devil is a "fallen angel." But for the Fathers he was beyond redemption.

This form of solution, while retaining the element of fixity, surrenders outright the conception of absolutism. Doubtless most of us cherish a somewhat patronizing attitude toward this solution of the Fathers. Yet if we place it alongside some later accounts of how error and evil can be parts or elements of a perfect and unchangeable world, it may seem less naïve than we have hitherto regarded it.

Turning now to the later philosophical treatments of the difficulty, all, past and present, 
whether of the mystical or rationalistic type, agree, as we might expect, that change, error, evil, must be "de-realed," or illusionized. They must be reduced to the status of "appearances" or mere "phenomena." This is attempted in various ways. The mystic tells us that we have but to take "the standpoint of eternity," to see all change, error, and evil disappear. As we move out to sea from the wharfs of a great city, the confusion of sound, smell, and motion gradually subsides until at last the whole "booming, blooming, buzzing confusion" becomes a hushed and motionless vision. Even so must we push out on the sea of eternity to the point where time and change, error and evil disappear. Here the cynic may suggest that at about the point where we are far enough out to attain this hushed and motionless vision we usually begin to have misgivings about the absolutely immutable character of the sea itself. And if we plead a little license for our homely figure, he will say: Even so, are you not then in the plight of the ancient mariner "in a painted ship on a painted ocean"? And how 
long, he adds, do you think it would be before you too would long for sight of "the rocky shore," "the kirk," "the weather-cock," and "the wood which slopes down to the sea"?

But apart from this longing, which after all might only show how deeply rooted were the seeds of earth and finitude in us, and apart from the suggestion that this taking to sea seems like running away from the problem instead of meeting it does not this fashion of getting rid of change, error, and evil also get rid of truth and right? How can an eternal vision or contemplation be either true or false, right or wrong? Or, if the vision be plural, what can we possibly mean by calling some true and some false, or some good and some evil? How may we test these distinctions in any particular case?

But the method of the more discursive and rationalistic-minded absolutist of "de-realing" error and evil has always been and still is to "interpret" error and evil as "partial," or "incomplete" truth and goodness. As the ethical problem will be discussed later, we shall here consider the absolutist's account of error. 
Probably most of us first heard of pragmatism as a doctrine of the nature of truth and error; or, if we first heard of it through some of its critics, as the doctrine that there isn't any truth or error. At any rate it is a fact that the form of the issue with which the present pragmatic movement started was that of the nature and criterion of truth and error.

Once more let us recall that the fixation of the real world took place precisely for the purpose of maintaining, not of getting rid of, this distinction. But no sooner was this conception of fixed reality born than it began, as we have seen, not only to demand the reduction of experience to contemplation and cognition, but to make knowledge nothing but an algebraic symbol-or at best a mere "imitation" or "shadow"- of the immutable reality. But what, now, do we mean when we say that sometimes our symbols or "imitations" are "true" or "adequate" and sometimes not? The absolutist's answer is interesting and perplexing. The reply is that our representations or "imitations" are true just in so far as they 
include and coincide with the whole of reality. ${ }^{x}$ To be perfectly true, an idea must completely include and coincide with its object. But such inclusion and co-incidence obviously mean identity. To be completely true an idea must not merely point at, or "imitate," but must be the whole of reality. In so far as it is not the whole, it is false.

Behold now, says the pragmatist, in what a web we are caught. (I) It is obvious that if there were any possibility of thought being true it would all have to be concentrated in a single idea or judgment. There is no possibility of ideas (plural) being true since an idea obviously can be but part of the whole. (2) But even this one all-inclusive thought or idea can never $\checkmark$ be true so long as it remains truly an idea. For as an idea it must be different from the reality and therefore false. Thought is thus incurably tragic. It "desires to be true" but is condemned by its nature to be false. We may well wonder how it can even "desire" to be true if its very essence is such that it must be false.

I Cf. Bradley, Appearance and Reality, pp. 366, 549 . 
Note now how the difficulty has suddenly shifted. A few moments ago, with a complete and immovable reality as the ground of truth, the problem was how to account for error. Now the difficulty is to discover any truth in sight. In making room for error, it appears, we have crowded truth out. Have we not here a real crisis? And as absolutists, how can we meet it? As good absolutists we must admit that so far no thinking can be true. But may we not avoid complete shipwreck at this point by reflecting that, while no idea can be wholly true, some may be more nearly true than others? When we speak of an idea or judgment as "true" and another as "false," we really mean that one is more nearly true or less false than another. This is the famous doctrine of "Degrees of Truth and Reality" which Mr. Bradley has so brilliantly expounded.

Now, there is no doubt that this conception of degrees of truth and error is good commonsense, and equally good science; but is it good absolutism? How, from the absolutist's conception of the relation between thought and 
reality as above sketched, is the truer of two ideas to be distinguished? The general and formal response comes very easily: The truer idea is the one which would require the least revision, the least change to make it coincide or become identical with the immutable reality. This answer is of course only a restatement of the absolutist's general conception and standard of truth. But our question asks how we can apply it in any particular case. How are we to tell which of two ideas, for example, the "corv puscular" or "wave" conception of sound and light, would require the least revision in order to coincide with the absolute reality? The case seems desperate, and doubtless calls for desperate measures. And this may account, says the pragmatist, for the bold move which the absolutist makes at this point. He calmly, as if no one in the world had ever dreamed of a changeless reality, appeals to the "facts." What facts? Why just the plain everyday facts of history and science! If we wish to know what ideas would suffer the least revision by the absolute reality, we have simply to go 
to history and science and observe, "as a matter of fact," what ideas and judgments have been and are being revised the least.

But, says the evolutionist, however much we may admire this coup for its daring, after all does it succeed? Is not history a dangerous court of appeal for absolutism? First, unfortunately for such an appeal, history does not seem to be all in. It still appears to be in the making and that very rapidly. ${ }^{\top}$ And probably no one would care to say that there is not as much history yet to be made as has been made. Moreover, it is difficult to see how from the history that has been made we can expect much aid and comfort. The highways and byways of history are strewn with the wrecks of scientific, political, and religious theories. The most cherished conceptions of one century are the superstitions of the next. Ideas and ideals for which one generation is willing to go to the stake are patronizingly characterized by the next as of "historic value" only. Scientific propositions that have ${ }^{r}$ Cf. Schiller, Studies in Humanism, chaps. vii and xix. 
stood for centuries as axioms are constantly being "reconstructed"; this too in mathematics where, if anywhere, we should expect to find some unalterable ideas. Most of the present frontier work in mathematics is precisely on the axioms, the "foundations." And if there be ideas that so far have undergone little or no reconstruction, how in the light of the history of axioms can we assert that they never will ? ${ }^{1}$ Finally, if history did show that there were ideas which had so far undergone no revision and if we should further concede that they never would or could be changed, we must remember that from the absolutist's standpoint they could not be "true," for they must still fall short of being the whole of reality and therefore in so far must be false.

Behold once more the mockery of the situation! The absolutely immutable world was to be the ground of a common truth and a common good, yet here we are not only without

I Developments of the present generation in mathematics would seem to justify the boy who, upon being told that a certain proposition was "axiomatic," replied: "That may be, but is it true?" 
any perfect truth, but unable to say which of our ideas are more nearly true than others. The conception which was to maintain the distinction of truth and error seems to have ended in its obliteration. We have consented to the reduction of our life to the one business of knowing the absolute reality only to find now that this is impossible; only to discover that knowing is a process whose very constitution and method are inherently opposed to its aim.

And what an anomaly this latter seems to be. Ordinarily we suppose that desire indicates the possession of some capacity, of some equipment, either capable, or capable of becoming capable, of realizing the aim. To be sure, a disappointing quantitative discrepancy between our ambitions and achievements is, alas, common enough. But we do not attempt to run without some kind of legs or fly without some kind of wings. We do not try to turn up the light to look at the dark or to escape death by committing suicide-all of which seem very much like what ideas are attempting in the absolutist's world. 
As we further contemplate the confessedly hopeless opposition between thought's ambition, and its ability, we marvel at the persistence of the tragedy. Why, after thought discovers the futility of its effort, does it not throw up the game? To be sure, the continued failure of thought serves to emphasize the absoluteness of the absolute, and perhaps as loyal absolutists we should be willing to be intellectually damned for the glory of the absolute. Indeed the older and in some respects more consistent absolutism virtually rested its case here. But at this point the modern absolutist begins a new attack on the problem by making a most important and significant concession-one which, some think, marks the first step in the abandonment of his position, and the definite beginning of the present pragmatic movement. This is the admission that, although thought may fail in its attempt to represent or become the absolute, it still is of indispensable service in constituting and maintaining our "practical" social life.

The social value of thought was precisely 
what Plato's absolute was invoked to defend. But we must remember also that, X then turned and devoured the reality of everything in that life except contemplation and left even that, as we have seen, in a very precarious condition. When, now, we begin to speak again of the value of thought in constituting and maintaining social life, this must mean that the instinctive, impulsive, emotional, volitional elements of this life have some worth of their own and are no longer to be regarded merely as signs of the fall from cognitive grace. They must now have at least enough reality and value to account for the persistence of thought in the face of its continued failure in its primary aim of attaining the absolute.

But can we make this reinstatement of the reality of these instinctive, emotional, and volitional elements of experience, and still hold fast to the conception of a changeless reality? Doubtless this restoration makes absolutism more human and hospitable, but by even so much does it not make it less absolute? 
Metaphysically these "practical" elements obviously cannot be left out of the absolute. On the other hand such things as impulse, volition, emotion are very embarrassing things to put inside a static absolute. They are redolent of movement and change, and are lacking in proper respect for absolute unity and completeness.

Heroic efforts have been made to relieve this situation by overhauling and reconstructing the conception of the absolute. The most notable of these attempts are those of Mr. Bradley and Professor Royce. For Plato's absolute system of ideas Professor Bradley proposes, as a substitute, a "whole of sentience." This sounds promising; it looks like a substantial recognition of the disfranchised elements of experience. But when we find that the fundamental attributes of this "whole of sentience" are logical consistency and completeness, the substance of the recognition melts away. And this disappearance testifies again to the difficulty of divorcing absolutism and intellectualism. It is the difficulty in retaining a con- 
ception of a changeless reality that shall not be something simply to be cognized.

Professor Royce's metaphysical revision is at once less and more radical than Mr. Bradley's. Professor Royce retains the Platonic form of a changeless "system of Ideas" for his conception of the absolute. So far it appears to be metaphysically more orthodox than Mr. Bradley's "whole of sentience." But the more radical nature of Professor Royce's revision appears in his introduction of purpose into the absolute. Now the difficulty of investing a changeless reality with purpose scarcely calls for elaboration. But if we say reality is not "invested with" but is the one all-inclusive purpose, and if it is to be nothing but purpose, we have then the anomaly of a reality which is yet purpose only. And if we try to avoid this, as Professor Royce does, by thinking of this purpose as "completely fulfilled," we seem only to repeat the paradox in reverse and aggravated form.

As we should expect, precisely the same difficulties are encountered from the logical 
standpoint. If thought, while failing in its attempt to reach the absolute, is yet indispensable for constituting and maintaining our social life, are we then to regard thought as having two separate and independent functions: first, and primary, to continue forever its hopeless attempt to become the absolute; second, to help constitute and maintain our social life? And shall we have then two criteria of truth-one which is "strictly logical," and which consists in the identity of thought with the changeless reality; the other consisting in the success of thought in its rôle in social life, whatever that shall be found to be? But no absolutist can tolerate such sheer and brutal dualism as this. He must therefore make the attempt to establish the connection between the work of thought in social life, and its ever-failing attempt to become one with the absolute. Prima facie, the project does not look encouraging. To make out an organic connection between the logical failure and the practical success of thought seems a big undertaking. To set out to show how theoretical 
failure is to bring practical success may well raise misgivings at the start. On the other hand, if thought did succeed in reaching the absolute, it would certainly be useless for purposes of social life.

To be sure we may recall here, first, that a difference in degree has been claimed for these "logical" failures of thought; and second, that thought has its defeats as well as its triumphs in the "practical" realm. As for the degrees of success and failure in reaching absolute truth, we have already encountered the "difficulties" in that doctrine. We have seen how impossible it is to distinguish the greater from the less degree of absolute truth without assuming that these are identical with the greater and less degree of practical, social truth. And even if we allow ourselves this assumption, which seems to beg the whole point, we still must show just what kind of intrinsic connection exists between thought's attempts to become the absolute and its rôle in social life.

Here again Professor Royce is the central 
figure, and again as in the metaphysical problem he seeks this connection in "purpose." Professor Royce begins by contrasting the "representative," or "correspondence" character of the idea with its "purposive" nature. He says that modern psychology has discovered that the "primary" character of an idea is not that of algebraically representing or corresponding to something beyond itself (though this may be involved), but consists rather in the fact that every idea is first and fundamentally "an embodiment of purpose," "a plan of action."

Your intelligent ideas of things never consist of mere imagery of the thing, but always involve a consciousness of how you propose to act toward the thing of which you have ideas. . . . Complex scientific ideas are, as Professor Stout has well said, plans of action, ways of constructing the object of your consciousness. . . . The primary character which makes it an idea is not its representative character . . . but is its inner character as relatively fulfilling the purpose ... . which is in the consciousness of the moment wherein the idea takes place. ${ }^{\mathrm{r}}$

I The World and the Individual, 22-24. The italics are mine. 
But how now does this purposive character of ideas in our finite social life make connection with the relation between ideas and the absolute world? In substance the answer is: The idea in its relation to the absolute is also a purpose; or rather in this case has a purpose. Both are thus connected with purpose. But after all, just how close a connection is this? First, there is certainly a considerable difference between being a purpose and having a purpose. But more important is the difference between the purpose which the idea is in its finite practical function and the purpose it has in relation to the absolute. The purpose which the idea is in its practical function has the character of an ideal or "plan of action." But the purpose which the idea has in relation to the absolute is that of algebraically corresponding to it. "It is true, this instant's idea, if in its own measure and on its own plan it corresponds even in its vagueness to its own final and completely individual expression." I

At the outset the purposive function of 'Ibid., 330 . 
ideas is sharply contrasted with the representative function, and is expressly made their "primary" character. But now this contrast disappears. As in Greek and mediaeval absolutism, life had to be reduced to contemplation, so here the attempt to recognize purpose and still retain the conception of a changeless reality ends in the reduction of purpose to representation or "correspondence." An idea is or has a purpose. But that purpose is just to correspond with its eternal and immutable form in the absolute. At the beginning the primary and fundamental character of ideas is that $\checkmark$ they are acts of will; in the end this will is just the will to correspond to the absolute system. And with this we have come full circle; for we must forthwith start again at the task of distinguishing truth and error; that is, of distinguishing between correspondence and lack of correspondence, or between a greater and less degree of correspondence.

Once more the dilemma is: In order to effect a real connection of the absolute with human experience, purpose must be filled 
with all the rich content of human impulses, wants, and all the machinery of social organization for controlling and satisfying and developing these. But in order to preserve the changeless perfection of reality, purpose can have for its content only an algebraic correspondence with the absolute system of ideas which makes it even more vacuous than Plato's "contemplation." 


\section{IV}

\section{THE RISE OF PRAGMATISM}

If the pressure of the difficulties which we have considered in the previous discussion, increasing with each generation, was the negative stimulus to the development of the pragmatic movement, there were correlative, positive forces equally powerful.

In general, the pragmatist believes that his doctrines constitute a substantial part of the advance of the whole modern period. That march he believes has been-with of course the usual amount of counter-marching-in the direction of a self-supporting, self-controlling, self-propelling experience. Whether political or philosophical, scientific or religious, always and everywhere the issue has been essentially the same, namely, whether experience can stand and go upon its own legs; whether it can supply its own motor; whether it can find within itself the source and support of its values of truth and error, right and wrong. 
Let us recall with what high hopes and enthusiasm this expedition of the modern spirit toward freedom and self-determination began. With a confidence as sublime as it was naïve, each of the early leaders, whether in philosophy, politics, science, or religion; whether empiricist or rationalist, materialist or idealist, believed he had discovered the entire way. But when "natural rights" became as tyrannous as "divine rights," and Luther's Bible as infallible as the pope, and when in philosophy Locke reached the frontier of Bacon and Descartes' advance, and Hume confessed that he had completely lost his way, people began to realize that the pilgrimage was to be long and difficult.

But whatever the differences between empiricist and rationalist, sensationalist and idealist, materialist and spiritualist, one common aim stands out-all alike were seeking to escape a world which is merely given, which we must take just as it comes. The modern spirit is bent on helping to make it come. The very essence of modern humanity is the desire 
and determination to have a voice and a vote in the cosmic councils. It is, again, the spirit of democracy.

Such ambition assumes, of course, that the world has, or can be given, (I) plasticity, and (2) continuity enough for the operation of will and purpose. Hence we find the rival doctrines charging each other either with too great rigidity or with discontinuity, or both; and this often in quite a paradoxical fashion. The idealist professes to find the world of the empirical naturalist on the one hand too inexorably rigid for freedom, and on the other, too discontinuous for order and law. Nature, he complains, will not guarantee one of her so-called laws for an instant. That water now seeks its level is no guaranty that it will the next minute. The empirical naturalist can have only lively hopes of the future, but no logical confidence in it. Only in case the world is so organized that we can, through ' ideas or categories, "lay down laws to nature," as Kant says, have we any basis for certainty. Very similar are the indictments which the 
empirical naturalist brings against the rational idealist. What boots it, he asks, to rescue the world from chance or from the clutches of an inexorable system of natural laws, if it is at once delivered over to an equally inexorable system of "ideas" or "categories"? And is not this indeed just what Kant discovers when he faces the problem of morality at the close of the Critique of Pure Reason? He finds that he has only substituted one rigid system for another; that instead of having laid down laws to nature, he has only translated nature's laws into other terms, but without any real reconstruction of them. There is no real gain in plasticity. The certainty of the categories is even more fatally "universal" than the tides or eclipses. As there was yet no evolution of species in the "nature" of Kant's day, $\checkmark$ so there is no evolution in the world of Kant's categories.

To be sure, starting from the apparent discontinuity of Hume's world, Kant's aim was to re-establish continuity, but it still remains that the continuity he reaches is precisely of the 
type of the fixed laws and species of the naturalism of his time-a type which can maintain unity only at the expense of plasticity. On the other hand, when to secure plasticity we appeal from the ridigity of the system of cate" gories to "will," the empirical naturalist says we are again "out of the pan into the fire." We have only exchanged the caprice of nature for an even greater psychical caprice.

The next notable attempt at the problem is Hegel's. He heroically attacked the rigidity of Kant's world, and some of his ardent followers believe to this day that he succeeded in breaking it up. But there have always been too may doubters of this to leave.Hegel a clear title to the claim.

But now comes one whose contribution toward the solution of this problem is unmistakable. And lo! he is not a philosopher, but a naturalist. We may debate. whether Hegel really destroyed the fixity of the Platonic ideas and Kantian categories, but no one doubts that Darwin shattered the rigidity of the naturalism of his day. One wonders that 
there was not a general holiday in celebration of this event. Was not this what the whole modern world-empiricist and rationalist, naturalist and spiritualist-had been struggling toward? If it should be true that not only biological species, but all species-chemical, physical, geological, astronomical, mathematical, political, and religious-are mutable, and therefore amenable to manipulation and control, what possibilities loom! But no holiday was declared. On the contrary, Darwin's doctrine, as we know, met a very cool reception. And a second thought shows the reason. First, mere "mutability of species" as a general conception was not new, and it was not known in just what respect Darwin's view differed from what had preceded. Moreover, what was wanted was not "mere mutability," but a mutability that was connected with, and responsive to, will and purpose. And people were not sure that Darwin's mutability was of this sort. And this is not strange, since Darwin himself was uncertain. Indeed, Darwin's conception of natural selection of acci- 
dental variations seemed to point the other way. It looked, as absolutists said, as if Darwin's mutability might be just another exchange of uncontrollably fixed species for equally uncontrollable change. But Darwin, as all great explorers, went farther than he knew.

At this point the pragmatic movement claims to make its connection with, and its contribution to, the conception of evolution. Up to this time the problem of the connection of the mutability of species with purpose or design was always made the question of whether all possible changes were already included in one all-embracing purpose. But here the pragmatists, or those who were to become pragmatists, observed that, if all possible changes were already purposed, our experience is again just as given and uncontrolled as in the system of natural selection of accidental variations. That is, an all-inclusive purpose is logically the same as caprice so far as the problem of human self-control is concerned.

But, waiving this, does not the conception of 
the mutability of species at any rate make an opening for purposive, ideational control as a type of change? Whether or not all changes are already purposed, does not the simple recognition of the variation of types open the way for any type of variation that may be efficient, and therefore possibly of the ideational, purposive type of variation? That is, must not variation in species admit variation in species of variation as well? The admission of variation of types, with the limitation of the type of variation to merely "natural," that is, non-purposive selection, seems dogmatic, to say nothing of the facts. Variation in species implies at least the possibility of a purposive species of variation.

Meanwhile, the technique of the actual operation of such teleological variation was gradually being worked out in different directions: (I) logically, in the recognition of the control value of the working hypothesis in science; (2) psychologically, in the detailed analysis $(a)$ of the volitional, purposive character of ideas, $(b)$ of their social character. 
The working hypothesis, as employed in modern science, marks the appearance of the conception of evolution in logic. As it is the logical expression of mutation of species, so, on the other hand, it marks the appearance of ideas in the process of evolution. As it is an evolutionizing of logic, of science, so it is a logicizing of evolution. The working hypothesis is the recognition of the efficiency of "final" causes-the rather does it abolish the metaphysical character of the distinction between "efficient" and "final" causes. It means that an idea is itself a real variation, not merely a record or algebraic symbol of a "spontaneous" variation. It is a variation whose value consists precisely in the control it introduces into the "spontaneous" or non-purposive variations. The working hypothesis means, in short, that thought is an actual manipulation of our "spontaneous" experiences, e.g., of motion, light, sound, our pains and joys, our loves and hates, in which these are brought to bear upon one another in such wise as to lead to the control of these spontaneous variations, and to the 
introduction of new variations. Consider, for instance, the enormous consequences of thinking of-of getting an idea of-motion as gravitation; of physical things as made up of atoms or electrons or ions; of light as propagated through the ether.

But this conception of ideas as "real variations" was being worked out more fully in fresh psychological investigations of the volitional or purposive character of ideas. It was the results of these investigations, together with the development of the conception of the working hypothesis, that finally forced the hands of the absolutistic logic and metaphysic. ${ }^{\text {I }}$ The difference between the idea of the psychologist and scientist, and the idea of current logic and metaphysics, became so glaring that it was fast becoming a "scandal." We have seen how absolutism attempted to hush it by recognizing the purposive character of thinking. But we have also seen that this recognition was little more than a social amenity,

"On "The Relations of Psychology to Philosophy," see Angell's monograph, Decennial Publications of the University of Chicago, Vol. III. 
since it reduced purpose to mere representation-the very conception which the purposive character of ideas was supposed to replace.

In these investigations the issue was, once more, whether thinking is only a process of forming symbols of things, or whether it is a process in which things pass into new interactions, and therefore new mutual modifications of one another. If we hear a sound or have an ache and form an idea of it or about it, is the idea nothing but a mental $x$ or $y$, a psychical John Doe for the ache, or is it an act through which the ache or sound comes into connection with something else? If the idea of the ache is that it is a "tooth-ache," this, surely, is something more than a mere algebraic symbol for the ache. Obviously it connects the ache with a tooth and the tooth with the ache. The ache is thus idealized, not by setting up some sort of an algebraic, psychical symbol for it, but by connecting it with something else. If we say, "Yes, but still are we not, after all, just finding out what the pain is?" we must still insist that it is in- 
significant that we take this view of what it "is" - that we should make the is-ness consist in part in its connections with other things.

This conception of ideation as consisting in a connection of things, in its general form, is not new. It has been a cardinal tradition of idealism since Kant, especially since Hegel. Hegel's constant appeal to the process of "othering" has its counterpart in English philosophy in T. H. Green's apotheosis of "relations." This, I take it, is the essential contribution of Hegelianism to logic-the insistence that an idea is not a mere algebraic symbol, but that it is an act in which things pass into new interaction. And no one is likely to overstate the importance of this insistence. But in the form in which Hegel leaves it, there are serious difficulties. If having the idea of a thing means referring it to something else, what is this something else to be? Does it mean to anything else whatever, or everything else, or to a certain thing, or things else? And if the latter, what determines these certain 
things? As soon as we put these questions to the Hegelian logic, its fundamental difficulty appears, viz., the lack of any principle to limit and to control the "othering." There is nothing to determine whether the ideaizing of the ache shall connect it with one thing rather than another. So far as Hegel's general principle goes, anything would do-the moon quite as well as a tooth.

And obviously, with nothing to set any limits to, or to determine the direction of, this "otheration," there is no basis for distinguishing between a true and a false "othering." If knowing is just referring anything to some "other," then any "other" is as true or as false as any other "other."

Recognizing the absurdity of this, but with no method or principle of selection and limitation, the Hegelian logic, in spite of its vehement emphasis of the importance of "limit" and "concreteness," is forced finally to maintain that a true idea of a thing must consist in connecting it with everything else. Once start to define your ache and as a logician you dare 
not stop short of the universe, even if, as a suffering mortal, you do stop at the dentist's.

To be sure, Hegel, perhaps even more frequently than many of his followers, insists upon the thing and "its other," and upon the necessity for selection and specification. But nowhere does he lay down the principle-the basis for it. He recognizes that science consists in the connections of things, but with no basis for limiting the process of connection, it runs into endless regression, and forthwith must be pronounced, and properly, "appearance." In the toils of this dilemma, says the pragmatist, the Hegelian logic languishes unto this day. As a finite sufferer seeking relief, or as a physician seeking to relieve, I cannot go on to connect my ache. with the entire universe, but as a logician I cannot stop short of this, though, as Mr. Bradley has shown so tragically, there is no more hope of succeeding in this than of curing the ache by it.

Now the pragmatist believes that there is an efficient limiting principle for this "othering" process, and that it is to be found in the 
fact that this "othering" does not take place wholly on its own account, just as the expression of a separate self-contained and independent instinct for "othering." He finds that it is connected with our direct experience of the value of the sound or ache, and with our desire or purpose to retain and develop that value, or to get rid of it. If the experience is of such a character that we have not already an acquired, habitual method of holding fast to it or getting rid of it, or such that we cannot operate upon it directly through a shift of attention, we then seek its control through something else as its "condition" or "cause." For a pragmatist, the "other" of a thing-"its other"-is just that thing (or things-“"content" if we prefer a little more idealistic term) which helps to retain or get rid of-in short to control-that thing, and an idea is just the act by which a thing is brought into relation and interaction with its controlling "other."

Little wonder that Hume felt that the whole problem of knowing-i.e., of synthetic, valuable knowing-is bound up with the relation of 
cause and effect. Hume's emphasis of cause and effect is his half-conscious recognition that knowing is purposive and not a mere connection of things in any and every way. I say half-conscious recognition-for his failure to carry this element of purpose and desire over into the process of the connection, his leaving it as a process of mere association and habit, shows that the recognition was very vague.

Now, if an idea is something more than a mere algebraic symbol, if it is the essence of an idea to so connect one experienced thing, or quale, or content, with another, that it may be maintained or eliminated, or in some degree altered, it would seem to follow that the chief difference in the character of ideas would be the difference in efficency in effecting this kind of connection, and if "true" and "false" are the positive and negative terms for this primary character of ideas, the "true" idea of the ache or sound will be the idea in which it is brought into connection with something, with an "other," which, directly or indirectly, conditions its alteration or maintenance. 
This brings us to the much-discussed and much-misunderstood definition of truth as the "working" quality of an idea, about which the earlier discussions raged. 


\section{V \\ HOW IDEAS "WORK"}

When true ideas were said to be the ideas which "work," the loose and very general phrase "which work," taken out of its connections, was an easy mark for the critic, who lost no time in reminding us that false ideas seem to be as industrious as true ones, that error gets up as early and stays up as late as truth, and often appears to work overtime.

But the pragmatist hastened to point out that these shafts lose most of their point and force as soon as the phrase is put back into its context, where it clearly means "which work in the way they set out to work.") The idea of an ache as the ache of a certain tooth is true, if an operation on the tooth alters the ache. If "pulling" the tooth does not stop the ache, the idea is not true, even though it bring some other, and possibly greater, satisfaction, e.g., the restoration of eyesight. If Saul goes to seek asses and finds a kingdom, while the 
kingdom may be a very satisfactory substitute for the asses, it does not make the idea of the whereabouts of the asses true. The idea is a $\downarrow \checkmark$ proposed connection of things for a specific end, and is true when it works in the way proposed. But it is important, says the pragmatist, to keep in mind that the proposed working means, in the end, control of the original experience which is the "subject" of the idea. If having an idea of a thing means only the possession of some sort of a psychical symbol for it, why should there ever be any failure? Anything will do for a symbol. Every idea would work. There could be no error.

The critic next propounds what he regards as a far more crucial question, namely: "Are ideas true because they work, or do they work because they are true?" Must not the ache be related and connected, realiter, with the tooth in advance of the idea of this connection, in order that the idea may work successfully and so be true? Is not therefore the entire preceding account of the idea of the ache, as an act of connecting the ache with the 
tooth, up-side-down in so far as it speaks of the idea as if it were making a connection? Is not this connection simply found, and are we not therefore thrown back again upon the strictly representative function of the idea?

This objection is credited as the special contribution of the "neo-realist" critic who defends $v$ the thesis that thinking makes no "essential" difference to the things thought of or about. Verily it is not politics only that makes strange bedfellows. Here, in the face of his tradition of the "active" character of thought, of the essence of thinking as consisting in a relating activity, the absolute idealist joins with the realist in maintaining against the pragmatist that our ideas can only find, not make, connections between the ache and the tooth. However, we have only to recall our earlier discussion of absolutism to see that this alliance is, after all, quite consistent. We there saw that the "active," "relating," "connecting," "constitutive" character of thought, of which historic idealism makes so much, applies, in the end, only to the ideas of the absolute, not to ours. In its conception 
of finite thought, absolute idealism is as realistic as any arch-realist could wish. And as it is precisely finite thought that is under discussion, the absolutist finds himself shoulder to shoulder with the realist against the pragmatic contention that finite thought, our thought, makes a difference in the "things thought of."

Returning to our particular case, suppose we agree that there exists a connection, objective and realiter, between the ache and the tooth before there is an idea. It surely does not follow that this connection must remain the same after the idea arises, or that all the idea can do or aims to do is algebraically to symbolize this connection. Nor does it follow, as some critics have assumed, that, if the situation is objectively altered in and through the act of ideation, the idea is therefore the creator of all the connection there is, and even of the "things themselves."

But, says the realistic-idealistic critic. We admit that ideas make a difference. They make just the difference of the addition of thought. The ache and tooth are now objects of thought, 
whereas before they were not; but the only difference is just this addition of ideas to the situation.

But, returns the pragmatist, if thought is something merely added to the situation, without making any "essential" alteration, (I) why is it added? (2) how are we to tell whether it is rightfully or wrongfully, i.e., truly or falsely, added? (3) if the ideation of the ache as toothache is merely an addition of a factor which makes no "essential" difference in the situation, again, why not refer the ache to the phase of the moon, the day of the week, or anything else we may fancy?

Let us consider further the situation before and after the idea. We have agreed that before the idea the tooth and ache are "objectively" connected. Indeed, in one sense there is too much connection. They are so merged that mutual reference and mutual control are impossible. What is needed is a certain amount of disconnection, of disentanglement, and of re-articulation. If we wish to say that before the idea the tooth is the "cause" of the ache, 
after the idea it certainly is something more. The moment the pain is referred to the tooth, the tooth ceases to be merely the cause of the pain. Indeed, it then begins to cease being the cause of the pain. It now begins to be the cause of the pain's cessation. From being a mere condition of the pain, it begins to be through the ideating process a condition of not-pain. As Hegel would say, it is now aufgehoben, and passes into its opposite. Here, indeed, is the source of Hegel's riotous dialectic, but here also is the principle for the control of that riot. For Hegel, this passing of a thing over into "its other" is just a peculiar and ultimate effect of thinking. Think about anything, and presto! it begins to become something else. And so it does. This, indeed, is just the pragmatic thesis. But what it becomes depends on the problem and interest. Let us suppose there were no desire to get rid of the pain, and that in some way-as an act of an "ideational instinct" - the pain should be connected with the tooth. What transformation of the tooth or the pain would there be? Nothing would be aufgehoben in 
this case. The whole dialectic would be stopped in its tracks. Is it not clear that the reason that there is a dialectic of thought is because at bottom thought is a part of the total process of an efficient desire and effort to effect a change in experienced values?

But our realistic critic will still insist that this reference of the pain to the tooth is not the "real" beginning of a new interaction between the tooth and the ache. It is just a preliminary, a getting ready for the beginning of such an interaction. ${ }^{x}$ The tooth doesn't "really" take on any new relation to the ache until the dentist gets hold of it. But how does the dentist come to get hold of it? Is it not precisely because the tooth has been actually operating as a guide to both the patient and the dentist from the moment the pain is ideated as pain-of-atooth?

But what now, says the critic, of the case in which the pain is referred to the wrong tooth, or

r The question of where a beginning begins should have no terrors for the pragmatist. Greek discussion showed once for all that the only method for the solution of that and all other questions of the kind is the "teleological," i.e., the "practical" one. 
to the ear, or a demon, instead of to the right tooth? Is this, too, a "real" and objective transformation of a "real" situation? "Verily," rejoins the pragmatist. "Is not an act which culminates in 'pulling' the wrong tooth, or the treatment of the ear instead of the tooth, or in making a libation instead of a potation, a very 'real' alteration of a very 'real' situation?"

But, rejoins the critic, the pain after all doesn't belong to the other tooth, nor to the ear, nor to a demon, and does continue to belong to "its" tooth after the idea, whether true or mistaken, as before. If this were the case, rejoins the pragmatist, it would not be to the point, which is-not that nothing remains after the idea as it was before, but that the idea marks the initiation of a new connection between things, which, even if it occurs through an idea, is none the less real. As a matter of fact, after the ideation the ache not only "belongs" to the tooth as it did before, but through its reference to the tooth by the idea, whether this be true or false, it is put into connection with other 
agencies such as the dentist, or a potation, or a libation, etc.

Nor does the fact that the new relation and interconnection may be false or wrong, i.e., not effective for removing or altering the ache, make it any the less "real." Once more, the "pulling" of the wrong tooth is certainly no less "objective" than "pulling" the right one. In short, error, says the pragmatist, is just as strong a witness as truth for the contention that thinking is a process in which things enter into new and "real" interaction."

To the question, What of the madman's ideas? the pragmatist says that the guards, the barred cells, the taxes ought to be a sufficient answer. If a madman thinks you are his enemy and therefore to be destroyed, you will scarcely feel safe on being told that you are "really" not his enemy and that his idea is false. And, to be

I If anyone complains that the toothache-case is one which offers the least resistance to the pragmatist's interpretation since in it the thinker is the one who has the pain, the pragmatist will reply: (I) that "the toothache case" is not of his own choosing but one selected by the critics as a "poser" for pragmatists; and (2) that in principle it makes no difference whether the pain is "in the same head" with the idea or in another. 
sure, safety does not arrive merely by thinking of having the madman shut up, but it starts with some such idea.

Another way of stating the source of the difficulties in the realist's position, says the pragmatist, is that the realist thinks of the situation which precedes and leads up to thinking, wholly in existential terms. He omits the elements of motion, of impulse, and of desire in it. Thus in the instance cited he thinks of the "real" situation preceding thought as made up of the "fact" of the pain, the "fact" that, entirely independent of any ideas, it is already connected with a certain organ; and, if we extend the boundaries of the case a little, the "fact" that the physician is in a certain place, whatever the patient's or anybody's else ideas about his location may be. This, with as much more of detail as one wishes, is the objective "real" situation which it is the business of thought merely to represent or point at.

But this is a very incomplete statement of the whole situation. First, there is the desire to get rid of the ache. It is this desire indeed that 
develops into ideas of the location of the ache and the physician. These ideas are but this desire getting into definite, efficient working form. And, as we have seen, this stops with no mere process of algebraic symbolization. The idea of the ache is of it as a "toothache" or "earache," or ache to be cured by the physician and of the physician as the curer of the ache.

Further, there is the "fact" that, however certain, definite, and complete may be the physician's location from the standpoint of those to whom the finding of the physician is no problem, it is no less a "fact" from the standpoint of the patient that his location is "uncertain" and "indeterminate." And if the patient's standpoint is as important in the situation as the physician's - and it would be hard to convince the patient that it isn't - what right have we to state the fact of the physician's location entirely from the standpoint of those who happen to be in an unproblematic space relation to him and call his location fully and completely determined, when for the patient and perhaps 
for many others it simply is not? Isn't this sheer superstition? Whatever the physician's space situation, it is "such that," to use a favorite phrase of the mathematician, although it may be determined for $\mathrm{A}$, it is just as undetermined for B.

Here we shall doubtless be told that this problem of "location" is a space problem, and that space relations at all events are not dependent on ideas; that the space relations of the patient and physician are perfectly definite and determinate and wholly independent of the "aches" and "wants" and "ideas" of either the patient or the physician; that an object in space cannot be both determinate and indeterminate, or determined on one side and not determined on the other. Surely, it will be said, it is just the essence of the space world to be completely defined. Every object in space must be a perfectly definite and determinate relation to every other, entirely independent of wants and ideas. ${ }^{\mathrm{I}}$

I This objection suggests that this conception of space may be the prototype, not to say parent, of the whole realistic con- 
First, we should observe that for the mathematician this conception of complete and independent determination of the space relations of objects applies not to such "objects" as a person with a pain or a physician seeking patients. The only "object" whose location for the mathematician is so completely determined is just a point of space itself, not an object in space. The moment we apply this complete determination to an object in space we land at once in the Eleatic's motionless world and have on our hands all of Zeno's puzzles. The conception of complete spatial determination will not apply to a moving object. A moving object is as much undetermined as determined. Any attempt to include motion itself in the complete determination reduces it to space, for in the conception of completely determined motion, all possible motions must already have taken place-all aching teeth must have been eternally "pulled." The objector will doubtless admit ception of "independence." The realist does not, to be sure, speak of his world of "independent things" explicitly, in terms of space relations, but the problems it presents are so homologous to those of space that it suggests a close kinship. 
that there is the pain of the patient and his uncertainty of the whereabouts of the dentist, but these-well, they just belong to the patient, not to the real and objective situation. In short, the location of the physician as a physician, in Plato's phrase, not a mere "point" in space, depends in the last analysis upon his operative relations to the patient; and uncertainty and ambiguity in this relation-no matter how unambiguous may be the relations of points in abstract space, and no matter whether the ambiguity is at the patient's or physician's end of the relation or both-are "real" characters of the situation to be overcome with the help of ideas, if so be. ${ }^{1}$

No doubt the realist will still insist that this ambiguity and indeterminateness of the physician's location is all in the patient's "mind," not in the world of "things," but the pragmatist persists (and here he would side with the idealist, if the idealist would only include our ideas in his idealism) that this indetermi-

r Of course, no situation is wholly indeterminate; the ache is already defined as the "ache of the tooth or of the ear," and the physician as "somewhere in town," etc. 
nateness and uncertainty of mind is an indeterminateness in the "real" operative (not the abstractly spatial) relations of things. The location of the physician-as a physiciannot as a point in space-is determined surely by the part he can play in altering aches and pains. Space is not something in which the physician merely is; it is a relation in and through which he operates. Take away this element of operation and there is nothing left with which to determine either distance or direction. The final test, as it is the final source of all determinations of space and motion, is the capacity for the maintenance or alteration of such values as our long-suffering and suffered toothache, the sound of a symphony, the imagery of a poem, the love of a friend, etc.

But the difficulty which the realistic critic regards as the most crucial for the pragmatist's thesis-that thinking is a perfectly continuous part of the real interaction of things-is knowl- $v$ edge of the past. However it may be with present and future things, the past surely undergoes no alteration in "being known." It can 
only be represented, symbolized, pointed at. "What's done's done." "Banquo's dead and cannot come out on's grave." Yet what say we of Macbeth's miserable cry, "If 'twere done when'tis done," and of Brutus' "Thou art mighty yet"? Are they after all "mere rhetoric"?

In general it is difficult for the pragmatist to see how pastness can be a special or specially difficult case of knowledge since from his standpoint it is involved in every act of thinking. For him thinking is just a process in which "things" produced in the past recombine or interact to produce new "things." It is to be noticed that the crucialness of these cases of the past seems to be greater in proportion to the amount of the pastness. Hence we find the instances usually selected from the remote past; "Caesar's passage of the Rubicon," and "The discovery of America" are the well-worn citations. And yet perhaps some who would at first be disposed to agree with the realist that our knowledge of Caesar's passage of the Rubicon makes no difference in it now, might hesitate to say that its "being known" by the Senate and popu- 
lace of Rome, and its being expected by Caesar to be so known made no essential difference in it then. But in principle the case is the same, whether the pastness be a second or a century. To be sure, the present operations of Caesar's act through acts of knowledge are doubtless less extensive and important than they were 50 B.c. But whatever the character of its operations, even if they are confined to the second year of high school, the method of operation, that is, through the process of knowledge, is still the same. And it would not seem to be a great strain upon the imagination to think that a man of affairs in time of a crisis might still be influenced by Caesar's example. But whatever the extent or the nature of the operation as a matter of fact may be, Caesar's act, like John Brown's, "goes marching on." Like all other historic acts, it is not yet finished, and never will be $\checkmark$ so long as it continues, through acts of knowledge, to produce new "results."

Let it be remembered, insists the pragmatist, that this doctrine of the real efficiency of thought does not teach that thinking undoes 
or reverses or blots out any thing or event that has happened. It insists only that in becoming known or entering into knowledge a past act is altered in the sense that it takes on additional functions and consequences.

This last statement will doubtless suggest to the realist: (I) that the pragmatist is entirely overlooking the distinction between a thing or an act and its "consequences"; that being $\checkmark$ known does not add anything to the past act itself, but only to its "results"; (2) that the thing or act must first be "known" before the "real consequences" can occur, in so far as they occur through knowledge.

The first point precipitates the ancient metaphysical puzzle of the possibility of separating a thing from its effects, its is-ness from its does-ness. It is the old problem of the thing-in-itself. The realist's objection implies that the line between a thing and its consequences can be drawn ontologically and existentially, and is a fixed one. Yet when we apply this distinction to a specific case we are forced to make it a "working," not a metaphys- 
ical one. That is, we find that its location varies with our problem. Where, for instance, are we to draw the line between the "thing", typhoid fever, and its "effects"?

This of course does not mean that the making of this distinction is a matter of the arbitrary whim of the moment, as some have imagined. It means, only, that it shifts with the analysis and development of the problem. Nor must this "functional" interpretation of the distinction be considered, as it often is, as an attempt to abate or cheapen its importance and reality. It intends only to state in what this importance and reality consists.

However, the essence of the pragmatic view does not depend on this distinction. Whether we say the change is in the "thing" or "event" or only in its "consequences," the pragmatist's contention is that this change actually begins in the act of thinking. And this brings us to our critic's second point, namely: Granting that things and events acquire new consequences or new functions as a result of acts of knowledge, yet even so they must be known before these 
new consequences or functions can begin. The general form of the problem here is the same as in the first point, viz., the problem of introducing an ontological separation into. a continuous process without destroying continuity. If by "first being known" is meant that the thing or event enters into a relationship of a unique self-contained character called "knowledge," and is not even the beginning of the process of "real interaction," then we must ask: When does this "real interaction" begin? If the interaction "depends" upon knowledge and yet is no part of it, how then is this state of $\checkmark$ just "knowing" or "meaning" or "pointing at" a thing transformed into "real interaction"? Psychologically it is the old question of the connection between cognition and will. If knowing is so qualitatively and functionally different from alterative action, how do we make the transition from it to efficient action?

These are some of the questions ${ }^{\mathrm{I}}$ which the

I For additional questions and a keen analysis of the realistic position, read Schiller's discussion of Nunn's paper on "The Independence of Secondary Qualities in Perception" in the current volume of Proceedings of the Aristotelian Society. 
realistic critics have not yet met, and it is the pragmatist's belief that when we come to deal in detail with such problems, we are forced to transform a "representative" into "operative". realism.

For the pragmatist, knowledge is the beginning of new interactions or, if we prefer, of new "consequences." But the beginning of a new interaction is always to some extent ambiguous and confused. This first stage of new activity, therefore, is occupied with getting rid of this confusion and this process the pragmatist calls "thinking." On this view we do not have to jump out of a unique and separate and selfsufficient state of knowing into "real" activity. The knowing is our desire, our will, our "practical" interests getting out of ambiguity and confusion into order and efficiency. If, as a matter of terminology, we wish to say that the "real interactions" and the "real consequences" do not begin until after this confusion is cleared up, then we may say that the thing must first be known before, or in order that, "real" consequences may occur. But the 
process is a contimuous one; it is all of a piece; it is not split into parallel strands of "thought" and "will."

Concerning the way ideas "work," the case then between the pragmatist, the realist, and the idealist stands thus:

$\downarrow$ The pragmatist agrees with the realist (I) that the "world" or "experience" (the term does not matter here) does not consist of "a system of ideas"; (2) that ideas do not aim or "desire" to absorb, or be absorbed by, the rest of the "world" (or "experience"); (3) that at any given time some of the world (or experience) may be "independent" of knowledge in the sense that it is not then "being known," that is, it is not in the knowledge mode or stage of action. But at the next step, where the "unknown" part of the world (or experience) passes into knowledge, the pragmatist and realist part company. For the realist this passage occurs with no "essential" alteration in the material which enters into knowledge; while the pragmatist believes knowing to be a part of the process in which the world of 
"things" or "events" or "experience" brings forth new "things" or "events" or "experiences."

Between pragmatism and idealism there would be a vital point of agreement in the conception of the "active," "constitutive" character of thinking if it did not turn out that for most idealists this character does not belong to "our" thinking, but only to the absolute thought. Here the pragmatist declares that the idealist's faith in the fundamental article of his own creed falters, and that pragmatism in teaching the efficiency of "our" thinking is saving idealism from its own unbelief.

Owing to this lack of faith, idealism agrees with realism that our ideas can only algebraically represent or "mean" or "point at" a world of reality "beyond." The disagreement consists in the fact that while the realist's ideas are quite content with this rôle, the ideas of the idealist long to swallow, or be swallowed by, the rest of the world.

Nore.-This chapter was published in the Journal of Philosophy, Psychology, and Scientific Methods, November го, г910. 


\section{VI \\ TRUTH-VALUE ${ }^{\mathrm{x}}$}

As I read the note of the committee on program inviting me to present a paper on "Truth-Value" I thought at first: How delightful to have a subject so free from the "dust and blood of the arena." For however much we may disagree, about the nature and the criterion of truth, we are all sure of its great "value." We are all prepared to say, as one of Professor Angell's elementary pupils once said of the nervous system, "What should we do without it!"

But, alas for him who reckons without the guile of the program committee! That committee knew full well that it might have difficulty in finding someone-even a pragmatistwilling to talk further at this time on the "nature" or "criterion" of truth. And it

I One of a series of papers read at a symposium on "Value" held at the meeting of the Western Philosophical Association, in Chicago, January, 1908, and afterward published in the Journal of Philosophy, Psychology, and Scientific Methods. 
knew equally well that any attempt to expound the "value" of truth, apart from its nature, could end only in pious exclamations. It knew that every attempt to describe truthvalue and to discriminate it from other values, must be a description of its nature. So when the familiar refrains and the old shibboleths sound in your ears, I hope you will remember who is responsible. Not that the last word has yet been spoken on the nature and criterion of truth, but that so much has been said in the search for that word that I fear many of you would fain turn awhile to other problems.

If we begin with the most general and formal phase of the subject, the usual statement is that truth and error are values belonging to the experience of judging. But such a statement is obviously verbal until we go on to state what the value of this judging experience is. And this brings upon us at once the entire problem of the place and function of judging in the whole process of experience, and with it the issue between logical-absolutism 
and certain forms of realism, on the one hand, and "instrumentalism" on the other.

The contention of the logical-absolutist is that truth and error values are the satisfaction and the dissatisfaction of a special and independent "want" or "side" or "aspect"using Mr. Bradley's phrases-of our nature. In his article on "Truth and Practise" (Mind, I904), Mr. Bradley says: "Reality is the satisfaction of all the wants of our nature, and theoretical truth is those perceptions and ideas which directly satisfy one of those wants." Thinking, then, appears to be the operation of a specialized instinctive want co-ordinate with the other instincts, as eating, drinking, reproduction, etc. Indeed Mr. Bradley comes near to saying this in so many words, albeit somewhat facetiously, when he says: "Metaphysics is a finding of bad reasons for what we believe on instinct-but to find these reasons is no less an instinct."

With truth-value thus based on a special

r In his paper which followed this at the symposium, Professor McGilvary frankly states and defends the special-instinct view of thought, using eating and drinking as analogues. 
and independent instinctive need, an uninitiated observer might at first sight wonder that the supporters of this view are so shocked at Professor James's metaphysical pluralism, for this conception surely appears pluralistic enough. But a second look dispels the wonder. For with so much logical and psychological pluralism as this instinct-view of thought involves, nothing short of an omnipotent metaphysical absolute can save unity and continuity. On the other hand, Professor James can revel freely in his metaphysical pluralism just because he has so fortified his logical and psychological continuity in human experience that he can rest assured that no pluralistic metaphysical horde, however great, can ever destroy it. In general it appears that what we neglect in our psychology and logic we try to make up in our metaphysics. Metaphysics seems to be a sort of clearing-house for the accounts between our logic and unreflective experience.

And while we are about it another paradox or two in the situation may be worth a glance. Behold the immediate-empiricist, Dewey, insist- 
ing upon the mediate, instrumental character of thought, while the absolutists are contending for its independent immediacy. Again, the logical-absolutist not only professes to accept the instrumentalist's doctrine of the relativity of truth and error to need, want, and purpose, but characterizes it as a "truism." In the article above cited, Mr. Bradley says: "To me it seems obvious that if some function belongs to our nature there will be a need and a desire which correspond to that function. Hence if the free use of the intellect is really one aspect of our being, we shall in consequence have a need and a desire for that use." Likewise we find the absolutists, Royce and Taylor, and the realist, Perry, all agreeing that true judging is the satisfaction of a want-a purpose-namely, the purpose to judge truly!

The instrumentalist's reply is that this is indeed not only a truism, but an unblushing petitio of a real issue, and that to him the truly pathetic thing is his critics' complacent satisfaction with it. Suppose we say: "Truth is what satisfies the cognitive need." "How 
trifling!" Locke would say, until we go on to show what the cognitive need is, how it differs from other needs, and how it goes about satisfying itself. In such questions as these the real issue between the absolutist's and the instrumentalist's logic is defined.

If truth be the satisfaction of a special instinct co-ordinate with the other instincts, obviously we must at once ask: What is this instinct's peculiar satisfying material or object? And here we seem halted; for there appears to be no special object analogous to those of the other instincts. The content of any thought always turns out to be the material of some other instinct. Besides, if thought has its own special material, what becomes of its universality?

"Universality"! That word gives us a new cue and suggests that we may have been on the wrong scent for the object of the cognitive instinct. For does not universality belong to such things as major, minor, and middle terms? Here, then, perhaps, is to be found thought's satisfying portion. The cognitive need is a 
hungering for universals and particulars, a thirsting after subjects and predicates, a yearning for syllogisms and episyllogisms; while negatively it is a congenital horror of such things as illicit majors and minors and undistributed middles.

This gentle mockery, I am sure, cannot give offense, for nothing could surpass the contempt with which absolutists themselves have rejected formal logic-for instance, the hilarious scorn which Mr. Bradley heaps upon the devoted head of the syllogism. The reasons for this repudiation are familiar. I need mention only a few of them. First, if the formal processes were the satisfying content of thought, the material ought to be perfectly indifferent. The length of the Devil's tail or the color of Eve's eyes should be as satisfying material as anything else. Again, if the material be indifferent and thought goes on according to its own independent and immutable laws, where is there any place for error, for dissatisfaction? Once more, if dissatisfaction does somehow arise, what is to determine when truth is reached 
again? If we answer: "Simply the sense of consistency peculiar to the cognitive instinct," what saves thought from the subjectivism alleged to characterize the other instincts, as hunger, thirst, etc. ?

The situation at this point is, then, that, if the formal processes are rejected, thought, though a special and independent instinctive need co-ordinate with the other instincts, has yet no corresponding peculiar satisfying material. What is to be done? What has been done so far in history of logic is to compromise by admitting the dependence of thought for v its material upon the other instincts, but still clinging to its independence as a process. The consequence of this compromise has been the train of incurable "contradictions" and "antinomies" which have harassed the entire history of logic, and which end in the confession that so long as the cognitive instinct must be dependent on the other instincts for its materials no "perfect" satisfaction, no genuine truthvalue is possible. The indispensable condition of reaching such a state, says Mr. Bradley, in 
effect, is that thought should be independent, not only as a process, but in its material as well. That it should, in short, produce its own material. ${ }^{\mathrm{x}}$

We all know how, at this point, Professor Royce came valiantly to the rescue with his famous map of England and the self-representative number-series as illustrations of how thought could produce its own material. But many think: (I) that even in the self-representative number-series the contributions of the other instincts are discoverable; and (2) that, as an illustration of what thought can do in the way of producing its own differences when the other instincts are shut out as far as possible, the result is not very promising in the way of variety.

At about this stage of affairs the "instrumentalist," "pragmatist," or "evolutionist" (whatever you will) came into the discussion. He began by agreeing with Bradley and Royce that the one thing needful is continuity between the process and the content of

I Appearance and Reality, 2d ed., Appendix, 562 ff. 
thought. But the attempt to secure this by having thought produce its own material had, in his opinion, failed. Falling back, then, upon Bradley's position that thought draws its materials from the other instincts, and groping about for a new clue, he kept putting such questions as these: What determines when thought draws upon the other instincts for material? And what determines what material it selects and just what it is to do with them? Observations in response to these inquiries seemed to show: (I) that the materials selected are always those of instincts which have come into conflict in the process of satisfying or "expressing" . themselves; (2) that it seems to be the work of thought to deal with this conflict; (3) that it sets about this through analysis and synthesis; (4) that success or failure in effecting the resolution of the conflict marks the limits of this process of analysis and synthesis, i.e., determines specifically truth and error. Concerning truthvalue he could say, so far, at least this much: that thought's satisfaction is not independent of the satisfaction of the other instincts. 
Rather does it seem to find its satisfaction precisely in quelling the dissatisfaction due to the conflict of the other instincts. Their extremity is thought's opportunity.

Still the breach between the process and the material of thought remained. But, said the instrumentalist, there is yet an alternative, namely, the reverse of Royce's experiment. That is, instead of attempting to meet Bradley's demand for continuity by having thought produce its own material, why not have the material produce its own thought? The term "produce," however, leaves the connection still too loose. Rather, why not regard these instincts in con- flict as developing into both the process and the content of thinking? Just as the contents of the conflicting instincts are not left behind when thought begins, but go on over into the thinking as its content, so, on the other hand, there is no thought machine or faculty already there in advance waiting to receive the material of these instincts. The process of thought is just the process of this conflict of instincts working itself out through interaction with other and for the 
present purpose more stable values. Here no specter of the "given" need haunt our logic. For this ghost pursues only that logic which assumes a pre-existent, purely cognitive faculty, or machine, or agent, or entity of some sort, to which this instinctive material is to be "given."

It should be understood that we are not speaking here, as so many have supposed, of an absolute origin of thought in the universe. The instrumentalist may readily agree that as this conflict of instinctive values has always existed, so thought has always existed. And that as this previous thinking results in reconstructed instincts, so any present conflict is, in this sense and to this extent, an outcome of previous thinking. But he insists that this previous thinking, as the present, was not performed by a purely cognitive agent, or faculty, or instinct, upon a material "given" to it by the other instincts.

Also this view does not mean, from the standpoint of value, that this readjusting, revaluing stage into which the contents of 
the conflicting instincts pass has not its own peculiar value; nor that it may not be regarded as an "immediate" value, as all value, in a sense, must be. But it insists that we must keep in mind that the content of this "immediate" value is just this entire experience of conflicting instinctive values undergoing mediation and revaluation. It is the value of experience as undergoing control in contrast with experience in chaotic conflict; but not control by a special faculty or instinct of control. Control is a "stage" of experience, not a "part," or "side," or "phase" of it.

There is, to be sure, always in this revaluation or control stage some value (or values) that serves as the end or purpose. But the control is not all lodged in the purpose. The end is only one pole of the whole process of gaining control. In this sense the end is a means of control. But, again, the main point here is that the end is not furnished by an outside, independent faculty or instinct which operates as a special "end-factory," whose 
business it is to keep a supply ahead or, failing this, to make one "while you wait." This end is born of the conflicting instincts. It is bone of their bone and flesh of their flesh.

The implication is, then, that truth-value is not the satisfaction of a special instinct coordinate with the other instincts, but that it is the value of the entire experience of readjusting conflicting values through the process of redistribution of values effected by interaction with a wider and more permanent range of relevant values. $^{x}$

I am painfully aware of the extremely general character of all this; that it gives no details of this revaluating stage; that it leaves unnoticed the different elements in the constitution of truth-value out of which spring the ambiguities of the term "truth," in which it is identified now with the subject, now with the predicate, of the judgment; now with what we have attained, again with what we are

'One of the best papers I know of on the relations of thought and value is Professor H. W. Stuart's paper on "Valuation as a Logical Process" in Studies in Logical Theory, $227 \mathrm{ff}$. 
seeking. I am mindful that we have not touched that old, but ever-perplexing, tangle of relationships between truth-value on the one side, and ethical, aesthetic, and economic values on the other. We say in one breath that truth is a value belonging to judgment as such, and in the next we speak of ethical, aesthetic, and economic "judgments." Does truth, then, belong only to one kind of judgments? Or are ethical, aesthetic, and economic judgments special forms of truth? Or are they all coordinate values belonging to every judgment? Or are they stages through which every judgment passes? And if so, what determines these stages? But in the time allowed for the paper much must be sacrificed, and I wish in the minute or two left to anticipate two or three general objections.

The first is likely to be the usual challenge of - this whole conflict-mediational view of thought and its value. "How," it will be asked, "can $\checkmark$ it apply at the level of perceptual judgments?" e.g., "This is paper," or "This paper is white." Where is the conflict here? "Well," the instru- 
mentalist will answer, "there may not be any conflict. But if there is not, then there is no judgment." And he will declare that here, as so often in philosophy, language bewrayeth us. We assume that, because we repeat the words that have expressed, or might express a judgment, they do now. And he will suggest that a simple but effective way to test the presence of a real "live" judgment, to use Dr. Thompson's term, is to preface the alleged judgment with the term "I think," or "I judge," or "I have an idea." If the statement "This is paper" means "I think," or "I judge," or "I have an idea" that it is paper, then it is a real judgment. If it does not mean this, it is merely a direct articulatory response to the visual and tactual stimulations, and is no more a judgment than tearing it, or poking it, or setting a match to it. Once more, judging means inquiry; inquiry means doubt; and doubt means conflicting impulses.

Again, it may be said even if conflict in immediate experience does lead to thinking, it is no less obvious that thinking leads to conflict. 
What experience more common, alas! than to find that the more we think the worse the tangle becomes. But this is only the familiar paradox of "fighting for peace" or a "painful cure of a pain." Obviously, as the conflict develops into the thinking stage it may prove to be much more far-reaching and deep-seated than it was immediately felt to be. Fortunately, on the other hand, it often, if not so often, turns out the other way.

Admitting once more the conflict character of knowledge, it will be said, as it has been said, that this problem is not experienced as a conflict of instinctive values, but is experienced from the very start as a cognitive problem, as a problem of knowledge. The answer is: Of course it is. For when the conflict in immediate values has gone beyond the blind pull-and-haul, thrashing-about stage, and has developed into the problem form, it is already in the cognitive stage, and is, of course, so experienced.

As for the objection that this view of thought value "subordinates" the intellectual "side" 
or value to the other "sides" or values, I confess I am unable to see how the conception of thought as the experience in which already constituted values are reconstituted, revalued, makes it subordinate to these values. The converse would be as true-and as false. As true and as false as to say: "Speaking is subordinate to words or painting to colors."

Finally, it may be said that this "instrumental" view of thought destroys the character of immediacy which is fundamental in value. This assumes that the value of an instrument must itself be instrumental. But this is akin to the psychologizing that regards a perception of a heap as a heap of perceptions. The mediating character of thought no more conflicts with the immediacy of its value than the movements of a horse conflict with its color. 


\section{VII}

\section{PRAGMATISM AND ITS CRITICS ${ }^{x}$}

Since Professors Royce, Creighton, and Baldwin, at the Princeton meeting of the Philosophical Association, started the American reaction against a philosophical movement variously known as "pragmatism," "humanism," "instrumentalism," and "radical empiricism," reinforcements for the reaction in great numbers and under many different colors, "absolutist," "realist,", "personal idealist," ${ }_{3}$ etc., have appeared in every direction. While there is yet no decisive outcome, there has been enough "skirmishing" to warrant a general canvass of the situation.

In the first general survey, perhaps the most noticeable and interesting feature is the bold

I Published in the Philosophical Review, XIV.

2 Cf. Professor Woodbridge on "The Field of Logic," Science, $\mathrm{XX}, 5^{8} 7 \mathrm{ff}$.

${ }_{3}$ Cf. articles by Professors Bakewell and Rieber in University of California Publications, I. 
move of the absolutists in abandoning at many points the defense of their own camp for a flank movement upon their opponents. The pragmatist's main point of attack has been on the absolutist's criterion of truth and error. Instead of defending this point, the forces of absolutism have largely moved out upon the pragmatist's flanks, attacking his incomplete, diffused, and often crudely fortified positions. So general and well executed has been this movement that, as one has put it, "One would think pragmatism a complete system set forth for centuries in hundreds of ponderous volumes, and that its critics were engaged in a tentative development of new and undogmatic ideas."

Not only has the pragmatist been thus suddenly flanked, but he finds himself confronted with this own weapons, some of which, at any rate, he fondly supposed his opponents could not wield. The pragmatist could scarcely ask for a better tale of his own shafts than Professor Creighton's summary of his objections to pragmatism, which runs as follows: ambiguity in the use of the term "practical 
purpose"; (2) the necessary subjectivity and relativity of the position; (3) the lack of any principle by means of which experience can be unified; (4) the sharp opposition amounting to a real dualism between thought and the antecedent experience out of which it is said to arise; (5) the fact that the position presupposes as its indispensable background a logical and ontological system very different from that to which it explicitly appeals. ${ }^{\text {T}}$

However, it could bring the pragmatist little but ridicule to complain that his opponents had stolen his weapons and countered upon his works before they were completed. If the pragmatist regards his constructions as strong enough to serve as a base of operations, he must expect them also to become an object of counter-attack. At any rate, the point of interest is: What has come of it thus far? How have the pragmatist's positions stood the test? And has any inroad been made upon the works of absolutism? For even if the pragmatist's constructions may be found demol-

I Philosophical Review, XIII, 295 ff. 
ished at some points, it still may be that some breach has been made in the walls of absolutism-especially at the point of the criterion of truth and error.

Dropping the martial figure, which after all is of doubtful aptness in philosophic discussion, let us recall that the point which the pragmatist has constantly pressed, and to which there has been so little direct response, is that there is no connection between the absolutist's general definition of truth and error and the standard actually employed in testing any particular judgment. There is no relation between his metaphysical and his instrumental logic. There is not so much obvious contradiction as simple irrelevance. The general statement is that truth, or "the degree of truth" which any particular thought has, consists in the extent to which it "agrees with" or "expresses" or "touches reality." " But when now we further define reality as fixed, as unmoving and unmovable, whether it be a "system of immutable ideas," a "fixed purpose," or a

IIbid., $29 \mathrm{r}$. 
"changeless sentiency," and then pass to the decision of the degree of truth or error in any specific case, it appears that our actual tests have no discoverable connection with the general definition.

The critics of pragmatism seldom face this issue squarely. Both Mr. Bradley and Professor Royce deal with it rather indirectly, and Professor Pringle-Pattison, in his otherwise admirable review of the Studies in Logical Theory, overlooks it entirely. ${ }^{\text {' }}$ One of the most direct attempts to meet this difficulty is Professor Creighton's paper on "Purpose as Logical Category." ${ }_{2}$ This I wish to examine briefly before passing to a consideration of the "objections" to pragmatism.

If we say with Professor Creighton that "every real thought has some degree of truth," we imply that it also may have some degree of error. If it "touches reality" at some point, it also may fail to "touch" at others; and the problem is: How are we to tell when, where, and to what extent it "touches" and fails to I op. cit., $666 \mathrm{ff}$. 2 Ibid., 284 ff. 
"touch" reality? In Mr. Creighton's words, "The real problem in any given case, therefore, is to determine which of two or more possible $r$ ways of judging about reality is truer and more adequate." Here, he says, "the appeal is to experience itself, but to experience as systematized by thought." This last clause is of course intended to reserve a place for the absolute system, though it does not follow that this systematization must be of the absolute, static sort. Continuing the account of the experience to which any thought appeals for verification:

It is to be noted that the system to which we appeal is not a fixed circle of abstract ideas that have the power of determining truth through their own internal consistency. It is rather the concrete and fluid process of thinking, in which the nature of reality functions effectively, both as something already partially determined, and also as that which sets the ideal for further determination. As thus an active process of transformation directed toward the realization of an ideal, thought seeks to extend and supplement its present content. It looks before and after, and seeks guidance and direction from every quarter.

×Ibid., $29 \mathrm{r}$. 
To this end, it appeals to direct perceptive experience, and makes use of trial and experiment as its instruments. . . . It makes use of the opinions of other men, testing and correcting its own conclusions by the light which these results afford.

So far as it goes, no pragmatist could ask for a better statement of his own doctrine. For all that is here said, the very ideal itself is open to reconstruction, although this possibility is soon cut off when we read that this ideal, "though a part of present experience, points always to a system of reality in which it is completely fulfilled and realized." I I have just said, "so far as it goes"; for there still appears no satisfactory answer to "the real problem" of determining "which of two ways of judging about reality is truer and more adequate." For this "active process of transformation" must be in some direction and to some extent true and to some extent false. What determines this? How shall we decide where it "touches" and where it falls short of reality? In seeking to "extend and supplerOp. cit., 293. 
ment its present content," there must be some success and some failure. How shall we distinguish? In "looking before and after," in "making use of trial and experiment" and of "the opinions of other men," there is some true and some false "looking" and "using." Again, what is the criterion?

The difficulties here are: First, that the account consists of a general description of thought-processes in which the point at issue, viz., the criterion of truth and error in this process, is overlooked. Second, the issue is further obscured by neglecting the negative side of thought. It is assumed that it is "the very nature of thought" to "touch" reality, or, as Professor Creighton quotes from Hegel, "to shut us together with things." I Hence all we have to do is simply to think and describe how we think, in order to see how we reach truth. But this forgets that thinking generates error as well as truth; that it is also "its very nature to shut us together" with illusions as well as with things; and that our problem

I Ibid., 29 I. 
is to distinguish one from the other. So far, then, it still seems that the connection between our criterion for truth and error, or for "degrees of truth and error in any given case," and a completed fixed absolute has not appeared. But the end is not yet.

We are told that, "if the nature of a larger whole does not function constitutively within it [any particular experience], then all tests of truth are impossible, theoretical no less than practical." To this all pragmatists would freely subscribe. But the question is, What is the nature of this "larger whole"? It surely does not follow without more ado that this "whole" must be an absolute system "completely fulfilled and realized." If it be said, "If not, then there is no whole," we must rejoin that the conception of a dynamic whole, e.g., a living organism or a society, is of as good repute and service as "wholes" of the static, geometric type.

Nor is the whole made absolute, static, and complete, if we admit with Professor Creighton ऽ Op. cit., 290. 
that "the appeal is to experience, but to experience as systematized by thought"; or that the conditions under which the practical test is applied "presuppose logical thinking as their necessary framework and background." On the contrary, it is just the contention of the pragmatist that the sole material of experience is the outcome of previous experience including all the results effected by previous thinking. But what puzzles the pragmatist is to see why we should still be working at this organization, if it were absolutely complete and final. To answer by an appeal to "the finite standpoint" seems a petitio of the simplest type.

Still no obvious connection between the absolute system and the test of truth and error "in any given case" appears. Nor do I see that, in the next and final stage of Professor Creighton's presentation of the case, we get any nearer such a necessity. To the pragmatist's contention that "present ideas must be tried by their future results," Professor Creighton says: 
But we can maintain with equal reason that the present system of knowledge furnishes the standard by means of which we must judge of the future. . . . . Now this reciprocal implication and determination of parts presupposes that these parts are elements of a rationally co-ordinated system. It follows, therefore, that the so-called practical test that judges of the truth of an idea by its results is applicable only when it is used within a rationally determined system of thoughts that contains as immanent ideal its own principles of criticism. ${ }^{\mathrm{I}}$

Now, anything like an adequate consideration of this passage calls for an analysis of the whole time character of experience in its relation to thought. This would carry us beyond the range of this very general discussion. But a few things may be said without such an analysis. (I) Here "rationally co-ordinated system" must mean an absolutely fixed and completed system, else the whole passage is thoroughly pragmatic. But (2) such a system does not appear to follow merely from a reciprocal relation between present and future. Geometric determination is surely not the only

× Op.cit., $292 \mathrm{f}$. 
and possibly not the fundamental form of reciprocity. The mutual determination may (in fact, I think, must) be of such a character as to change both interacting contents, and issue either in a state of immediate satisfaction in which the particular contents in tension disappear, or in a new problem requiring new determination. Thus, when "the future looks back to what for it is the past" (I confess this is somewhat puzzling), it does not merely "look" but "strikes" back. The past is constantly changing character under this backstriking (of the future). (3) Once more, if the system is absolutely complete, how can there be any "present looking forward to the future for correction and completion"? And what can be meant by its "containing its own principles of criticism"? Criticism, surely, has to do with change, and if these "principles" belong to the system as a whole and not merely to the finite part of it, the reconstruction must be real. (4) Finally, the negative side confronts us again. The present "looks to the future for its completion and correction." But once 
more, the future brings some things that succeed and some that fail in "completing and correcting." What distinguishes these? Everything cannot simply "complete" and "correct" everything else without failure anywhere; for the very continued need of completion and correction implies failure somewhere, and without failure the whole problem disappears. Doubtless failure is no more final than success, but it is also no less real. If it be said that it is not as the immediate criterion itself, but as the postulate of the possibility of such a criterion, that the absolute system functions, the reply must be again, that the account thus far shows only that the specific case must occur in some sort of a larger matrix, and this the pragmatist daily preaches. But nowhere is there any detail to show that this larger whole must be an absolute, static system "completely fulfilled and realized."

At the close of this part of the discussion the conviction still abides that whatever troubles of its own pragmatism may have, (and it has its share) static absolutism has so far not dis- 
posed of the difficulty in the statement of which the present pragmatic movement started, viz., that there appears no necessary connection between the absolute system and the determination of truth and error "in any given case."

It would be both proper and interesting at this point to give a pragmatic reinterpretation of some of the fundamental categories of Professor Creighton's account, such as, "rationally co-ordinated system," "completion and correction," "necessity and universality." But I am under bonds in this discussion to consider some further "objections" developed by the critics of pragmatism.

Perhaps the charge most universally and conspicuously brought is that of "subjectivism." This, of course, is the time-honored objection to any theory of knowledge. It seems to be the general formula for epistemological breakdown. And yet one may justly wonder just why it should always be the "object" that disappears in an inadequate epistemology. Surely Hume and Kant long since pointed out that in this case the "subject" 
also vanishes. Perhaps, however, it is because this is taken for granted that "subjectivism" is used as a general term for failure. At any rate, it may be interesting to know that it was the prediction of some pragmatists that, when the returns should come in from the critics, it would be found that instead of the old objection its opposite would be urged. It was surmised that, when it should be discovered that "fact and idea," "existence and meaning," "subject and object," "purpose and means" were regarded as functions in experience, the alarm would spread that the self had disappeared; that for warm, intimate, vital personalities had been substituted a cold, mechanical objectivity, more uncanny, if possible, than Mr. Bradley's celebrated "unearthly ballet of bloodless categories." The author of this prophecy now consoles himself for its pathetic failure with the reflection that, at any rate, there is just so much the more hope that pragmatic doctrines may be more hospitably received when they are better "understood."

A canvass of the passages in which the charge 
of subjectivism is set forth shows that the charge rests upon the assumption that "specific," "definite," "need," "present," "immediate" are all purely subjective categoriesan assumption somewhat difficult to understand in view of the assurances of Mr. Bradley, Professor Bosanquet, Professor Taylor, and others, that it is in the immediate perceptive experience that we "come in contact with reality"; indeed, that the very nature of the Absolute is "immediate sentient experience." In view of assurances also, on the other hand, that it is just the universal, the general, that is "hypothetical," "merely ideal," and belongs to "the world of internal meanings."

"Need" may appear to some to be in a different case on account of its close connection with feeling. But I see no ground for regarding feeling as merely subjective, especially in view again of Mr. Bradley's and Professor Taylor's exposition of the immediate "sentient" character of the Absolute! Again, mere immediate feeling can scarcely be called a "need."

I Royce, The World and the Individual, I, chap. vii. 
A "need" must have some definition and therefore some idealization. The critics grant that the "need" arises in, and is relative to, what Professor Dewey calls the "situation," though they do not agree among themselves in their interpretation of the "situation." On the one hand, it is regarded as itself a merely "present" momentary individual, and therefore "subjective" affair. On the other hand, e.g., Professor Pringle-Pattison views it "as the very type of an independent world"; but he at once charges the pragmatist with inconsistency in appealing to it. At any rate, on this interpretation "need" as arising in, and relative to, the "situation" cannot be considered "subjective."

As for the subjective interpretation of the "situation," it is difficult to avoid the suggestion that it is a case of imputatur quod putatur. Starting with thought relative to "need," and "need" as arising in a "situation," the "situation" is, without any attempt at justification so far as I can discover, forthwith written down by the critics as itself "merely 
present," "momentary," and "subjective," and this presumably with such passages as the following before them.

The situation as such is clearly objective. It is there; it is there as a whole; the various parts are there; and their active incompatibility with one another is there..... Every reflective attitude and function, whether of naïve life, deliberate invention, or controlled scientific research, has arisen through the medium of some such total objective situation. The abstract logician may tell us that sensations or impressions or associated ideas, or bare physical things, or conventional symbols, are antecedent conditions. But such statements cannot be verified by reference to a single instance of thought in connection with actual practice or actual scientific research. ${ }^{\mathrm{I}}$

Are not such passages as this, I submit, sufficient ground for the prophecy above mentioned, and enough also to make the pragmatist a little hard of faith regarding the kind of reading some of his doctrines have received?

But after all, it may be said, does not the pragmatist regard "situation" as something occurring in an "individual mind" or "con-

× Dewey, Studies in Logical Theory, 38-39 (italics mine). 
sciousness"? On the contrary, the individual consciousness is regarded as an element inside $\checkmark$ the "situation." The "situation," if you will, is the pragmatist's absolute. Just how the individual is constituted, just what is his rôle in the situation, are questions demanding more serious attention from pragmatists and absolutists alike than they have so far received. The array of assumptions, masked behind the lines of personal pronouns thrown up on every page of philosophic writing, is, in Mr. Bradley's phrase, "scandalous." Meanwhile will not the critics look more carefully into the pragmatist's view of the "situation"?

As already remarked, Professor PringlePattison's review is an interesting exception to this subjective interpretation of the "situation." He finds it to be "the very type of an independent world." In so far as this recognizes the thorough objectivity of the "situation," the reviewer here, as in most of his statements, reflects truly the pragmatist's view. But in so far as he would make thought external to, and independent of, the "situation," in 
so far as he would interpret the whole "situation" as a fixed "nature of things to which our ideas have to adapt themselves"; or as "a real world independent of our ideas and unmodified by what we think of it," " the pragmatist could not follow. The pragmatist's "objective" is not that which is indifferent to, "independent of," and "unmodified [at least in the sense of unmodifiable] by," thought. There is, to be sure, and this is the reason for the parentheses just used, in every situation a content which from the standpoint of the purpose or problem now at issue is unchanging. From the standpoint of certain problems of the physicist and chemist, the table upon which I now write is conceived as undergoing violent changes. In my present situation, it is stable. The permanent thus appears as that content in a "situation" the changes of which are irrelevant to that "situation"- not the absolutely unchangeable, nor yet that which is independent of, and indifferent to, thought.

Even so, it will be said, "the nature of things" × Op. cit., 669-70. 
must be such that these changes can be irrelevant, can be ignored, in some cases, and cannot in others. To all of which the pragmatist cheerfully assents. Far be it from the pragmatist, of all men, to question the presence of "the stubborn grain" in experience of which the critics make so much. Indeed, this "stubborn grain in things" is fundamental to the whole position of the pragmatist, as should be apparent to the most casual reader,

$\checkmark$ in the central rôle which habit everywhere plays in the pragmatist's accounts of the "situation." It is just the stubbornness of habit that constitutes half the stimulus to thought - the other half consisting in the fact that, however stubborn it may be, habit is after all plastic. While a stimulus involves resistance, the resistance must not be absolute, else hope yields to despair, and despair to paralysis. If habit, then, be stubborn, thought can be correspondingly strenuous. But it is a far cry from this "stubborn grain in things," which constitutes the very stimulus of thought, to an absolute fixity which defies thought. Indeed, the latter should 
not be called "stubborn," for stubbornness implies the possibility of change, if only the effort be great enough.

This suggests as next in order the Eleatic objection, to which Professor Bakewell devotes special attention in his article on "Latter-Day Flowing-Philosophy" in the recent interesting volume of California Contributions to Philosophy -the objection, namely, that pragmatism $\checkmark$ resolves the world into sheer flux. Professor Bakewell himself, however, thinks that there is a "necessity of a revision of the conception of the fixed"; that "the fixed itself must be $\checkmark$ conceived dynamically." "The permanent shall not be found in a world of immutable ideas, nor in some mysterious psychical entity," nor yet in "a static plan external to the process and constraining us therein; but rather the solvent conception must be sought in the nature of self-activity." ${ }_{2}$ And yet, after this and much more excellent pragmatism, when Professor Bakewell comes to point out specifically where the permanent lies, he finds it in "the end I P. 106. 2 P. II 2. 
toward which it [experience] tends, in so far as that end can be, as it were, appropriated by the life of the individual." Or in "a system of purposes within which each particular purpose has its place and relative value." ${ }$ And, finally, he can write: "I may not, in the words of the familiar hymn, 'ask to see the distant scene'; . . . . but I must believe that there is a distant scene to which the steps as they come one by one are, or may be, surely leading." But if this "end," this "system of purposes," and this "distant scene" are absolutely fixed, as they appear to be, it is hard to see how they have any logical advantage over "a static plan," a fixed "psychical entity," or the "world of immutable ideas," the difficulties in which Professor Bakewell seems to appreciate.

This apparent failure to "conceive the fixed dynamically" seems to be due to two things: First, and less important, the inference that, if thought is to change the "situation" at all, it must change everything in it, and must change everything at once; either of which

× Pp. rog f. (italics mine). ${ }^{2}$ P. II 3 . 
suppositions annihilates both change and permanence. Second, and more fundamental, permanence is still sought as a quality of a certain content. Then forthwith appears the problem of getting it into any connection with the moving content without itself being drawn into the stream-a world-old puzzle the changes on which have been rung from Zeno to Bradley. But if, instead of a fixed quality of an immutable content, we make permanence a true category, ${ }^{\mathbf{}} \mathbf{v}$ a function of experience, some of the puzzles would seem to disappear. Permanence now becomes the function of making permanent. v As such, it is a form of activity, instead of a form of inactivity correlative with change as the form of activity. It is as active as change. Permanence and change are thus correlative functions of that self-activity which, as Professor Bakewell says, constitutes "the solvent conception." But, again, we must beware of translating these correlative functions into fixed qualities of unchangeable contents. Between

I Kant's difficulties with his categories are due to the fact that he takes them now as functions and now as qualities, and then confuses these. 
these functions there is a constant interchange of content as in the case of the table above cited. In some such direction as this, it seems to me, we must reach the "dynamical conception of the fixed" which Professor Bakewell so much desiderates.

One may think, as apparently most of the critics do, that we escape the difficulties of an absolutely permanent content by giving the $\checkmark$ permanent the form of a purpose. But, again, if this purpose be absolutely final, the old objections seem as competent as ever. No one professes to have discovered what this final purpose is. And if we say: "Ah, but we are finding it out little by little"; what, again, are we to do with our mistakes? Professor Bakewell says: "In so far as that end can be, as it were, appropriated by the life of the individual." ' But what are we to do with the misappropriations? Shall we simply close our eyes to mistakes and failure, and dream that everything we know and do is an "appropriation" of this final purpose? And it affords × Op. cit., rog. 
no relief from this difficulty to say that the purpose "functions implicitly," for whether it controls implicitly or explicitly there is still no room for mistakes; and another difficulty is added in that it seems as if a standard as such must be explicit. But even if this final purpose be explicit, if it be simply "appropriated," what guaranty is there of its relevancy to the material which it is to organize? In the form of an antinomy, the case is this: The ultimate purpose as a standard must be appropriated; it cannot be constructed; for if it be constructed, there must be a standard for this construction, and so on in infinite regression. On the other hand, the standard must be constructed; it cannot be simply "appropriated," else there is no guaranty that it will apply to the situation; its relevancy will be wholly a matter of chance.

We cannot here deal in detail with this antinomy. The key to it appears to lie in the failure to see that in every situation the purpose is the standard. Purpose and standard are not two things. When we ask for the purpose 
of a purpose, it is equivalent to asking for a standard of a standard. Though we may tolerate this in words, yet in fact when we ask for the purpose of a purpose, this last purpose is really no longer regarded as a purpose. It is either an incomplete purpose, of which the other "purpose" is simply the completion, or it is some immediate activity seeking a purpose, i.e., an outlet which carries over the name "purpose" from a previous situation in which it did function as such. Of course, these really are not two distinct cases, but different stages of the same development. If we say the standard of a violin is the sort of tone it gives, and then ask what is the standard of tone, we are not here appealing to another purpose, to another standard. We are simply trying to complete the statement of the purpose, the standard. We may still loosely call the first statement a "purpose," since it may previously have sufficed as such. But here it needs further definition.

Moreover, the question will again be raised: "How does the purpose, the standard, com- 
plete itself ?" First, it is significant to note again that it does complete itself-enough, at any rate, to stimulate the manufacturing and playing of violins. The terrors of the infinite regress appear reserved for logicians and metaphysicians. Artists, artisans, and scientists do not seem to be seriously disturbed by it. The purpose can attain completion just because here its completeness does not consist in an abstract point-for-point participatory correspondence with an absolute purpose, but in the way in which it gives outlet to the activities, in this case the musical activities, which it serves. In this sense, the means justifies the end; in this sense, the purpose is itself a "means." The purpose is not trying to complete itself as an independent thing; it finds its completion as it provides an outlet for the activities which are seeking expression through it.

But, one may say, the case here is too simple. Suppose the actions seeking expression in violin making and playing are in conflict with other activities. How shall this conflict be decided, 
if not by an appeal to an ultimate purpose? As for simplicity, of course, unless there is some conflict, some resistance, the whole affair becomes automatic. Nor in the case of conflict can there be any doubt that an ultimate purpose (i.e., ultimate for that problem) must be reached. To say, however, that there must be an appeal to an ultimate purpose implies a purpose ready made for the case, which is just the point in dispute. Now the very insistence upon conflict seems incompatible with such a conception of the ultimate purpose. For, waiving the question of relevancy already mentioned, if the purpose were really complete and ready made for the situation, it would apply itself just as fast as the least need of it developed, which would keep conflict at the minimum, and, pushed to the limit, run again into automatism. The very presence of conflict involves the absence of any complete , purpose. A part of the whole struggle is to construct a purpose, not to decide between purposes already formed. But how, after all, is this to be done? Here is where the "look- 
ing abroad and before and after," the recalling of the contents of other purposes, the remembering of one's largest life plans, perhaps even the formation of a hierarchy of ends, takes place. But all this is in the process of gathering material for the purpose through which the conflicting activities must be unified here and now. Even our most cherished ambition is to be considered rather as material for further purposes than as a completed, final purpose. ${ }^{\mathrm{I}} \quad$ At all events, such an ambition is of a very different type from the unchangeable absolute purpose; for it is usually a gradually matured construction out of a wide range of social material, and the constant modification of such general ideals is notorious. $^{2}$

But after all, just what marks the completion of the purpose? Here it would seem as if

I For an excellent detailed statement of teleological as opposed to absolute finality, and the nature of a standard, cf. Professor H. W. Stuart's articles on "The Logic of Self-Realization," in the University of California Contributions to Philosophy, I.

2 And here let it be noted also, that, instead of begetting a spirit of resignation to the passing moment, instead of preaching laissez faire, this conception of purpose places a premium upon the farthest reach into the past and future, since this is a 
there should be no great difficulty with the answer, since absolutist vies with pragmatist in insisting that the purpose through which $\checkmark$ this conflict finds its solution is that plan which gives the "freest" and most "harmonious" outlet to the conflicting activities. But when such a purpose is reached-and obviously it is reached -it is for that situation complete, final, and absolute. Purposes come and purposes go, but purposing goes on forever. The absolutely permanent in the form of purpose turns out to be the hypostatized abstraction of the function of purposing. The poet should have written: "For I doubt not through the ages one increasing purposing runs."

And yet, someone may say, however unanimous may be this appeal to the "sense" of freedom and harmony as the test of the finality of purpose, does not this "sense" bring again the taint of "subjectivism"? The answer is: Yes; if we gratuitously separate this "sense" part of the process of surveying and analyzing the scope of the activities involved in the conflict. As a basis for resignation, this view of purpose cannot hope to compete with the ready-made unchangeable absolute purpose. 
of freedom and harmony from the thinking and purposing out of which it issues, and take it alone and in its naked immediacy; and if we equally gratuitously suppose that all the factors of the original situation, the feeling, and thinking, and purposing, are located in an individual mind, then we may indeed have what it is the fashion to call subjectivism. But if we say-as we must say, if we are to deal fairly with the whole matter - that this "sense" of freedom and harmony to which we last appealed is not any bare, detached, unmediated fragment of feeling that we may happen to find, but is the issue of a process of purposing and thinking, includirg "experimentation and verification" based on results of previous thought and action, involving as many individual minds and as much of the "material" world as you will-if we remember, in short, that this mediated "sense" of harmony and freedom issues from a "situation" having all the objectivity of the whole world of reality in itthe last suspicion of subjectivism disappears.

This intimate relationship of thought and 
sense brings us to the next count against the $\checkmark$ pragmatist, viz., "dualism." As already indicated, with "concreteness and continuity of experience" as his watchword, this was the last charge the pragmatist expected to meet. According to the critics, the pragmatist is afflicted with dualism in two forms: (I) a genetic dualism due to his alleged conception of thought as "a product of evolution," I as arising as a "variation" of an antecedently existing matrix;" (2) a dualism in the immediate operations of mental functions, found in the sharp "opposition" and "subordination" of thought to immediate experience. ${ }^{3}$

Even if these passages correctly reported the pragmatist's views of the relation of thought and evolution, it is not clear how the genetic dualism is made out. Suppose thought did appear as a "variation" of a pre-existing nonthinking "prius," how would that prevent it from being "in any sense organic" when it did appear? That would seem to be the best

I Professor Royce in Philosophical Review, XIII, I 27.

2 Professor Creighton, ibid., 286-87, 297.

3 Ibid. 
guaranty of its "organic" character. But, says Professor Creighton, "it comes not as the development of a principle already immanent in, and constitutive of, the earlier stage, but as a variation, or deus ex machina, that introduces something entirely new." But as a "variation" of the prius, how can it be anything but a development of something in it? What else can vary? And how can development fail to produce variation? Development, surely, is not a mere quantitative expansion of some unchanging quality. But, on the other hand, how can a variation introduce something "entirely new"??

But the statements above quoted by no means represent the views of any pragmatist whom I know regarding the relation between thought and evolution. The following passages illustrate:

Since Reality must be defined in terms of Experience, judgment appears as the medium through which the $\checkmark$ consciously effected evolution of reality goes on. ${ }^{3}$

I Ibid., 296.

2 Italics mine.

3 Professor Dewey in Preface to Studies in Logical Theory. Italics mine. 


\section{Again :}

In self-activity there must be a constant reorganization of the results back into process. .... This implies that (self) activity involves both a mechanical and a reconstructive function. .... Habit is the conserving .... thought the reconstructing function. Habit and thought are thus constituent poles (functions) of experience (of self-activity). As such neither can be regarded as an ultimate (or prius) out of which the other is evolved. ${ }^{\mathrm{r}}$

The radical misapprehension of the pragmatist's view of evolution is due apparently (I) to the critics having overlooked the fact that the pragmatist's conception of evolution differs in some rather important respects from that of Herbert Spencer, which is evidently the one from which the criticisms are made. For the pragmatist, thought is not a "product" $\checkmark$ but an organic factor in the process of evolution. (2) The misinterpretation is further due to the fact that the critics have mistaken descriptions of the "conditions and antecedents" of particular acts of thought for accounts of the absolute origin of thought, and statements of

${ }^{1}$ The writer's Existence, Meaning, and Reality, I6-ז7. 
the antecedents of reflective thought for antecedents of all thought. Thus, the descriptions of the "conditions and antecedents" of thought, as contained in the first two chapters of the Studies in Logical Theory, are simply statements of the conditions under which the reflective function operates, or rather, in which experience passes into the reflective form, since the function of reflection exists only as it operates. Such an interpretation of thought in relation to its antecedents should be evident from the repeated description of the relation between reflection and immediate experience as one of "rhythm." "We recognize a certain rhythm of direct practice and derived theory; of primary construction and of secondary criticism." Again: "Having busied itself to meet the special difficulty, thought releases that topic and enters upon further more direct experience." Many other passages could be cited.

If thought is thus spoken of as derived and as secondary, the direct experience is no less

I Professor Dewey, op. cit., 2-3. 
secondary and derived, since it is held to be just the business of reflection to develop new content in immediate experience. "Secondary" and "derived" here mean only, in Professor James's words, that "one part of our experience leans on another part to make it what it is." Thus, there is no more a "pure" emotional and impulsive prius than there is "pure" thought. Emotions and impulse are permeated with the results of previous thinking. Indeed they are, in large measure, its results. "Doubtless many and many an act of thought has intervened in effecting the organization of our commonest practical-affectional-aesthetic region of values." ${ }^{2}$ If these citations and comments suffice to remove the misapprehension of the pragmatist's general conception of evolution and of the relations of reflection and immediate experience, there would seem to be little foundation left for the charge of genetic dualism.

As for dualism in the de facto working relations between thought and immediate experience,

I "The Essence of Humanism," Journal of Philosophy, Psychology, and Scientific Methods, II, No. 5.

2 Professor Dewey, op. cit., 43. 
due to the "sharp opposition" and "subordination" of the former to the latter, it would be difficult to imagine a finer instance of historic irony than this: That those who hold with Mr. Bradley that thought is a special impulse, ${ }^{\mathrm{x}}$ that it satisfies itself in complete independence of the feelings and impulses, that "in its actual exercise [it] takes no account of the psychological situation," it is the purpose of thought to attain "a certain absolute system of ideas" ${ }_{3}$ - that these should accuse of "dualism" those whose creed is: "Since the act of knowing is intimately and indissolubly connected with the like yet diverse functions of affection, appreciation, and practice, it only distorts results reached to treat knowing as a self-inclosed and self-explanatory whole-hence the intimate connections of logical theory with functional psychology." ${ }_{4}$ And the irony continues in the present interesting spectacle of James, the pluralist, defending

I Appearance and Reality, 153.

2 Mind, N.S., No. 5r, p. 309, note.

3 The World and the Individual, I, 36, et passim.

4 Studies in Logical Theory, Preface, $\mathrm{x}$. 
the unity of experience against the pluralizing attacks of Bradley, the absolutist. ${ }^{\text {I }}$

A quotation of such general character as the one just given, of course, proves nothing in detail. It states only a standpoint which should be kept in mind by the critics in interpreting other passages. It seems, indeed, as if this objection of dualism grows largely out of the fact that, in the very effort to get this "independent," "self-sufficient," and "selfinclosed" thought back into organic connection with immediate experience, the pragmatist has been obliged to bring out the differences between it and the more direct forms of experience-differences which expositions of "pure thought" have little occasion to mention, and which, when brought out by the pragmatist, are taken as symptoms of dualism instead of real bonds of connection as they are intended, and as they really are. Of course, if mere difference of function as such be regarded as dualism, then we must all be, not dualists,

I Journal of Philosophy, Psychology, and Scientific Methods, II, No. 2. 
but pluralists. The question is, however, what, in spite, of, or by means of these differences, is the kind of connection between reflective and "direct" forms of experience. Mr. Bradley says: "I agree that there is no such existing thing as pure thought." But he adds: "On the other side, if in the end there is to be no such thing as independent thought, thought, that is, which in its actual exercise takes no account of the psychological situation, I am myself in the end led inevitably to skepticism." I

But is it not clear that, just in so far as thought in its operation "takes no account" of its relation to other experience, it is functionally as "pure" as any of which Plato ever dreamed? Thought now simply goes on alongside feeling and impulse. This, then, joins the issue squarely. The pragmatist contends that the relation between thought, on the one hand, and feeling and impulse, on the other, " is something more than that of mere parallelism in somebody's head. He insists that thought

× Mind, No. 51, p. 309, note (italics mine). 
and feeling and habit are mutually conditioning processes; that, in Professor James's phrase, they "lean on" each other; that each receives from the other its stimulus, its material, and its limits, and that without this interrelationship he "is inevitably led to skepticism." The pragmatist admits the difference between thought and the other moments of experience, but denies that this difference means "independence." He grants, too, that thought has its own technique of operation, and that this has its own immediate felt value. But he denies that its whole operation is in "independence" of the other processes. From them thought receives its problem and its material; to them, as its goal and its test, thought returns.

In an appeal, at this point, to what $\mathrm{Mr}$. Bradley calls "the plain [?] facts," Professor Baldwin cites the time-honored instance of mathematics as the type of "pure" and "independent" thought-of thought that "dispenses with the test of fact." Now even so thoroughgoing an idealistic absolutist as Pro-

I Psychological Bulletin, I, No. I2, p. 427. 
fessor Royce admits that mathematical thinking must find its "satisfaction" in "presented fact"; " and, we must add, its origin also. First, the problem must be a certain kind of mathematical problem; it must arise out of a certain kind of immediate data and must look forward to a specific sort of result. This means that the problem originates in some kind of a tension or discrepancy between certain immediate data in the form of imagery of some sort and certain other imagery equally immediate. Furthermore, the process of mediating, of amalgamating these conflicting data involves, as Professor Royce shows, hypothesis and experimentation as truly as does the work of the chemist. In other words, no matter how deeply involuted the process of reflection may become, there will always be in it some content serving as fact and other serving as idea. ${ }^{2}$ Finally, what

'The World and the Individual, I, chap. vii.

2 By way of a "sweeping" generalization at this point, I would say that no other one thing has been so productive of criticisms that seem to the pragmatist beside the mark as the failure of the critics to see, or at least to continue to see, that for the pragmatist the distinction of "fact" and "idea" is a distinction of ways in which a content functions-not an odor or color of the idea. 
shall determine when the process of mediation, of working back and forth between the conflicting elements, reaches its goal? "When it reaches fact," says one. But it has had some fact all along. "When it reaches a harmonious, a satisfactory idea," says another. But if it ends in a mere idea, we still have the opposition of idea and fact, and the need, therefore, of further mediation. The goal, then, must be the amalgamation of the conflicting activities into a new immediacy in which the opposition between fact and idea disappears.

By this time there should hardly be any necessity for a paragraph on the "subordination" of thought, if subordination is taken as a category of value. One might as well speak of the subordination of the heart to the lungs. Yet, on this same point of "subordination," the position of the critics does not appear altogether univocal. On the one hand, thought is to be "independent" and "self-sufficient"; on the other, it must be dependent on, and conformed to, the facts, to the "stubborn grain in things." 
Concerning ambiguity in the use of the terms "practice" and "practical purpose," there seems to be some ground for complaint on both sides. ${ }^{\mathrm{x}}$ Yet in some cases the allegation is due to a real difference between the author and the critic in the meaning of the terms. Everyone now recognizes that it profits nothing to say that thought is true when it "works," since it must "work" in some way for absolutist and pragmatist alike. All now see that the issue concerns the kind of work it is to do. But when the pragmatist is charged with ambiguity because he uses "practical purpose," now to denote "material ends for the sake of which physical movements are necessary," and now to denote "purely theoretical problems," ${ }^{2}$ he must reply: (I) that an "end" cannot as such be "material"; as end it must be ideal; and (2) that "purely theoretical" begs the issue, since it is just the pragmatist's contention that, in so far as both

I Cf. Dr. Schiller's account of Mr. Bradley's offense in this direction, Mind, N.S., XIII, No. 52; and see also the writer's paper in Studies in Logical Theory, 349, on Professor Royce's uses of "purpose."

2 Professor Creighton, Philosophical Review, XIII, I8I. 
involve thought, there is no generic difference between starting a fire and manipulating mathematical equations. Indeed, the latter may easily be a part of the former, and even in its most ideal stages depends at every point on the "physical" side of the machinery of visual, motor, etc., imagery. ${ }^{x}$

It would be a grateful task, did space permit, to turn from these "differences," which a paper of this nature necessarily emphasizes, to the constantly enlarging "common ground." As Professor Bakewell points out, there is marked , agreement in the common emphasis of the volitional character of thought and feeling. To this might be added a general agreement as to the mediating character of thought-though for the absolutist this is only one of its functions-and further an agreement that thought finds its limit and standard in a "harmonious experience," though again there is disagreement concerning the character and significance of

"Mr. Bradley thinks this sort of "alteration of existence" is irrelevant for logic, which is again one way of stating the whole issue. Cf. Mind, N.S., No. 51, p. 3 I9. 
this harmony. Fortunately the differences are still numerous enough, if I may close with a Hegelism, to insure a long period of fruitful co-operation in philospohic development. 


\section{VIII}

\section{THE PRAGMATIC “UNIVERSAL"}

In a suggestive article on "The Limits of Pragmatism" " Professor Baldwin finds, as do many others, one of the chief "limits" to be the inability of pragmatism to make universal judgments. He finds it "interesting to note that the word 'general' does not occur in the rather full index to the Chicago Studies in Logical Theory," which is freely cited as representative literature of pragmatism. Now if Professor Baldwin had but recalled what he must well know, that even an index-especially a philosophical one-has to be "interpreted," he would have turned to "universal," especially as he interchanges this term with "general," under which he would have found eight references, some of them with "ffs." And in my monograph on Existence, Meaning, and Reality, to which he also refers,

x Published in the Psychological Bulletin, I, No. I2.

${ }^{2}$ Psychological Review, XI, No. I. 
there is space to the amount of five octavo pages given almost entirely to the discussion of "universality." Indeed it is difficult to see how one could go through the "Chicago Contributions" and emerge with an impression that this topic had been overlooked.

As there is a conception of abstract universality, which is difficult to reconcile with any sort of pragmatism, so there is current, largely among its critics, a conception of pragmatism which is difficult to square with any kind of universality. So far as I have seen, the imputations of "Atomism," "Nominalism," etc., are based, not on a criticism of the fundamental conceptions of pragmatism, but on an atomistic interpretation of Professor James's pluralism. I say "an atomistic interpretation," for it seems to me that it does not require a second look to discover that Professor James's pluralism is not atomism. Everywhere there is "interaction," "stimulus and response," "generation," "continuity," and "growth." The emphasis of the pluralistic character is simply a reaction against a lust for a unity so absolute that there is no 
room in it for any movement of differences. And here, again, we touch the "metaphysical" nerve of the whole pragmatic movement. Pragmatism is not concerned primarily with the question of unity and plurality, although experience is as manifestly a plurality as a unity. Its chief metaphysical problem is that of change, of development. It is an attempt to reach such a conception of unity, and differences, as shall permit of "real" movement. It is a crusade to release change from the limbo of "appearances," and reality from the stocks of a changeless unity. This "metaphysical" problem is for the pragmatist, of course, but a part of the larger ethical and social problem of thinking of the world (or experience) in such a way as to leave the individual a chance to be truly and therefore responsibly efficient.

Seeing that the champions of unity have almost with one voice insisted that the unity of reality involves its unchangeableness, some, who cherish convictions against such cashiering of change, have apparently accepted this verdict 
of absolutism and said in effect: "If the choice is between absolute unity with absolute fixity on the one hand, and pluralism with movement, development, on the other, we accept the latter." But the pluralist at once restores unity by his categories of "interaction," "stimulus and response," etc.; only now he has a dynamic instead of a static unity. It is quite possible, then, that one may be a pragmatist and insist emphatically upon this moving unity. At all events, the critic's plea to take the pragmatist's case away from the jury at the start on the charge of "atomism" is certainly not to be allowed.

Returning to Professor Baldwin's "limit," he finds that pragmatic logic, while perfectly capable of making particular judgments, is impotent when it attempts to deal with the "universal" (pp. 5०, 52 ff.). Now most modern logicians, including perhaps most pragmatists, would say that such an indictment could be drawn only on the conception of a separate and independent relation between the particular and the universal. They would insist that it is 
impossible to have a valid logic of particular judgments apart from a logic of universals. For every judgment is a development of experience through a universal. A standpoint, therefore, which is able to construct a valid logic of the particular judgment must be, at the same time, a logic of the universal.

In Professor Baldwin's account of the universal it seems to play, as in the statements of Professor Royce and Mr. Bradley, two quite different rôles, and the relation between them is very difficult to discover. " (I) "It is just the meaning of a general mode of thought that it stands for the particular case in the sense of organizing it with other experiences" (p. 53). (2) On the other hand, "the general concept pre-

I As another illustration of the strange tête-d̀-tête a philosophical discussion may bring about, the following is interesting: On p. 53 Professor Baldwin says: "This may be a way of saying, with many modern logicians, that only particular, not universal judgments carry the affirmation of reality: if we limit ourselves to pragmatic tests, available only in concrete experience, I see no way of avoiding such a view. But such a position it seems to me allies pragmatism with extreme nominalism." But what about the "many modern logicians" holding this view, who are not pragmatists? (Indeed I know of no pragmatist who holds it.) It is, in fact, just the absolutists who are the chief expounders of this view. Behold, then, according to our author, the pragmatist and the absolutist sitting together in the tent of nominalism! 
tends to be valid as a vehicle of the real apprehension of the world." Now this latter is capable of an interpretation quite in agreement with (I); and indeed Professor Baldwin comes near giving it such a meaning on the page cited, as will be shown below. But on the very next page we read that this world, the real apprehension of which it is the business of the universal and normative aspects of experience to give us, is one that transcends the experiences of real life. "How can practical life adequately test the validity of modes which essentially claim to transcend the experiences of real life?" "How indeed ?" responds the pragmatist.

On the test of the universal Professor Baldwin says (p. 53):

No appeal to a concrete situation can validate an aspect of reality which is ipso facto a systematization of various such situations or cases. There must be, therefore, if such thinking is to have any control or positive validation, certain principles of logically apprehended reality as such. This would throw us back upon the traditional "laws of thought," I suppose, or some analogous self-applying criteria of sound thinking. 
At the risk of appearing captious, the discussion at this point will have to run somewhat to an exposition of terms. If we take "concrete" etymologically it should mean the unified harmonious grown-together stage of experience which does not need "systematizing." It is the immediate outcome or forerunner of systematization. It is only when experience ceases to be "concrete" in this sense that organization is required. The general, therefore, is not a system "of various concrete experiences as such." It is only when experience is broken up and becomes material, a "matrix," a "platform," to use a term of Professor Baldwin's, for further experience, that it needs organization.

The point can be stated in terms of the conception of "system." Why should various "concrete" experiences need systematizing anyway? And in just what does the systematization consist? And how is it known when systematization is reached? Professor Baldwin says that systematization consists in "organizing a particular case with other experience." Here, of course, we have only exchanged terms. For 
we have forthwith to answer for "organization." Nor are we much better off in the next sentence. "It introduces organization, relationship and systematization into experience just to the dropping off of those aspects which are individual." Thus, experience becomes general by being organized with other experiences, and it is organized by becoming general, that is, by "leaving off the individual aspect." And what, by the way, are these individual aspects? Does every experience have a certain quality that is in itself individual and a certain other that is in itself universal? But of this more below. So far, at any rate, we have made little progress in finding a criterion of organization and system. And the difficulty in starting out to systematize and organize experiences just as large is very great. None of this is intended to call in question the fact of system and organization in experience. It desires only to call for an interpretation instead of a mere assumption of them.

And what do we gain by "falling back upon the traditional laws of thought"-consistency, 
contradiction, etc.? For we must at once face the question: What is the meaning of "consistent," or, as Professor Baldwin calls it, "flawless" thinking, in terms simply of the process itself? Professor Baldwin does not explicitly deal with this question, but I imagine the only answer he could make is the one generally made, viz., that it is simply "the $\checkmark$ sense of a harmonious, unified, unimpeded flow of the thought-process within itself." If so, are we not caught on the very sands of "sub-

- jectivism" and "atomism" from which we have been so frantically warning the pragmatist? If the test of thinking is consistency and the mark of consistency is simply the immediate sense of harmony and freedom in the process in itself, apart from any limit in further experience, and if we take this as in itself yielding truth, reflecting reality, is not this the very essence of subjective atomism? The abstract universal is thus just as subjective and atomistic as the abstract particular. Nor can we escape by an appeal to "the essential uniformity of intelligence as such." This is as gigantic a petitio- 
to say nothing of the facts - as its "empirical" correlative, "the uniformity of nature."

There appears, then, to be need for some further analysis of "system," "organization," "consistency," "contradiction," etc. Roughly sketched, the pragmatist's contribution to this demand runs somewhat as follows: he points out that every experience (and the distinction between "experience in general" and "my experience" matters not just here) has two values: (I) it has a unique value of its own as immediate experience; (2) it has a value as the basis, the "platform," of further experience. And it is to this latter function that the categories of "organization," "consistency," "universality" and "particularity," "validity," "truth" and "error" belong. Taken in its bare immediacy, experience is neither valid nor invalid, true nor false, systematic nor chaotic, consistent nor inconsistent. It is only as a means to, or as an outcome of, other experience that any content takes on these characteristics. Of course the process of systematizing has its own immediate sense value. But the point is that when we 
get at the conditions and significance of this "sense" we find that they lie in its relation to further experience. Shorn of this developmental character, organization, system, validity, etc., are indeed left without any "limits" by which to define them. They remain terms referring to immediate qualities of experience offering and requiring no credentials of any sort.

If we pass now to the process of systematization itself, Professor Baldwin says that it proceeds by "dropping off those aspects which are individual." Taken as it stands, this certainly has in it a suggestion of old-time "realism." It reads as if there were in experience something per se individual and something else per se universal. But even if this were the case, why should the "dropping" of the individual characteristics produce system or organization? Why would not the individual aspects themselves make as good a system as the universal? Now I do not think that anyone who has read Professor Baldwin's most suggestive chapter on "Selective Thinking" and his debate with I Psychological Review, January, I898, and chap. xvii of Development and Evolution. 
Mr. Bosanquet ${ }^{\mathrm{I}}$ about it could regard any such statements as the above as representing his "settled views." Just as we there are taught that a content of experience "is not selected because it is true, but is true because it is selected," so, while the point is not explicitly treated, the whole trend and tenor of "selective thinking" would lead us to say that systematization is not something determined wholly in and to itself, but is a process which is relative to, and has its goal in, a further concrete experience. ${ }^{2}$ The doctrine of that chapter, also, would lead us to say, not that certain elements of experience are "dropped" because they are per se particular, and others are retained because per se general, but the rather that they are particular because they are dropped and general because they are retained. It is just the fact that a certain content persists as the basis, the "platform," the point d'appui, of further concrete experience,

'Psychological Review, X.

2 Here it must be remembered that "concrete" is used, not as the correlative of universal, i.e., not in the sense of particular, but as meaning that stage or "aspect" of experience to which the universalizing and particularizing process leads and in which they, as such, disappear. 
that makes it general. Also since Locke's analysis of essence it has been well understood that what is "dropped" as particular in one situation is retained as general in another. Generality, therefore, is not a kind or quality of content, but is the relation which any content bears to the further development of experience. In short, universality does not mean an absolutely changeless possession of all intelligence. It means rather the continuity of experiencethe fact that experience is a self-developing process.

If this be the meaning of universality, and if by "concrete" we mean just the further experience in which both the general and the particular disappear, then what else but the "concrete" can be the "test" of the universal? To be sure, it cannot test it as a representation or reflection of a reality which "transcends all real life." But it can test it as a developmental device inside the process of "real life." It is when we lose sight of this productive, developmental, this forward-moving function of the universal, that we have nothing left but to "fall 
back on the traditional laws of thought" for the test of its validity.

Now, pragmatism is not an attempt to sponge these "traditional laws of thought" from the statutes. It simply insists that in themselves they do not constitute the final test of truth. They constitute the cues and guides of the generalizing process. They are part of the technique of thinking. In terms of habit they are, as Professor Baldwin well shows, part of the machinery whereby a hypothetical selection of material for adjustment is made. Here is where the so-called "universal judgment" appears with its technique of "consistency," "contradiction," etc. The universal judgment is an expression of the habit elements involved in every judgment. ${ }^{r}$ Hence, indeed, its "hypothetical" character. But again not "hypothetical" in itself. As an immediate experience it is as "categorical" and

r Here may be the place to remark that it is possible that the treatment in the logics of the universal judgment as a kind of judgment, apparently complete in itself, tends-despite subsequent qualifications-to nourish the notion that there must therefore be a special kind of reality corresponding to it-which, not being found of course in "real life," must exist in a "transcendent" realm. 
"real" as any other. It is "hypothetical" only with reference to further experience, only because it is not only an immediate but at the same time a mediating experience. And in this latter rôle, the test of its validity cannot lie merely "within itself."

And this suggests that the solution of the different views of the function of the universal in "real life" is perhaps to be found in the avoidance of a confusion of the immediate and mediating values of experience. The critics of pragmatism insist that thought is just as "good" and "real" and "true" an experience as any other; to all of which the pragmatist enthusiastically subscribes. Aye, an intellectualistically bred pragmatist (parodoxical as this may sound to some) might go further and say that all the rest of experience is just to furnish material for thought.

But even so, this yields the pragmatist's whole contention, namely: that thought is not sufficient unto itself. It must have "means." It can renew and feed itself only in and through the great stream of instinctive, emotional, and 
volitional content. It too must lose its life to find it. In insisting on the "real," "true," valid-in-itself character of thought, the critic is taking thought in its immediate character. But this is not thought as a logical process; and "true," "real," "valid" are here not logical categories. It is the mediating function of thought that gives it its logical quality, and to speak here of "truth" and "validity" with no reference to the goal of the mediation is surely a flagrant case of Hamlet without the Prince.

Such an omission too would seem to be pretty nearly equivalent to cutting off the second part of what Professor Baldwin in his "Selective Thinking" gives as, "The test of truth in the external world." "The first test is that of assimilation to established habits." [Instead of "test," etc., I should prefer to say, "step toward constructing truth," and instead of "assimilation to" I should prefer "response of."] Professor Baldwin continues: "This is the test of the general character of a new experience." [Again, instead of "test of" I should write "con-

I Sec. 6 of the chapter. 
stitutes."] Second, "there is the environmental test or test of fact." That is, "there is a further selection from these established habits of those which work in the specific environment." [Here, for "selection from," etc., I should prefer "reconstruction or modification of."] At any rate it is here clearly recognized that there may be an internal technique of generalization that does not as such give truth. Thought does not become "true," is not "validated," until it is tested by its results under the specific conditions. "A truth is an item of content which is expected when issuing in a movement to work under the exactions of fact." Again: "There is no question of truth until both these selective functions have been operative." ${ }^{\prime}$ Here it is certainly implied that in the first "test" alone we get only the abstract, formal universal-the mere statement that whatever the outcome is to be, it will be some kind of a reconstruction of certain established habits.

But from the standpoint of his paper on "The Limits of Pragmatism" Professor Baldwin

I Development and Evolution, 25I (italics mine). 
might be expected to reply: "Ah, but you have been quoting from my account of 'tests of truth in the external world,' ${ }^{\prime}$ whereas my point here is that there is a realm of purely universal truth as expressed in the universal judgment, which is independent of 'the test of fact' or environment." The rejoinder obviously would repeat the burden of the whole preceding discussion, the net outcome of which is that when thought is thus cut off from the rest of "real life" and is regarded as a self-sufficient, self-perpetuating process, it becomes essentially a subjective and atomistic affair. Truth and error consist merely in an immediate sense of harmony or contradiction unchecked by any "limits" in further experience.

As already intimated, this consequence is masked under the assumption of "the essential unity of intelligence as such." This really is a back-door resumption of the social and other "real-life" tests and checks of thought denied in the premises. For this means that the established habits which are the basis of the universal

I Italics mine. 
judgment have been developed, as Professor Baldwin has long contended, in a thoroughly social matrix. Hence we can trust the sense of consistency, in the responses of these habits, for a working hypothesis in the world of "real life" - the world in which the habits grew and to which therefore they are relevant.

To this Professor Baldwin could say that he has freely admitted that in a social pragmatism (and who has ever preached any other?) "a strain of universality and generality is imparted to knowledge in the aspect which constitutes it public to a social group." "But," he adds, "the limitation remains that such a theory would give a logic of a stage of cognitive process, that at which pragmatic tests are transferred to the social group, rather than a philosophy of the entire movement of reality."

Now, in his logic, the pragmatist does not profess to state all the content of "the entire movement of reality." The business of logic is to discuss the part thought plays in reality. This, of course, cannot be done without giving

$\therefore$ The Limits of Pragmatism, 5 . 
a general statement of one's view of the nature of reality. Hence, any logic seems bound to this extent "to blow itself up into the dimensions of a philosophy." I However, it is true that in so far as he is thus forced to state his view of reality the pragmatist confesses that the only reality he can find in which thought is playing a discoverable part is just the world of instinctive, emotional, volitional, social, "real life," and this he says too without prejudice to the conviction that this world of "real life" may have in it things not yet dreamed of in our philosophies. And he would insist that when thought is thus placed in such a world it can claim not a mere "strain" of universality but all it is capable of - all it can use and verify.

Elsewhere it seems to me Professor Baldwin has regarded this sort of verification as quite sufficient, not merely as a confirmation of a theory of the "genesis" of thought, but as logical verification-as a criterion of truth. In his effective rejoinder to Dr. Bosanquet ${ }^{2}$ he

I Ibid., 48.

2 Psychological Review, July, 1903. 
says: "Genetic theory therefore explains both under what influence we have come to hold (often wrongly) certain judgments to be true and also by what character judgments are true." To be sure this is prefaced with such statements as, "I agree with Dr. Bosanquet in confining genetic theory to questions of genesis. ... . Personally I am not a pragmatist. .... I think pragmatism is not able as such to explain the general or universal aspects of reality." But if it is valid as a theory of genesis and if genetic theory can explain " $j u s t$ by what character judgments are true," it has gone beyond the question of mere genesis. It is in the thick of logic. And if truth involves universality, and if truth must be conceived in some sort of intelligible relation to reality, it is difficult to see just what there is left to be explained or interpreted by some other kind of logic.

I Italics mine. 


\section{IX}

\section{PROFESSOR PERRY ON PRAGMATISM ${ }^{1}$}

In the innumerable replies and rejoinders of pragmatists to their critics there has been a pretty constant and often plaintive contention that much of the critic's case against the pragmatist is due to the fact that the critic at some point attributes his own conceptions to the pragmatist and then exhibits in triumph the impossibility of harmonizing these conceptions with other pragmatic doctrines.

In his interesting and able review of pragmatism $^{2}$, Professor Perry has obviously aimed to avoid this. And in a larger measure than usual among the critics he has succeeded. However, it seems to me that in spite of this good intention there are some passages that are likely to call out the old complaint.

Professor Perry's interpretation of the factors

I Published in the Journal of Philosophy, Psychology, and Scientific Methods, IV.

${ }^{2}$ Ibid., Nos. I4, I6. 
involved in the pragmatist's view of the logical process is:

I. Reality, or beliefs already fixed.-This element of experience is the object (this term now appearing for the first time) in so far as already known. The pragmatists would seem to disagree among themselves as to whether sensation belongs to this category or to the next. Let us designate this factor of the situation by the letter $M$.

2. The object as problematic.-This is the disturbing factor, consisting in a sensation as yet unresolved, or in a general discord which makes the situation practically unworkable. Let us designate this factor as $X$.

3. Ideas, or, to quote Professor Moore's phrase, "Instruments of reconstruction."-These elements, which we may designate as $a^{\prime}, b^{\prime}, c^{\prime}$, are tentative interpretations of $X$ and mark the period of deliberative hesitation.

4. The noetic interest.-Herein appears for the first time the subject or the knower himself, experienced as a particular need actively attempting to relieve itself. Let us designate this as $S . \quad S$ is not to be identified through its content so much as through its "polar" relation to $O$.

With the understanding that, in equating the datum or fact element with reality, the latter 
must be taken in a strictly logical, not a metaphysical, sense (since metaphysically the ideas are as real as the reality in paragraph I), and with the agreement that the fixity of this reality is not absolute, most pragmatists would, I think, accept the essence of the first three paragraphs. But the fourth is pretty sure to raise a protest at once. Here, it will be said, is where the imputations begin. First, the protestor will say, the very heading of the paragraph, especially since it appears independent of the ideas in the third paragraph, suggests an antipragmatic view - that of a pure, isolated, and sufficient-unto-itself noetic interest. The pragmatist speaks freely of interest as noetic, but he is likely to shy a little at the noetic interest when it appears as something over and above ideas. $\mathrm{He}$ is likely to say that one form of the issue between pragmatism and its critics is precisely whether the noetic activity is a special and original form of interest or only a function of or in interest.

On the relation of the noetic interest to the ideas in the third paragraph, the objector will 
probably insist that the noetic interest, or, rather, the noetic phase of interest, is carried by the ideas, and will inquire how there can be a noetic interest outside of ideas.

But if there is any question about the antipragmatic character of the heading of the fourth paragraph, many pragmatists will be sure that there is none in what follows about the necessity of a subject or knower over and above or under, at any rate in addition to, the ideas in the logical process. On the preceding page Professor Perry quotes from Professor Dewey's article ${ }^{\mathrm{x}}$ on "The Experimental Theory of Knowledge" and presumably must have read the entire article. In that article is the following: "The second [referring to the view that the object is immediately known by a subject] is a pseudoimmediacy, which in the same breath that it proclaims its immediacy smuggles in another term (and one which is unexperienced both in itself and in its relation), the subject, or consciousness, to which to relate the immediate." Again: "It is the identification of presence in ${ }^{1}$ Mind, N.S., XV, No. 59. 
consciousness with knowledge as such that leads to setting up a mind (ego, subject) which has the peculiar property of knowing (only so often it knows wrong!)." To this might be added: "The moment it is recognized that the logical fact-meaning duality is not to be identified with the technological object-agent duality, a large part of the present confusion of logic and of psychological epistemology clears itself up-it simply evaporates." ${ }^{\prime}$ Yet in the face of this, we find the "polar relation" between a subject, on the one hand, and an object, on the other, set forth as the pragmatist's own view of the noetic process!

To be sure, pragmatists do not all state the logical process alike. It is described now "as a relation or interaction between ideas and things," and again "as a relation or interaction between things through ideas." Whether in the end these two statements come to the same thing, they certainly do not regard a subject or knower in addition to ideas as necessary to the logical process as such. This does not say

I Journal of Philosophy, Psychology, etc., IV, 255. 
that there is no knower, nor does it imply that there is no self. It means that whatever of a self there is, it appears in the logical process only as the ideating activity. The idea is the self as knower. And in support of this the objector would probably ask: "Just what logical function does this extra-ideational subject or knower perform which the idea does not?"

That this is one of the cases of attribution of the reviewer's own ideas of which the pragmatist has so often complained, seems clear from the identity between the conception of knowledge attributed to the pragmatist in this paragraph and that upon which Professor Perry bases his objections to pragmatism throughout the discussion. The principal theses of Professor Perry's own view appear to be: (I) that truth must "envisage" or "coincide" with or be "identical" with reality (pp. 372, 374, 422); (2) that the object "is the element which plays the determining part in the constitution of truth" (p. 374); and (3) that the only purpose or intention to which truth is relative is just "the intention to know .... not the intention 
to put the knowledge to some use" (p. 368). So here in this interpretation of the pragmatist's view the subject or knower is further described: (I) as "a particular need" or interest which is satisfied when the object as problematic is "assimilated to" or "becomes homogeneous with" $M$, which is reality as fixed; (2) at the close of the paragraph the noetic problem appears also as that of overcoming the "objectivity or difference" of the object from $S$, the subject. In his summary at the close of his second article Professor Perry speaks of the problem entirely in terms of the relation between the knower, not the idea, and the object.

At any rate, pragmatists will hardly accept either of these statements as they stand. They will insist that the essence of the logical problem does not lie in the opposition between a self and an object, nor does the process of solution consist in "assimilating" the object as unknown "to beliefs or reality already fixed." In all the accounts I have read, pragmatists teach that knowing consists as much in the assimilation of the already known to the new as the reverse; 
that the already known is not finally known once and forever; that in new situations it has to be re-known. But still, since the new develops out of the old, the old is sufficient to serve as a base for further operations. But while a base is the relatively fixed element, it must nevertheless be movable unless our march is to be ever in a circle. Over and over pragmatists have insisted that "the given" is a point of departure rather than a fixed stake to which we are bound hard and fast. Of course, after the departure there is a return to the given, but only to discover that the work done during the departure necessitates a reconstruction of the given with which or from which we started.

The same point is raised at the beginning of the second paper, where Professor Perry says: "According to the pragmatist's own analysis, the satisfaction is legitimate and sound when a judgment has been found which is consistent with that which is accepted as real." Now it is quite possible to interpret this pragmatically. But it is quite certain from the context that Professor Perry does not so interpret it. For 
by "that which is accepted as real" Professor Perry means that which is accepted as unalterably real before the judgment is made. And for "consistent with" he uses elsewhere "coincident," "identical," and "homogeneous" with. But for the pragmatist "that which is accepted as real," i.e., as logically real, is one factor in the judging process, not something outside to which the whole judgment must conform. Moreover, that which is accepted as real in the beginning of the judging act is so accepted provisionally, and may be quite different from that which is accepted as real at the end of the process. And if Professor Perry should say that it is this latter which he has in mind, the rejoinder would be that the judgment is no more made to consist with this than this is made to consist with the judgment; for this reality at the end is a reality with all the work of judging in it and never could be experienced without this operation. An ox or a monkey may die of tuberculosis, but he does not experience tuberculosis. That is reserved for a being who can through science, through thought, make 
a connection between the pains, fever, etc., and a certain kind of bacteria.

Passing from Professor Perry's exposition of pragmatism to some of his criticisms: his first point is that while he accepts the pragmatist's doctrine that truth and error are always relative to some intention, yet we must remember that that intention is nothing but the intention to know. This reminds one of Bradley's, Royce's, and Taylor's treatment of the categories of "consistency," "harmony," "unity," etc. They tell us that the meaning of these categories is "always relative to some particular problem and purpose," but when we ask to what particular purpose their application to absolute reality is relative, we are told simply to "the purpose to be consistent, harmonious, unified, etc." So also the idea is a form of will, but its only will is to know, that is, to be an idea. Formally this looks suspiciously like the "vicious circle."

But, formalities aside, as above the issue was between the noetic interest and interest as notice, so here it is between the intention to know and knowing as intention. In short, we 
are back to the original question-just what is the process of knowing, and what is an idea? There is very little directly on these questions in Professor Perry's papers. Perhaps he thinks the announcement of his standpoint as "realism" should be sufficient. But there are so many brands of realism these days that one must have some details. ${ }^{x}$ However, the following general statements may give a line on Professor Perry's position. In the concluding paragraph of the first paper he says: "In this criticism I have not resorted to a general and vague insistence that true knowledge must 'correspond' to its object. I agree with the pragmatist that this is to take refuge in confusion." Yet elsewhere we find the following: "A judgment is true in so far as it coincides with a proposition or complex entity which is found with its distinguishing character upon it and its consistency about it" (p. 379; italics mine). "So far as truth is concerned, the important element of the situation is identity or consist-

I It would be interesting to "match up" the varieties of realism with Professor Lovejoy's "thirteen varieties of pragmatism." 
ency with reality" (p. 422). "For realism truth consists in an experience of identification, such as, 'Here is $a$ or $M+a$.' . . . . Because it is truth it must envisage reality" (p. 374).

But if to state the relation between the idea and the object as one of correspondence "is to take refuge in confusion," it is difficult to see how a substitution of "coincidence," "identity," or "envisaging" for "correspondence" mends the matter. Most of those who think "correspondence" confusing are likely to find in "coincidence" and "identity" confusion doubly confounded. At any rate, it seems to me that, in spite of Professor Perry's disavowal of correspondence, it is difficult to see what these passages mean if not a good old-fashioned envisaging, photographic realism.

Now, there is a realism, a functional, a dynamic or "operative" realism, which has very close affiliations with pragmatism-a realism, namely, which teaches that ideas lead into, and help bring about, other experiences different from themselves. In this difference between the ideas and the other experiences which yet 
allows a free passage from one to the other consists the realism. With the old realism it holds to the difference between the idea and its realization, but it contends that this difference consists in something more than that one is an envisager of the other.

If Professor Perry's realism is of the photographic, envisaging type, it seems in order to recall once more the questions which pragmatists from the beginning have been urgingquestions which no one so far has dealt with directly and specifically-such questions as: If truth consists in identity and coincidence between an idea and reality, just what then is the significance of the difference between an idea and reality? Why when we have one do we want the other? And if there is a difference, must not truth be defined as much in terms of this difference as of the identity? Again, when there is doubt about the correspondence or coincidence or identity of the idea with reality, how is the doubt resolved? What is the criterion of successful identification? Yet again, if the object is the determining factor 
and the object is always there, how can there ever be any uncertainty? How can there be any problem of knowledge, to begin with? Why should the object ever fail to determine, or determine falsely? And if the object is not always there, how can it always be the determining factor?

There is a proneness on the part of the critics to confine the discussion to the nature of truth as a product, whereas the pragmatists insist on the problem of doubt, inquiry, and error. This tendency to take truth as a product only, appears in Professor Perry's interpretation of the pragmatist's view of the relation between truth and use. Professor Perry speaks of the pragmatist's appeal to "the use of truth" in a way which makes the use begin after the truth is reached. But the "use" with which the pragmatist is concerned is the use of an idea which constitutes its truth. The pragmatist could readily agree that after the truth of an idea is established the continued use of it in similar situations would not affect its truth.

The meaning of this may become clearer if 
we follow Professor Perry's illustration. He says (p. 368):

I may intend to vote for the man with the cleanest record, and proceed to discover him; but it is the latter intention alone, the intention to discover that one among the candidates who has the cleanest record, to which my ensuing belief is relative as respects its truth or error.

Now I think a little analysis shows that the relation between the intention to discover the cleanest candidate and the intention to vote, and, therefore, the relation between the truth of the idea of who is the cleanest and the intention to vote, is closer than Professor Perry allows. Of course, Professor Perry would grant that there is a pretty intimate relation of motivation between the intention to vote and the intention to find the cleanest candidate, but he will insist that the content of the latter is already there as a separate and independent affair "with its distinguishing characters upon it." But is it? What is the meaning of the cleanest candidate? Suppose there were no voting, no office-holding, no political party, 
would there be a cleanest candidate? It probably would be quibbling to insist that in such a case there could be no "candidate" at all. So let that be waived and let the question be, Would there be any cleanest man in the sense here meant, that is, politically cleanest? Does not the concept "clean" here mean a man to be voted for, to be put into office, to be intrusted with funds, etc.? Again, Professor Perry's conception of the cleanest man is different from that of the ward-heeler; for the latter the cleanest man is the one who will be "white" to his friends. However, in either event, Professor Perry's case rests upon the assumption that the cleanness is there quite independent of the voting, and that the voting occurs because of the cleanness. But once more, suppose the whole voting system, with all that it implies, never to have started, would the kind of cleanness here sought still be there? If not, is it not just as obvious that political cleanness exists because of the voting, as the voting because of the cleanness? However, neither of these antithetical statements of the situation 
does it justice, for the quality of cleanness and the activity of voting develop together as mutually conditioning differentiations within what Professor James calls the same social "fundamentum."

Following the illustration into the question of use raised above, suppose we have reached the point where the idea of $A$-as-a-clean-man emerges. In so far as there is only an idea there is not certainty. We "think" $A$ is a clean man. How is this hypothesis to be verified or rejected? How, indeed, except by using, by following, this idea until it leads or fails to lead to further experiences of $A$ 's cleanness sufficient to satisfy the demands of the original problem of whom to vote for.

No pragmatist has ever held that the transition from one experience to another, or, if the word experience is objectionable, the movement from one reality to another, takes place in a vacuum. He has never taught, as one might gather from some of the critics, that ideas create new reality out of the void. He speaks of the further development and reconstruction of 
experience or reality through ideas; of the idea as the form reality or experience takes to maintain and further itself. Of course the idea cannot lead to a new experience unless the material for the experience exists. But the pragmatist holds, on the other hand, that, before the appearance of the idea of a-politically-clean-man (still keeping to the illustration), whatever quality men as husbands, fathers, merchants may have, these qualities are yet only possible material for political cleanness and become the "real" political cleanness as they are transformed through the idea of political cleanness. The idea of political cleanness converts this material into political cleanness by bringing to it, or bringing it to, the demands of a new problem. And the pragmatist holds that this is a real transformation, that the idea brings things, i.e., already organized activities, into new relations of interaction which result in a new reality. No doubt the paper with which I have just kindled the fire was already there, but it was not there as kindling until the idea of kindling appeared. It was through this idea that it 
came into relation with my hands, with the match, the wood, etc. So it is through the idea of political cleanness that $A$ 's qualities as husband, father, merchant, etc., are turned into a new direction and thereby undergo some actual qualitative change. The real political cleanness, then, is not there independent of and determining the idea of political cleanness. It is there only in relation to this idea. The idea is as much a determinant of the reality as is the already existing material. The whole of the matter is that the idea and the already existing material, the habits of father, husband, merchant, etc., are together working out a new reality.

But, it may be said, granting that prior to the idea of political activity there is only the material for political cleanness, even so this material must be recognized as material for that end and not some other, and this in a purely envisaging, photographic fashion. In other words, there must be the direct identification of the material. But the pragmatist could not allow the begging of this point under the term 
"identification." He will ask once more: What is identification? And will insist that it does not consist in an experience of identity between the idea and the thing, but that the material is identified as it is found to satisfy the demand which the idea expresses. It is no more "identical" with the idea than food is identical with hunger. The relation is one of stimulus and response rather than one of identity, unless, indeed, we are willing to interpret identity as that which responds to and satisfies the demand which the idea defines and makes specific.

Professor Perry thinks that whatever strength the pragmatist's position has is due largely to the fact that he has selected for his illustration what he calls "truths of use" to the neglect of "simple perception," "in which the cognitive moment is seen to the best advantage" (p. 373). "To know," says Professor Perry, "is to see, whether with the bodily eye or with the eye of the soul" (p. 366). But is the case so simple as this? If knowing is just seeing, where does error come in? What distinguishes good from bad seeing? And is the reply of the Greeks to 
this, that the seeing is bad only in so far as it is not-seeing, sufficient? Also does not this conception of knowledge sink the distinction between immediate realizing experience and the mediating knowing experience? Surely there is a seeing that is not knowing. My seeing of a sun-lit cloud usually is not primarily cognitive. As I thread my way through a crowded street I am "seeing," but unless we are to abandon the distinction between practical and cognitive experiences the seeing here is a form of doing just as much as the walking. For the pragmatist seeing is knowing only when it occurs in connection with an inquiry. It seems impossible for the critic to keep in mind that for the pragmatist knowing is inquiring; and knowledge is the result of inquiry.

In this sense of belonging to a process of inquiry all truths, or, rather, all ideas, are "ideas of use." If sense perception can be simply given out of all connection with any sort of inquiry, it is not, as such, for the pragmatist cognitive. It is then directly practical or aesthetic. Once more, suppose there is doubt and consequent 
inquiry about a case of sense perception, what would be Prof essor Perry's account of its resolution?

The crucial thesis in pragmatism, Professor Perry says, is this: "The mark of the truth of knowledge is the satisfying character of the prac-

- tical transition from cognitive expectation to fulfilment, or of the resolution of doubt into practical immediacy" (p. 37I). In spite of the care which Professor Perry says he gave to phrasing this, the term "mark" still appears ambiguous. Ordinarily it means criterion, sign, or test. In this sense the thesis would be a familiar enough pragmatic doctrine. But then it would lose its crucial character for Professor Perry. The crucial character appears in Professor Perry's revision of the thesis a little farther on, in which he says: "The essence of the matter is the degree to which the satisfying character of the crucial moment constitutes its truth." Here, "mark" means "constitution," which is quite a different affair from "criterion" or "test," and is one for which Professor Perry should have given chapter and verse, for I am sure no pragmatist will 
own it. For the pragmatist, the truth of an idea consists in its capacity to "lead" to the experience which it promises. And as stated above, in discussing Professor Perry's illustration, this capacity is neither a matter of chance nor by the grace of the absolute, but is due to the fact that the idea is born out of that very "fundamentum" of "reality" or "experience" (what you will) in which it works. Professor Perry well says: "There must be a ground for this satisfaction." It is just this ground which, absolutism having failed to supply, the pragmatist has sought in the immediate activities of social life.

Professor Perry's remarks on the last topic"Knowledge Modifies and Adds to Being"have perhaps been sufficiently anticipated. However, the issue between Professor Perry's realism and pragmatism is here very sharply drawn and calls for an additional word. Professor Perry's point is, of course, that objects known are "not essentially modified" by the act of knowing. I wonder just how much reservation the qualifier "essentially" carries. 
Professor Perry would grant, I suppose, that if the act of knowing as such does not essentially modify the object known, it in some mysterious way leads to acts that do. But if the alteration does not begin in the knowing process, where does it begin? In what way does the knowing lead to the activity that does alter the object? If I am hungry and bethink me of a sandwich on the sideboard, and if I say that the act of thinking does not essentially modify the sandwich, where does the "essential" modification begin? When I reach for it? When I touch it? At the first bite, or the second ? ${ }^{1}$

Professor Perry here appeals to knowledge of past and future objects and events as the crucial support of his denial of the real efficacy of thought. At the same time he contends that past and future objects and events have as real an existence as the present. I am not prepared to discuss this point in detail here, ${ }^{2}$ but

I These questions bring up the entire subject of qualities and relations, into which there is not time to go here. But it is interesting to note that $\mathrm{Mr}$. Bradley finds an envisaging knowledge of reality impossible just because the establishing of new relationships is the beginning of "essential" modifications.

${ }^{2}$ See V. 
shall say that, if they do so exist and can enter into new relation with each other and with the present, then they must be subject to modification in the same sense as the present.

In concluding, Professor Perry says: "It seems absurd to contend that knowledge makes the world." But who has so contended? The pragmatist's contention is that knowledge helps to make, in the sense of assisting in remaking, the world. Professor Perry concedes, however, that "knowledge does make its world." "It may even be said to make our world. But there is a tremendous significance, practical, philosophical, and religious, in this difference between our world and the world." In appreciation of this "tremendous significance" the pragmatist would yield to no one. Indeed, it was just this "tremendous significance" that started the pragmatic movement. But for the pragmatist this "tremendous significance" consists in the belief that in so far as the distinction between our world and the world is widened by just so far the abyss of phenomenalism and skepticism is opened. 


\section{$\mathrm{X}$}

\section{PRAGMATISM AND SOLIPSISM ${ }^{x}$}

However astonished were the expounders of pragmatism at the indictments of "subjectivism" and "solipsism" returned by the critics in the early days of the movement, on reflection these charges were not difficult to explain. In general the explanation was that pragmatists had assumed, prematurely, as it now appears, that the specter of solipsism had been laid. For more than a decade preceding the beginning of the pragmatic movement, philosophers, especially in America and France, were busy expounding the social character of consciousness-of the "private," "individual" consciousnessboth in its origin and function. The outcome of this exposition seemed to be that the consciousness of an individual was not to be

I The materials of this paper appeared in the Journal of Philosophy, Psychology, and Scientific Methods, VI, and in the Philosophical Review, XV. 
considered a function, or a correlate of his "organism" or "mind" only, but that both the organism and "its" mind were to be thought of as arising in and belonging to a "social situation."

This conception apparently was generally accepted. And this acceptance would seem to have warranted the assumption that solipsism was dead. It appeared that everyone was ready to start with our everyday neighborly world of social intercourse and to regard individual consciousness as an organic function of that world. It seemed as if philosophy might now go on to a fruitful, detailed study of this social process, and might talk of consciousness, of ideas, needs, purposes, yea, even of "my" or "your" ideas, needs, and purposes without danger of solipsistic interpretations.

At any rate, this was the supposition of pragmatists whose writings followed close upon these studies of the social nature of consciousness. They assumed that solipsistic, windowless, monadic conception of the individual was a thing of the past. But alas, as the returns from 
the critics began to come in they discovered how ill they had reckoned. They found that the critics, many of whom ${ }^{\mathrm{I}}$ had themselves done yeoman service in developing this social conception, either attached no such significance to the results of these investigations or refused to allow pragmatists to do so. It was evident that, for some of the critics, the chief value of the social conception of consciousness was its supposed service in clearing up the conception of the relation between the finite and the absolute, though to pragmatists it seemed to "muddle," rather than clarify, that conception. For by just so much as this exposition of the social character of consciousness made the relation of the finite to the absolute conceivable, by even so much did it make it unnecessary. Hence the absolutist was obliged to nolle pros. his part of the case and to resolipsize the individual in order to preserve the necessity for the absolute. The dilemma was: if finite experience is such that the conception of the absolute

I Cf., e.g., the contributions of Professors Royce and Baldwin to the social conception of the individual and the solipsistic assumptions in their criticisms of pragmatism. 
is possible, it is such that the latter is useless; if finite experience is such as to need the conception of the absolute, it is such as to make that conception impossible.

For others, the results of these investigations into the social character of the individual were regarded as having special value for ethical theory. For still others, they were just interesting psychological "discoveries" whose logical and metaphysical consequences either were of no interest or were unappreciated.

Now the pragmatist confidingly took this conception of the perfectly objective and social character of consciousness at its full face value, with no discounts or rebates in favor either of absolutism or of intellectual realism, and set out to develop a logic and a metaphysics on that basis. Hence it seemed to him, at first, that the critics must be joking when they cried "solipsism." But as soon as it was clear that they were desperately in earnest, the pragmatist hastened to explain why he had put up no special guard against such an interpretation. Again and again he 
proclaimed that he had only accepted in good faith the social evaluation of consciousness, which the critics had themselves, in many instances, helped to make. Over and over he "explained" that he had supposed this view of consciousness had settled forever that ideas, hypotheses, are no more "subjective" because they are constructed in or through individual minds or brains than a house is subjective because constructed by individuals.

In the face of these specific, repeated, and vociferous protestations from pragmatists, it is difficult to comprehend how anyone, without at least discussing this social conception of consciousness, could blandly reiterate the solipsistic objection. And yet in the latest antipragmatist volume (Professor Pratt's What Is Pragmatism? - in many respects a keen and stimulating book), this is just what has happened. Professsor Pratt says: "It is interesting to note ... . that all Professor Dewey's and Professor Moore's contributions to studies in logical theory .... could perfectly well have been written from the standpoint of 
solipsism-and in fact it is difficult to see how some of them could have been written from any other" (p. I23).

And the wonder grows when one reads again Professor Dewey's explicit and, one would think, completely destructive answer to this same statement when it previously appeared in a "discussion" by Professor Pratt." In his reply, Professor Dewey points out that Professor Pratt's whole discussion is based on his conception of truth as a "correspondence" between an idea in "a private stream of consciousness" and "outer realities which never come within one's own private stream of consciousness." Professor Dewey then goes on to show how completely mythical such "a private consciousness" and "outer realities" are on his view of the judgment. Without even discussing this explicit and complete repudiation of "the private stream of consciousness," to say nothing of equally specific rejections by others, Professor Pratt reprints in his book his private-consciousness-outer-reality view of

I Journal of Philosophy, Psychology, etc., V, 375. 
thought, and his charge of "solipsism" based on the attribution of this view to pragmatists!

It is difficult to see how philosophy is to go forward at this rate. Had Professor Pratt given what he regarded as a vindication of his "private-consciousness" theory, he might then have appropriately reaffirmed his indictment, even though it precipitated the dilemma, that in the degree to which his vindication was successful, the indictment would return upon his own view. In a footnote (p. I23) Professor Pratt does quote a passage from Professor Dewey's refutation of "the privateconsciousness" view, but instead of dealing with this he drops it and goes on to answer certain questions which Professor Dewey had put. And these "answers" show not only that Professor Pratt still holds his "private-consciousness" view as if it had never been challenged, but that he still assumes that the pragmatist also is talking from this standpoint. Thus after granting that "certainly hypotheses and theories serve to direct observation and guide experimentation," he adds: "But the funda- 
mental question is, how is it possible for them to be instruments and what is it that makes some successful guides, and some unsuccessful? So far as I can see, the pragmatist has no answer to this." But the pragmatist's "answer" has been there, life-size, from the beginning. The reason Professor Pratt cannot "see" it, is that he is still shut up, and is trying to shut up the pragmatist with him, in his windowless "private consciousness."

Before passing to the pragmatist's answer, Professor Pratt's own solution should be noticed. He says: "The non-pragmatist's answer of course is, that hypotheses succeed in guiding experimentation in so far as they correspond to the already existing reality which is their object and which they mean."

Elsewhere Professor Pratt intimates that he finds pragmatists, as one might expect, somewhat naïve in matters of formal logic. How naive he regards them may be imagined if he expected that pragmatists would not see that his "answer" merely shifts the problem from that of "guidance" to that of "corre- 
spondence" and that they would not ask how "correspondence" is possible on the "privateconsciousness" view of judgment. This is the pragmatists' "prior and fundamental question" to the intellectual realist. Professor Pratt's answer to this (pp. 68-69), is that correspondence is an "ultimately simple," "irreducible," and "mysterious" relation, incapable of explanation, and that, therefore, the question "how it is possible" is "absurd."

In passing, the pragmatist will wonder, if correspondence is so "simple" as to make the demand for explanation "absurd," why "guidance" should be such a burning question for which the pragmatist has no answer. And he might also observe, that if he has found no answer to the question on "guidance" up to this time, surely with the model of Professor Pratt's answer to the "correspondence" question before him he need be no longer dumb. He would have only to say: Guidance is an "ultimately simple" and "irreducible," even if "mysterious," relation. Perhaps the pragmatist's naïve logical sense might suffer 
some misgivings that such a solution begs the whole problem, to say nothing of its depragmatizing tendency, but-that is another story.

It is already obvious that the pragmatist's "explanation" of how it is possible for ideas of a "private consciousness" to be "instruments" and "guides" lies in his view of the social origin, nature, and function of this "private consciousness." This, of course, is but another way of saying that while consciousness doubtless is in some sense "private," it after all is not so "awfully" private. Surely we are all prepared to grant that however "private" consciousness may be it is somehow born of a thoroughly social, objective world. So much I suppose would not be questioned. But at this point our ways of thinking begin to diverge. Some apparently believe that although the individual consciousness is born of our social world, it is either born blind or, as soon as it is born, it is cast into a solipsistic outer darkness, so dense that the possibility of its ideas or hypotheses agreeing with "things" becomes indeed a "mystery"; and a mystery 
which presupposes another equally dark, namely, how this outcast, abandoned "private consciousness" comes by its ideas.

Now the pragmatist, at least that "variety" of pragmatist with which I am acquainted, thinks of this "private consciousness" not only as born of, but as growing up in, and, therefore, continuing all the while vitally and organically related to, its matrix. Not only in its origin, but in its continued development and operation must it always be a function of the whole social situation of which it is born. However "private" or "individual" consciousness may be, it is never to be regarded as wholly or merely the function of an individual "mind" or "soul" or of a single organism or brain. I have just italicized the phrase: "of a single organism or brain." By this I wish to emphasize the fact that much of our "biological" and "functional" psychology, which often speaks so patronizingly of the old soul-psychology, is logically just as solipsistic as the latter. If consciousness is wholly a function of a single organism or brain, how much better 
off are we so far as the logical problem is concerned than we are with consciousness a function of a single soul or mind.

This "subcutaneous" conception of consciousness, as Professor Perry aptly calls it, ${ }^{\prime}$ has its correlate in the equally "subcutaneous" and solipsistic view of the nervous system which regards it as merely the "co-ordinator" of the rest of the functions of the organism only. The environment, to be sure, figures dimly in the background as that "to" which the organism is to adjust itself, whatever this can mean. With this belongs also the no less solipsistic conception of the activity of the organism as consisting merely in a competitive "struggle for existence" with other organisms.

How grotesquely inadequate these conceptions are, becomes apparent the moment we try to apply them to the concrete activity of a physician, a lawyer, an architect, or any other expert to whom I delegate the adjustment of

I Cf. Professor Perry's very suggestive paper on "The Mind Within and the Mind Without," Journal of Philosophy, Psychology, etc., VI, I69. 
"my" troubles. While the cure of the toothache, of the quarrel, of the house is "my" problem, it is also and no less and at the same time "his." Conversely his effort is as truly and as much to adjust me as to adjust himself. His thinking is as literally a function of my organism as his own. His effort is my way of making the readjustment, which belongs equally to both of us. When the pragmatist, therefore, talks of attention and thought as arising at the point of a need for readjustment, this need must not be taken to mean the need of some one, lone, marooned organism or mind only. The readjustment is always in and of a "social situation."

Now when one fully accepts, and steadily holds on to, this notion of the social origin and function of consciousness, it ought not to be difficult to understand why for him the question of the possibility in general of ideas and hypotheses of a private consciousness serving as "instruments" and "guides" would not arise. From this standpoint the presumption is all the other way. The question might 
much more intelligibly be: How ideas ever fail to guide? And indeed they never do fail to "guide" in some way. They are never absolutely impotent. They always effect some transformation.

This brings us around again to the problem of truth and error, which is a question not of the complete efficiency or impotence of ideas, but of the kind and degree of efficacy they have. At this point it is clear from the amount of writing which continues from the standpoint of "the private stream of consciousness" that there is need of a return to a direct discussion of the "social nature" of consciousness and to the judgment ${ }^{1}$ and of its application to the supposedly difficult "headache and toothache" cases. ${ }^{2}$

Another interesting imputation of subjectivism is contained in the very suggestive paper of Professor Fite on "The Experience Phi-

I The article by Professor G. H. Mead in the Journal of Philosophy, Psychology, etc., of March 31, I910, on "What Social Objects Must Psychology Presuppose?" is a fine illustration of the sort of detailed analysis here needed.

"My treatment of these cases which I "hoped" in this paper to "take up later" will be found in chap. v. 
losophy" in the Philosophical Review, XV. Professor Fite's arraignment is especially interesting and somewhat puzzling in view of the striking similarity between his conclusions and those of the standpoint which he criticizes.

Professor Fite allows that the pragmatist makes the distinction between "experience and subjective-experience." But he finds that, while the pragmatist thunders this abstractly in the index, in his context "reality is always precisely coextensive with subjective-experience." But nowhere does Professor Fite point out where and how and for what end this substitution occurs. The only direct evidence for the charge is the very brief statement that for the pragmatist "the chair when it disappears from thought ceases also to be" (p. I). But even in this statement, as it stands, experience must be reduced (I) to mere thought-experience, and (2) to $m y$ thought-experience before it becomes subjective. And I do not see that Professor Fite's observation in his footnote on my statement in the Review of May, 1905, offers any further support to the case. It 
simply reaffirms that the pragmatist has discarded the world of space and time for a "conception" in "some one's experience." My statement was to the effect that, if the pragmatist really does discard the objective world (not the world in space and time merely), there can be, as Kant taught, no mere subject left to have a concept, and that the critics therefore should include in their charge the destruction of the subject as well as the object.

Returning to the pragmatist's countercharge of his critics' own inherent and subjective bias, evidence of this appears at the very outset in the easy way in which Professor Fite brackets "the subjective idealism of Berkeley, and the phenomenalism of J. S. Mill" with "pragmatism, humanism, and radical empiricism of Professor James." "All of these," says Professor Fite, "deny that there is a world beyond experience; all in substance hold with Berkeley and Schopenhauer that the world is my idea" (p. I, italics mine). Apparently these two clauses are equipollent in Professor Fite's thought. This, of course, assumes again ( $I$ ) that experience is 
my experience and (2) that it consists of ideas only-is merely cognitive. If Professor Fite should say "the equipollence is not mine but one to which the various parties charged in the indictment are themselves forced in 'practice,'" then, in the case of the pragmatist at least, since he is the one under direct examination, this should be shown in detail, and reinforced by citations.

Nor do I see that Professor Fite succeeds in showing where or how pragmatism is forced from the conception of "experience" to that of "subjective-experience" in his next point, which is: "The fundamental position of the experience-philosophy is that experience and experience only is 'given' or 'immediately given'; all else, i.e., the world of things in space and time, is derived, inferred, constructed, developed, from experience" ( $\mathrm{p}$. 2, italics mine). The words "given" and "immediately given" are in single quotation marks. This may simply indicate that they are terms current in present discussion. If it means, however, that they are applied by 
pragmatists to the entire world of experience, as they are here, it would be interesting to have "chapter and verse" for this.

As for regarding the world of experience as "given," I do not see how anyone, Professor Fite especially, could have read, for instance, Professor Dewey's chaps. ii and iii, in the Studies in Logical Theory, without discovering that in pragmatism "given" has no meaning applied to experience as a whole; for the pragmatist "given" is a logical category applied only to some specific content in experience in its logical operations. If experience as such, as a whole, were "given," it is difficult to see how there could be any possibility of derivation, inference, construction, etc. Conversely, how could the given "from which" something further is to be derived or inferred be a whole? Some things in space and time may be inferred from others, taken as "given," but no pragmatist ever dreamed of "inferring" the world of space and time from another world of "experience." The world of space and time is part and parcel of the pragmatist's world of experience. What 
Professor Fite says of "the things in space and time" being "as good a datum" as any other experience, and of "neither as absolute," and of "the search for absolute data as not only illusory but logically unnecessary" (p. 2), -these are the first principles of the pragmatist's logic.

Conceding, however, for the moment, that the world of space and time is "derived from" experience, it is still a far cry to subjectivism. (I) If space and time are necessary to objectivity, they are equally necessary to the subject. Hence, in a world "prior" to space and time, the distinction of subject and object would not exist. I say "if," for (2) some may hold that "things in space and time" constitute only one phase of both objectivity and subjectivity; that the distinction of subject and object does not depend on space and time as such, but is a differentiation running across the space and time world. This alleged "prior world," then, might be one in which the distinction of subject and object did not appear; or it might be one in which it did not have a spatial and temporal 
character. In neither case are we warranted in calling it "subjective."

Although in the first formulation this alleged "datum" of pragmatism is "prior" to the world of space and time, in the next paragraph it is described as a "series" with distinctions of present and past (why not future also?) in it. To be sure, Professor Fite says the pragmatist "in his practice" attempts to ignore the time distinctions, and to treat the series "as if it were immediately given as a whole." Once more, the first thing is to ask: From what writings are such doctrines as these gleaned? Or, if they are not directly expressed anywhere, where are they implied, and what interest of the pragmatist standpoint do they serve? Professor Fite says the series may be, for the pragmatist, "merely a convenient working basis." But he does not show in what way it is "convenient," or for what it is a basis.

The next point the pragmatist would make is that if the attribution were correct it would still not bring us in sight of "subjectivism." What is there necessarily "subjective" in the 
conception of a series conceived as a whole? Even if it exclude the space-world (and that is all it does exclude here since differences of time are admitted), that does not make it "subjective." Space surely is not the criterion of objectivity. Where, then, is this notorious "subjectivism"? Thus far it has not shown itself in Professor Fite's own version of "the fundamental position of the experience-philosophy." It is, however, now ready to appear. And how? It simply appears. There is no introduction, not even a warning knock. It is quietly left on the pragmatist's doorstep without a syllable of explanation, clad in the scant but inevitable garb of the pronoun "my." Throughout the entire page two the conception of "experience as a whole," or as "a series taken as a whole," has appeared with no "subjective" qualifications. But in the last sentence of the page, with no word of comment or of qualification, it appears as "my experience as a whole" (italics mine). It may be said: "At any rate, the bundle is left where it belongs." But in the face of the pragmatist's 
repeated and vehement disavowals of the contents, some more substantial evidence must be submitted.

If it should be asked: "If not 'my' experience, whose then?" the question would only show how deep-rooted and ineradicable is the subjectivism of the asker. The inquiry assumes that the world of experience must belong, as a hat or a coat, to some particular individual, instead of being itself the world-process in which individuals, along with other "things in space and time," live and move and have their being. Doubtless much needs to be said from the pragmatist's standpoint of the nature and rôle of the individual in such a world. Meanwhile, aside from the bearing of pragmatists' discussions of other points on this question, it would seem that the repeated statements even of the bare outlines of the conception should be sufficient answer to charges of subjectivism equally bare and unsupported.

Most of the remaining portion of Professor Fite's article is an excellent refutation of the subjectivism and absolutism charged to the 
pragmatist in the introduction, with some additional imputations in detail (e.g., p. 8, on the basis of the pragmatist's distinction between "real" and "not-real") which the pragmatist could not accept. It is, therefore, in essence, first-class pragmatism. I say, "in essence," for owing to the subjective meaning given to "experience" in the first two pages, it has to appear in the further discussion in correlative contrast with "fact" and "thing"; whereas the pragmatist's correlative of "fact" is "idea," experience being the process within which these correlatives operate. Throughout much of this part of the paper one feels as if the whole issue, as Professor Fite draws it, were almost verbal. In the concluding paragraph of the paper, Professor Fite says: "We should then hold with the realist that reality is not limited to experience." Most assuredly if "experience" is regarded simply as " $m y$ idea," and if in this statement of Professor Fite's we substitute " experience" for "reality" and insert "cognitive" before the word "experience," we have good pragmatic doctrine and 
one which meets the essential point realism is contending for. I cannot here stop to argue why "experience" seems a better term than "reality." One obvious reason is that the latter has a classic logical use as the correlative of "illusion" which "experience" has not.

What Professor Fite says of the "present," as "no more given than the past," and of the present or past as internal, being no more given than external things, and practically all of what he says in sec. iii on the vanity of an "absolute datum," pragmatism has zealously preached from the beginning. Thus we read (p. II): "My point is that nothing is absolutely given and that for purposes of knowledge no absolute data are required." Again (p. I3): "A datum is not a finality, but a convenient abstraction for purposes of further analysis, depending for its validity upon the results that it yields." Compare these statements with the following:

The data are in truth precisely what is selected and set aside as present, as immediate. Thus they are given to further thought. [Again:] The datum 
is given in the thought-situation, and to further qualification of ideas or meanings. . . . To take what is given in the thought-situation .... as if it were given absolutely, or apart from a particular historical situs and context, is the fallacy of empiricism [of the Mill type].... . To regard the thought-forms of conception, judgment, and inference as qualifications of "pure thought apart from any differences in objects" .... is the fallacy of rationalism. ${ }^{x}$

If, again, it be said, it is not by what it abstractly preaches but by what it "practices" that pragmatism is to be judged-a criterion to which pragmatists should be the last to object-then yet again, the pragmatist must rejoin that this "practice" of subjectivism has not yet been exhibited.

× Dewey in Studies in Logical Theory, pp. 57 ff. 


\section{XI}

\section{THE SOCIAL CHARACTER OF HABIT AND ATTENTION ${ }^{1}$}

In my discussion of Professor Baldwin's Thought and Things, Vol. I, in the Psychological Bulletin for March of this year, I referred to Professor Baldwin's criticisms of the attempt to state cognitive experiences as a part of the whole process of the readjustment of conflicting habitual and instinctive activities through attention. Professor Baldwin's objection was that such an account cannot take care of the case of "a new and unwelcome object which simply forces itself upon us, .... which rides full armed through our walls and compels its recognition." My reply was to the effect that this very "new," "unwelcome," involuntary, "forced" character of the object, when analyzed instead of being accepted as ultimate and quasi-miraculous, turns out to be

I Published in the Psychological Bulletin, IV, under the title "Experience, Habit, and Attention." 
just as much a function of habit and attention as the "voluntary" cases.

Without any further attempt at analysis, Professor Baldwin in the May number of the Bulletin reaffirms his objection and adds another edition of it, from the standpoint of volitional instead of cognitive experience, to the effect, that in such a conception of experience there is no "motivation." $\mathrm{He}$ says, "I can't rest content with a dynamic that has nothing outside to move it and no reason inside for moving." This sounds wonderfully like an appeal to an outside "unmoved mover," the insoluble difficulties with which our Greek forebears, to say nothing of Locke, Hume, Kant, et al., discovered. To rehearse these would, I take it, be an unpardonable anachronism. As for "no reason inside for moving," what better reason could there be than the conflict of habitual and instinctive activities with its accompanying dissatisfaction?

Again, Professor Baldwin asks: "If experience proceeds by readjusting to situations, whence comes the situation that 'puts it up' 
to it to adjust" (italics mine)? Now the use of the preposition "to" both locates and at the same time begs the whole issue. In the view which Professor Baldwin criticizes, experience proceeds by situations of readjustment, not by adjustments to situations. The situation to be readjusted is one in and of experience, not one which is "put up" to it from without. That Professor Baldwin must be aware in some measure of this view seems implied in his next question: "Why does it [experience] grow discontent with its own habit world" (italics mine)? This certainly assumes that somebody regards the readjusting situation as made by the discontent of experience with "its own habit world."

As for the answer to the question: "How this discontent can arise," that is not far to seek. As has been pointed out again and again, it is due to the fact that habits are constantly coming into conflict. In more general form experience has constantly to face the results of its own work and utilize them as the material of its own further development. And if it be fur- 
ther asked how this conflict reveals itself, the answer is: through dissatisfaction and pain.

The same point is involved in the following questions on my answer to which Professor Baldwin says he "will stake the whole business":

First. How can experience of the dynamic-relative type secure or utilize knowledge that is socially valid without at the same time reinstating other things as valid, as the social fellows, including the thinker himself?

Second. How can an experience that has no environment except its own habit and no reality, save its present function, set up any dynamic at all?

Or to put these two questions in one: In what sense is the will of the mother spanking the child part of the habit of the child, and why does the child's experience take on this particular phase of relative dynamic-this occasional and very disconcerting phase of habit?

In this last inclusive and very concrete form of his question I assume that Professor Baldwin does not intend to put me at any empirical disadvantage by having the "mother" instead of the father do the spanking-an arrangement which, personally, both as a child and as 
a parent, I have always favored. As for "staking the whole business on my answer," that happily is not necessary, as that is a responsibility already shared by many others.

In general, Professor Baldwin's questions all reveal the chronic and apparently incurable determination of most critics of pragmatic doctrines to take, at any rate in their criticisms, the terms "experience," "consciousness," "habit," "attention," etc., in the sense of the "experience," "consciousness," "habit," and "attention" of some one individual. Whereas all these terms, when they are used without explicit reference to a particular individual, refer to the entire world of activity in which the experiencing individuals have their being-"experience" being the general term for that world of activity, the other terms meaning particular modes or functions of that activity.

This does not mean that these particular modes or functions, such as habit and attention, may be regarded as some sort of disembodied "things in themselves," capable of an exist- 
ence apart from individuals. They are the modes of the activity of social individualshabit being the conserving, the mechanical, the structural mode, attention the reconstructive, reforming, readjusting activity. While this conception does not then in any sense attempt to substitute experience, habit, or thinking in general or at large for the experiences, habits, and thinking of individuals, it does protest just as insistently against regarding these activities as shut up within the epidermic confines of some one individual. However much John Smith's habit and ideas belong to him, they belong also to the whole community in which he lives and which is affected in any way by them, be that as large or small as it may. Conversely, just this community center of habits and ideas is John Smith. That this is to be taken literally and not figuratively, Professor Baldwin himself shows in his volumes on Mental Development.

Now if this conception of the habits and ideas of the individual as also functions of the whole community life be kept steadily 
in view, it would seem that the impossibility of framing such questions as the above is as obvious as their answer.

Turning to the first question, Why should anyone speak of "reinstating social fellows" and "other things"? Who has turned them out? Surely not those who teach that problems arise, run their course, and find their solution, not in the solipsistic realm of John Smith's habits and ideas as a complete world in itself, but in the habits and ideas of John Smith as a conserving and reconstructive agent of the whole community life.

As for the second question, in view of what has already been said of the place of habit in experience, it seems redundant to add: that habit cannot be regarded as an external environment to experience, or (2) that experience does not have to "get up" any dynamic. The "dynamic" is already there: (a) in the obviously active character of the habits; (b) in their coming into conflict; and $(c)$ in the reconstructive work of attention.

Professor Baldwin's putting of the "spank- 
ing" case lends itself somewhat temptingly to facetious treatment, but as the matter is really a serious one for all parties concerned, I prefer to treat it so and to observe: first, that in urging the distinction between the experience of the mother and that of the child, the question seems irrelevant to the original issue, which is the possibility of stating the whole situation, whether it involves one person or a thousand, few or many things, in terms of a conflict of habitual activities resolved through attention. It insists that the whole situation, including the mother, the child, and the spanking, whether regarded from the standpoint of the mother, the child, or both, is a system of conflicting activities undergoing reconstruction. And from this standpoint there is no more need for identifying the ideas or will of the mother and the habits of the child in the sense of making them the same thing or making one a "part" of the other, than of identifying habit and will in the mother, or in running together distinguishable functions or aspects of any other process.

Admitting freilich, then, the distinction 
between the activities of the mother and those of the child, we must yet keep hold of the fact that if they are not "parts" of each other, yet they are "parts," in the sense of constituent interacting activities, of one situation. This is reflected, in general, in the very terms in which we state the case. The performance as a whole may be stated either as "the mother spanking the child," or "the child being spanked by the mother." It depends on the point of view. Again, the term "mother" implies that one of the individuals is the kind of an individual that has the habit, the attitude of caring for "her child." And the term "her child" implies that the other is the kind of an individual that is to be protected by the mother even to the extent of being spanked, if need be.

Following the analysis still farther, and still speaking from the standpoint of the entire situation, how can "the will to spank" be regarded as the exclusive work of the mother? It surely is the outcome of the conflict between the mother-attitude of perceiving and keeping the child in safety and the child's present 
activity of, say, playing with the fire. It is a joint product of these two sets of activities, and one is as essential as the other. The attempt to regard the willing as the exclusive production of the mother alone transforms the concrete will to-spank-this-child-now-playingwith-the-fire into an abstract "will to spank" überhaupt, with nothing particular to spankthe essence of a profoundly tragic situation.

But Professor Baldwin may say, after all "the spanking" is "forced" on the child as the perception of the-child-playing-with-the fire is forced on the mother, to which I would rejoin: (I) Even so, this but sustains the original contention that however "new" or "forced" or "unwelcome" the experience may be, it still is statable in terms of the readjustment of conflicting habitual activities through attention. And even if for any reason one wished to state the case from the standpoint of the mother or the child alone, there are no other terms so far as I can see for the statement. (2) The spanking is no more "forced" on the child than on the mother. In fact, psy- 
chically it may be much less so. However skeptical we may have been about it as children, we have since learned that our mothers spake truly when they said: "I am sorry that I am 'forced' to punish you." (3) For both, neither "the spanking" nor the playing-withthe-fire viewed as an occurrence is any more "forced" than anything else that may have preceded, as running, talking, sewing, etc. Even the image of the child playing with the fire is no more forced upon the mother than "her own" breathing, her impulse to rescue the child, or her will to spank it. In this sense, all those activities which constitute the "self" of the mother, upon which other things are said to be "forced," is as much "forced" as the other things. In this sense everything is "forced." "Forced" here means simply "happens." And in this sense things are no more and no less "forced" upon us than we are "forced" upon things, or "forced" upon ourselves. What goes on within our "walls" is as much "forced" as the thing "which rides full armed through them." As a matter of fact, this mere happen- 
ing of things, however "new" or "sudden," e.g., Professor James's classic thunder-clap, is not experienced as "forced" unless it conflicts with activities or attitudes already going on. ${ }^{x}$ And even then the "force" obviously is not all on the side of the "new" factor. It is met by the force of the activities already there. Pursuing the figure, the forces behind the "walls" are not asleep waiting to be aroused from without. They are already active. And if the new factor be recognized as an improvement, it may be made the basis, the ideal, of the reorganization, in which case the old habits, instead of the "new" content, will appear as the "opposition." It is, then, only when there is a conflict of happenings and some content is selected as the end, that the other activities, the readjustment of which this "end" demands, seem "opposed" and "external" to the end. But they are not "opposed" or "external" to the whole situation nor to "experience."

× Cf. Angell, Psychology, 5I, 37 I, 372. 


\section{XII}

\section{THE ETHICAL ASPECT ${ }^{\mathrm{I}}$}

If in the midst of the present division, not to say confusion, of tongues in the philosophical camp, a general password had to be selected which all could speak "trippingly on the tongue," doubtless that word would be "purpose." Absolutist, pragmatist, and realist, idealist and empiricist, intellectualist and voluntarist, all make fervent appeals to "purpose"; sometimes in reverent capitals; often in frantic italics; otherwise in humble lower case.

So at last it would seem that the philosopher might fairly meet the philistine's challenge to point to anything settled in philosophy by citing the ancient issue between mechanism and teleology. Whatever our differences, we are all professed teleologists. Prima facie the

I Read at the meeting of the American Philosophical Association held at Baltimore, December, 1908, and afterward printed in the Philosophical Review, XVIII, No. 3, under the title "Absolutism and Teleology." 
teleological problem is no longer that of teleology or no teleology. It is a question of the kind of teleology. But any fond hopes which the reader may harbor, on his first glance at the pages of current discussion, that "purpose" is to be a beautiful Hegelian synthesis of all philosophical differences, are doomed. $\mathrm{He}$ soon discovers that within this camp of professed teleologists the differences are as great as elsewhere; so great, indeed, that at the extreme each party regards the other's teleology as mechanism masquerading as purpose. Like the disputing theologians, each says: "Your God is my devil." In fact he finds that the issue here is the same as it is elsewhere; namely, the issue between absolute perfectionism, completionism, and developmentalism-evolutionism.

It may be said that this statement begs the issue at the outset, since many absolutists are also professed evolutionists. - And indeed it has been long since even Mr. Bradley has repeated his famous Eleaticism, "Nothing real can move." Let, then, the statement of the problem be: Can 
absolute perfectionism be reconciled with the conception of evolution as an essential character of reality? Can an absolutist be an evolutionist except in a very Pickwickian, not to say Spencerian, sense?

In metaphysical terms the problem is: Are there laws or forms of development which themselves do not participate in the development? In logical terms, it is the question which Hegel raised. Is there a real evolution of categories? In Hegel's attempt to answer this in the affirmative many believe that the reality of Hegel's evolution of the categories vanishes in his timeless absolute. From the biological standpoint the problem is that of the relation of structure and function. Can there be a development of function with no corresponding development in structure, or conversely? Putting it again from the standpoint of permanence and change, and granting the equal claims of each, the issue is: Can these claims be met by dividing up the world into laws and facts, categories and phenomena, structure and function, and assign- 
ing all the permanence to one side and all the change to the other?

In ethical terms the problem is: Whether the ideal in conduct can be absolute, all-inclusive, fixed, and given, or whether it must be constructed in the process in which it functions. ${ }^{x}$ So far, the logical and epistemological implications of the question have held the center of the stage in current discussion. We shall therefore pass to the ethical aspects where the issue is as crucial as it is in logic. The aim of this paper is not so much to develop new criticism, as to state the present situation in the hope that such a statement may help to start the discussion in the ethical direction.

Whatever may be the difficulties which the conception of an all-inclusive fixed purpose encounters in logic, in science, or in a metaphysics based on scientific concepts, it is supposed to come into its own in the field of ethics. If it has no place in science, that only shows, it

I A much more concrete and effective statement of what I am saying here will be found in Professor Tuft's address on "The Present Task of Ethical Theory," International Journal of Ethics, $\mathrm{XX}, \mathrm{I}_{4} \mathrm{I}-52$. 
is said, the abstract character of the "mechanical" standpoint of science. "Waiving the formal consideration that, if the scientific standpoint be abstract, it must leave that from which it is abstracted equally abstract, let us note," says the anti-absolutist, or "evolutionist" as we shall call him in this discussion, "what is of more interest and effect; namely, the historical fact that ever since the publication of Darwin's Origin of Species, science has become more and more teleological." The significance of this is that Darwin's work in science, as Hegel's in logic, revealed a new type of teleology-a dynamic, evolutional teleology which made it possible to introduce teleological conceptions into science without committing it to the absolute teleology which seemed to it more mechanical than its own "mechanism," from which it was all the while trying to escape. The mechanical character of pre-Darwinian science was therefore but the counterpart of the absolute type of teleology of which science was indeed very shy. But as soon as science found that it could talk of "wants" and "needs" and 
"purposes," without committing itself to the determinism of an all-inclusive and absolutely fixed purpose, it rapidly lost its teleophobia. For it found these categories of "want," "desire," "purpose" very serviceable, especially in biology.

"And it is interesting further to note," says the evolutionist, "that the development of this dynamic type of teleology in science since Darwin, has encountered its strongest opposition, not from scientists, as might have been expected, but from philosophers, who still insist that the method of science must be abstractly mechanical in sharp antithesis to the teleological character of ethics. And the implication of this would seem to be that an absolute teleology in ethics must maintain itself as the correlate of an equally absolute mechanism in science. In what respect this position is beyond that of Kant's second Critique is difficult to see. Perhaps it doesn't pretend to be beyond it."

Before passing to the more directly ethical considerations there is time only to mention 
two general psychological questions which meet us at the threshold. First: How can the absolute purpose be "all-inclusive" and still be selective, as psychologically a purpose must be? We are assured by Professor Royce ${ }^{x}$ that, although it is inclusive of all possible purposes, it is still selective. And this assurance certainly is from the very highest authority on the absolute. But there are probably very few psychologists with sufficient reverence for metaphysics not to ask how this can be. Second: This all-inclusive purpose is also, at the same time, its own complete fulfilment. This raises another nice psychological problem which we cannot here discuss.

Striking now into the well-known course of the ethical argument, we come at once upon what is most often urged as the crucial support of the absolutist's teleology-that, unless there is an all-inclusive fixed purpose, end, or goal, there is no standard for moral progress. Even if we admit for the moment that consciousness might possibly have a social character without

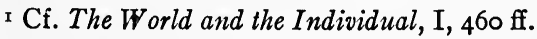


such an absolute, and that there might therefore be a certain degree of objectivity in a social purpose, yet how, in the case of a community, a national, or even an international ideal, are we to tell whether it spells moral advance or retreat? Without such a fixed and final goal is not the world a huge chartless craft, hailing from no strand, bound for no port-a vast derelict adrift on a shoreless sea?

But, asks the evolutionist: "After all, how much of a chart does the absolutist's conception furnish? Does it point the direction of the absolute goal? Does it show the rocks and shoals?" "No," confesses the absolutist himself, "it contains only the assurance that there is such a final goal, though its direction is known and can be known to no finite being." "How then," again asks the evolutionist, "shall we tell when we are headed toward or away from it?" Mr. Bradley says frankly that we cannot, and that therefore moral experience does not belong to reality, but to "appearance."

If the rejoinder be that this poor figure, taken 
from the world of space and time, is utterly inadequate for the conception of the absolute goal; that it is no particular "where" because it is everywhere; that it is at no particular time, because it is not in time but in eternity; the rejoinder is: What then from this standpoint do progress and regress mean? If the harbor is so infinitely extended that no voyage in time is necessary to make it; if, more technically, the absolute purpose is so all-inclusive that it has already determined and included all the means, how can we here talk of advance and retreat? Has not our conception, which was to be the standard of progress and regress, swallowed them both?

And more acute, if possible, grows the issue when we approach the problem of responsibility and freedom. As absolutists we must believe that only in the form of a fixed and all-inclusive purpose can the ideal have that kind and degree of objectivity and categorical authoritativeness which moral experience demands. On the other hand, the evolutionist insists that if our goal is already determined and if it is so "all- 
inclusive" that no matter in which direction we are headed we are bound to make it, or are always in it, then why be concerned at all? Why do we grow excited and rush into civic federations, labor unions, peace congresses, and suffragette crusades? Why should not our legend be, in the vernacular, "What's the use ?"

"Why?" repeats the absolutist. "How utterly vain the question when you come to see that your getting excited and rushing into federations, and unions, and crusades, and refusing to adopt 'What's the use ?' as your legend, are all included in the absolute plan."

"But," returns the evolutionist, "what then becomes of responsibility?" Waiving at present the problem of the relevance of an ideal not constructed in the process in which it functions, is not participation in the construction of the plan we are to help carry out the very basis of moral responsibility? How is it possible to feel responsible for the mere executing of a purpose which we have not helped to form? And is it not strange that a plan which we have helped to construct should have any 
less authority and binding force than one ready made and given?

"And here," continues the evolutionist, "we reach the heart of the ethical significance of the whole anti-absolute movement. It is the democratic movement in morals; it is the demand for the full conditions of moral responsibility. It is the claiming of the moral franchise-the right to participate in the construction as well as the execution of the ideal. In terms of our familiar figure, it means that if there is to be such a thing as moral experience aboard our craft we must have a real part, not only in hoisting sail and washing down the decks, but in laying the course of the ship. And, as a moral experience, 'this laying the course' means more than running for a harbor already built from all eternity. It means nothing less than that our moral craft carries within her the material and the machinery for the building of new shores. $^{I}$ And this material is simply the entire

I Of course it would be easy for a captious critic to break down this already overloaded metaphor by asking, What about the sea and the ship itself? For it is obvious that they too must be included in the process of reconstruction. 
world of organized habits and institutions; and the machinery, the method, is thoughtscience."

But long before this the absolutist is impatient to say: "First, all you have said about the necessity of participation in the construction of the ideal, and about the impossibility of the ideal being given to the agent, is entirely beside the mark so far as our position is concerned. For since the days of Plato have we not continually taught that, although all our efforts here on this bank of time do not alter by the least jot the absolute purpose, yet what you now seem to be doing for the first time is from the beginning (using "beginning" as a mere figure) an eternal part of the all-inclusive plan. The absolute purpose is, therefore, not formed independent of, and given to, the world of individuals in time; it is formed of all possible individual purposes. Hence, the thinking or planning of every individual or community is a contribution to the absolute purpose in the sense that it is an eternal part of it. What you are doing here in time is simply finding out 
what you have already contributed in eternity. Plato's doctrines of reminiscence and transmigration are, to be sure, awkward expressions of this conception due to his inveterate temporal imagery, which is the bane of all discussions of the absolute, including the present one."

"Second, when you speak of moral responsibility as involving the capacity for 'building new shores' once more, what is to determine when and where? Why in one direction rather than in another? Why now rather than then?"

To the static, timeless, geometric conception of participation in the absolute purpose, the evolutionist's answer is first of all a direct appeal to moral experience. He complains that he cannot square this account with moral responsibility as directly experienced. "I feel," he says, "as if I were, here and now, "in my weak and feeble way,' helping to create plans and ideals of society, of education, of art, that are somewhat new-somewhat different from any ever wrought before. And all the experimentation and deliberation through which I make my 
contribution-they simply do not feel like, in the language of the radical empiricist, are not 'experienced as' a mere bringing to the surface of present temporal consciousness parts of a purpose made in 'eternity.' On the contrary, just in so far as this timeless conception fills my mind, in so far do I find myself falling back into a 'what's the use' attitude." That this attitude does not characterize the absolutist any more than the anti-absolutist in practical life, the latter takes as evidence-not so much that he has misinterpreted the effect of the conception, as that it is not the one with which the absolutist actually operates-except in his discussions with evolutionists and pragmatists.

"But," returns the absolutist, "grant for the moment that you help to work up new content for the ideal, yet the goodness of it you surely do not even assist in creating. That you can only recognize, even as Plato taught, for it simply is." But the evolutionist is still obdurate or dense. He professes that he cannot strain out or skim off or otherwise separate the goodness as a special essence from the rest 
of the content and assign it to a world of different dimensions of being. And, moreover, if the goodness simply is and has only to be recognized, why is it that we have so much difficulty in the recognition? "No," confesses the evolutionist, "so far as I can see, goodness is perfectly concrete and is wrought out and comes into being along with every reconstruction of the ideal. Thus the goodness of honesty comes into being along with the ideal of honesty."

But this brings us to the absolutist's second point: that, in all this demand for participation in the reconstruction of the ideal, the problem of the standard for this construction is again overlooked. What is to determine when, in what direction, and in what material new goals, new ideals are to be constructed? This is, of course, only a little more specific form of the problem of progress which we left with only a negative outcome. The evolutionist's answer to this question is bound to seem to the absolutist very naïve, for he says simply: "First, whenever the old plans, the old ideals become inadequate, that is, unsatis- 
fying; and second, in the direction and in the manner which, in view of all the material and the machinery available, promises the largest satisfaction." This, when sufficiently defined and formulated to become a working plan, is the ideal, is the standard, and is progress. It is the outcome of a genuinely creative process, Fichte's "fact-act" in its evolutional formwith all the results of the past as the material, and thought as the method. "And, after all," continues the evolutionist, "what higher consecration, or what greater claim to our allegiance, could it have than that it is a plan for a larger satisfaction which we have helped to create? To ask for a further standard for this ideal, which is thus intrinsically worked out as the standard, is to go straight into an endless regress, or to make the ideal again external and given."

To all of which the absolutist again observes: First, that absolutists evidently have not a monopoly of hortatory philosophizing. Further, that, in the foregoing, two important points are overlooked: first, when it is said that the ideal is 
that which promises relief from dissatisfaction, is not the real situation reversed? Does not the dissatisfaction arise from the condemnation of the present status by the ideal, which therefore must exist in advance of and independent of the dissatisfaction? And again, we must ask, after all, just whose dissatisfaction is to be relieved and by whose thought are the ideals to be constructed?

Of the ideal as the basis for, and therefore independent and in advance of, dissatisfaction, the evolutionist observes, interestingly enough, that it was that arch-absolutist Hegel who first called attention to the fact that the dissatisfaction and the ideal are correlative parts of one process; that the idealizing activity arises with the dissatisfaction as its positive reconstructive correlate. In logical terms, this means that the judgment is not a process of applying ready-to-wear predicates, but is one of constructing new predicates out of old ones as material. And this applies with as much force to the moral as to the scientific judgment. As we have seen, this is just the meaning of 
responsibility and freedom. "And once more," adds the evolutionist, "if the ideal is there independent and in advance of all dissatisfaction and if it is infinite in power and allinclusive in extent, how in the name of the absolute does any dissatisfaction ever arise ?"

To the other question, "Whose dissatisfaction is to be relieved, and by whose thought is the ideal to be reconstructed?" the evolutionist's answer again appears unsophisticated. To "whose dissatisfaction ?" he replies: "everyone's." "By whose thought?" $\mathrm{He}$ answers: "Any thought that can contribute to a plan." "But" objects the absolutist, "there will be conflict in the planning itself." "Then," says the evolutionist, "there will be more planning, more investigation and experimenting, more getting together, until that conflict is settled." And he adds: "Are conflicts, as a matter of fact, ever settled in any other way? However much the absolute solution is already there, we must make the fight just 'as if,' in Kant's phrase, there were no solution but the one we help to reach." 
All this, of course, ignores the implication of "subjectivism" in these questions, of which so much was made in the earlier discussions of truth. It assumes that the "dissatisfaction" and the "thought" of which we have been speaking are not functions of a particular body or brain or mind only, any more than my standing here is a function of my legs only. It assumes that "my" consciousness is a function of a social process in which my body or brain or mind is only one factor. It presupposes that "my" thinking and feeling may be as truly a function of "your" brain or mind as of my own. My thinking of sending for you as a physician to treat my headache is as truly a function of your medically trained brain as of my own aching one. And "your" thinking as you diagnose my case is no less obviously a function of my head than of your own. You are thinking not merely of, or about, but for me-in my place. Your thinking literally "belongs" to me. You are in fact renting me for a few minutes your thinking apparatus, the which if I do not now appreciate I shall 
when your bill comes in. But the headachesurely that is all "mine." And yet do I not in a very true sense "turn it over" to you? And even before your arrival I experienced it as something related to you as truly as to myself. And you regard it and talk of it as "your" case. At any rate after your arrival it seems clearly to "belong" to both of us. And we both may then regard it quite objectively and speak of what "we" can do to get rid of "it."

With this conception of the ganz und gar social character of consciousness constantly in mind, is it strange that the evolutionist should find his explanation of the charge of subjectivism in the critic's own subjective conception of consciousness?

"With the limits and nature of the constituents of this social process," says the evolutionist, "the general principle of this discussion is not concerned. It may include infraand superhuman agencies; it may have all the unity consistent with development and all the differences possible with continuity. The prin- 
ciple insists only that the social process be real and that reality be a social process."

"But do you not see," asks the absolutist, "that this appeal to the social process begs the point of my whole contention, which is precisely that the social character of experience is impossible without the absolute? I, too, am a 'socialist,' but even therefore am I an absolutist. Without the conception of the absolute I confess I am a subjectivist. With no absolute the social process is to me one of the blind leading the blind." "But," returns the evolutionist, "if we do not know even the direction, much less the nature, of the goal to which we are being led by the absolute, while this may not be a case of 'the blind leading the blind,' it still is the blind being led; our blindness still remains." And when the absolutist devoutly responds: "Yea, verily, our blindness remains," "Then," says the evolutionist, "absolutism must content itself with being simply a religion and a gospel of resignation, not a call to works, much less an ethical theory of responsibility and freedom." 
278 PRAGMATISM AND ITS CRITICS

As for "the blind leading the blind," the evolutionist believes that it is just by this process of mutual leading-whatever the agents involved in it - that light and sight are created. And when the absolutist again asks: "Leading where?" the evolutionist's answer still is: "In the direction of the ideal worked out in and by the social process in order precisely to give itself a direction-a "where." " 
INDEX 



\section{INDEX}

Absolutism, Plato's, 33 f. ; Bradley's, 48 f.; Royce's, 63 f.; ethical aspect of, ${ }_{2} 6_{3} \mathrm{f}$.

Angell, J. R., preface, 79, $25^{6}$. Aristotle, 37 f., 49.

Arnold, M., 3 .

Attention, social character of, $247 \mathrm{f}$.

Bacon, F., 7 I.

Bakewell, C. M., I28, I49 f., I7 2.

Baldwin, J. M., I 28, r68, I 74 f., 222 note, $245 \mathrm{f}$.

Berkeley, G., 235 .

Bosanquet, B., I43, I85, I9394.

Bradley, F. H., preface, 37, 50, 55,6 r, 83 , II 2 f., I65, I72, I 78,218 note.

Change, $149 \mathrm{f}$.

Conduct, relation of, to thought and value, $3 \mathrm{f}$., I $9 \mathrm{f}$.

Conflict, and thought, I $24 \mathrm{f}$.; and attention, 256 .

Consciousness, individualistic versus social view of, 30 f., 225 f., chap. v.

Consistency, I8I f.

Creighton, J. E., I28, I32 f., I $60 \mathrm{f}$.
Darwin, C., 36, 75 f., 26r f.

Descartes, R., 49, 7 I.

Dewey, J., preface, 22, 44, I I 4, I 6I-62, I64, I98, 225 f., 237, 243-44.

Democracy, 22, 72 .

Dialectic, Hegel's, $92 \mathrm{f}$.

Dualism, of pragmatism, r6o f.

Eleatics, 35 .

Epistemology, origin of, $28 \mathrm{f}$. Evil, problem of, $49 \mathrm{f}$.

Evolution, 36-38, $76 \mathrm{f}$; ethical aspect of, $259 \mathrm{f}$.

Error, 49 f., chap. iii.

Experience, and subjectivism, $233 \mathrm{f}$.

Fite, W., on pragmatic view of experience, $233 \mathrm{f}$.

Freedom, and absolutism, $265 \mathrm{f}$.

Greeks, absolutism of, $23 \mathrm{f}$.

Green, T. H., 8I.

Habit, I 48 f., I 87, I 89 .

Hegel, G. F. W., 74, 8I f., 92 f., 273.

Heraclitus, 35 .

Hume, D., 7I, 84-85.

Hypothesis, $78 \mathrm{f}$. 
Idealism, and pragmatism, I7 f., 89, ro8-9.

Ideal, the ethical, $266 \mathrm{f}$.

Ideas, 2r; Platonic, $34 \mathrm{f}$; nature of, $80 \mathrm{f}$; realistic versus pragmatic view of, chap. $v$.

Inquiry, and thought, ${ }_{25} \mathrm{f}$.

Instinct, and thought, Ir $2 \mathrm{f}$.

Intellectualism, rise of, $23 \mathrm{f}$.

James, William, preface, I f., r64, I68, r 75, 2 r r.

Jowett, B., quoted, 39 .

Judging, as working hypothesis, $78 \mathrm{f}$; Hegel on, 8I f.; and truth and error, irif., I $32 \mathrm{f}$; ; and conflict, I24 f.; universal, $174 \mathrm{f}$; ; ethical, 273 .

Kant, I., I I f., 46, 73, 262.

Knowledge, origin of problem of, $23 \mathrm{f}$; realistic view of, chap. v.

Leibnitz, G. W., 49.

Lovejoy, A. O., I, 205 note.

Luther, M., 7 r.

Mathematics, 58; empirical character of, 169 .

McGilvary, E. B., Ir 2.

Mead, G. H., preface, 233.

Metaphysics, issue of, 22; origin of, $33 \mathrm{f}$.

Mill, J. S., 235.

Mysticism, and problem of evil and error, $5 \mathrm{I}$ f.
Naturalism, versus rationalism, $7 \mathrm{I} \mathrm{f}$.

Parmenides, 35 .

Past, knowledge of the, ror $\mathrm{f}$.

Permanence, defined, 147; I5 f.

Perry, R. B., II4, I95 f., 23 I. Philosophy, and science, $23 \mathrm{ff}$. Plato, and Sophists, 33 f., 49, 6r, 100, 270.

Pluralism, of James, II $3, \mathrm{I}_{6}$, I 75 .

Politics, and pragmatism, 22; Greek, political system, 42.

Pratt, J. B., on pragmatism, $224 \mathrm{f}$.

Pringle-Pattison, J., $\mathrm{r}_{32}$, $\mathrm{r}_{4} 6 \mathrm{f}$. Psychology, 19; individualistic, of Greeks, 3 I f., $79 \mathrm{f}$.

Purpose, and thought, I $3 \mathrm{f}$., $63 \mathrm{f}$.; and variation of species, 77 , $5_{52} \mathrm{f}$; ethical aspect of, $260 \mathrm{f}$.

Schiller, F. C. S., 57, 106, I 7 1.

Schopenhauer, A., 235.

Science, and conduct, $9 \mathrm{f}$; and philosophy, $24 \mathrm{f}$.

Social, motif of Plato, $35 \mathrm{f}$; character of thought, I $9 \mathrm{r} f$., $229 \mathrm{f}$.; character of attention and habit, $245 \mathrm{f}$.

Socrates, $3 \mathrm{I} \mathrm{f}$.

Solipsism, $220 \mathrm{f}$.

Sophists, psychology and logic of, $3 \circ \mathrm{f}$.

Space, and realistic view of 
knowledge, $98 \mathrm{f}$; and ob- view of, $23 \mathrm{f}$.; and truth jectivity, $238 \mathrm{f}$.

Species, variation of, and thought, 72 .

Spencer, H., I62.

Spinoza, B., 49.

Stout, G. F., 66.

Stuart, H. W., I23, 157 .

Subjectivism, and pragmatism, 4r f., 160 f., 224 f., $233 \mathrm{f} ., 275 \mathrm{f}$.

System, 180-83.

Taylor, A. E., I I4, I43, 204. Teleology, and evolution, $261 \mathrm{f}$.

Theological, issue in pragmatism, 19-20, 22.

Thompson, Dr. Helen, I 25.

Thought, and conduct, $3 \mathrm{f}$.,

I9 f.; and will, ir f.; Greek Zeno, 99, I49. and reality, chap. iii; effiçacy of, $89 \mathrm{f}$; and value, r rof.

Time, past, Ior f., 238-40.

Truth, and conduct, $\mathbf{1}_{3} \mathrm{f}$.; and error, $52 \mathrm{f.}$; and value, I I f., I $32 \mathrm{f}$.

Tufts, J. H., preface, 22, 260.

"Universal," the, in pragmatism, $174 \mathrm{f}$.

Value, and thought, i rof.

Voluntarism, and pragmatism, I $5 \mathrm{f}$.

Variation of species, and logic, $77 \mathrm{f}$.

Will, and thought, i I f.

Woodbridge, F. J. E., I 28. 


0 






\section{BINDING SECT. APR $1 \mathrm{U} 1360$}

\section{PLEASE DO NOT REMOVE CARDS OR SLIPS FROM THIS POCKET}

\section{UNIVERSITY OF TORONTO LIBRARY}

Philos

Y821

$$
\begin{aligned}
& \text { Moore, Addison Webster } \\
& \text { Pragmatism and its criti }
\end{aligned}
$$


